Florida International University FIU Digital Commons

$7-27-2010$

\title{
The Impact of Eliminating Extraneous Sound and Light on Students' Achievement: An Empirical Study
}

Rajarajeswari Venkata Surya Mangipudy

Florida International University, raji_venkata_surya@hotmail.com

DOI: $10.25148 /$ etd.FI10081219

Follow this and additional works at: https://digitalcommons.fiu.edu/etd

Part of the Curriculum and Instruction Commons

\section{Recommended Citation}

Mangipudy, Rajarajeswari Venkata Surya, "The Impact of Eliminating Extraneous Sound and Light on Students' Achievement: An Empirical Study" (2010). FIU Electronic Theses and Dissertations. 269.

https://digitalcommons.fiu.edu/etd/269 


\title{
FLORIDA INTERNATIONAL UNIVERSITY
}

Miami, Florida

THE IMPACT OF ELIMINATING EXTRANEOUS SOUND AND LIGHT ON STUDENTS' ACHIEVEMENT: AN EMPIRICAL STUDY

\author{
A dissertation submitted in partial fulfillment of the \\ requirements for the degree of \\ DOCTOR OF EDUCATION \\ in \\ CURRICULUM AND INSTRUCTION
}

by

Rajarajeswari Mangipudy

2010 
To: Interim Dean Delia C. Garcia

College of Education

This dissertation, written by Rajarajeswari Mangipudy, and entitled The Impact of Eliminating Extraneous Sound and Light on Students' Achievement: An Empirical Study, having been approved in respect to style and intellectual content, is referred to you for judgment.

We have read this dissertation and recommend that it be approved.

Mohammed Farouk

Aixa Perez-Prado

$\begin{array}{r}\hline \text { Sneh Gulati } \\ \hline \text { Vish C. Viswesvaran }\end{array}$

M.O Thirunarayanan, Major Professor

Date of Defense: July 27, 2010

The dissertation of Rajarajeswari Mangipudy is approved.

\begin{tabular}{r}
$\begin{array}{r}\text { Interim Dean Delia C. Garcia } \\
\text { College of Education }\end{array}$ \\
\hline Interim Dean Kevin O’Shea \\
University Graduate School
\end{tabular}

Florida International University, 2010 
(C) Copyright 2010 by Rajarajeswari Mangipudy

All rights reserved. 


\section{DEDICATION}

This work is dedicated to my daughter Rashmi Shankar who gave continuous support, and encouragement throughout the entire process; to my professor Dr. Thiru who always encouraged me with the same philosophy that he had, that is to set high expectations and take the necessary measures to live up to them and to my gurudev, $\mathrm{HH}$ Shree Shree Bhaktimarga Swami who always said that you cannot rise to low expectations. 


\section{ACKNOWLEDGMENTS}

As I near the end of this most challenging and rewarding endeavor, I must remember those who helped and supported me throughout the process. First of all I thank Lord Krishna, who is the head of my life, for choosing, using, and sustaining me in the mighty way that He did. It is because of Him and the way He orchestrated my life throughout this endeavor that I had the strength to overcome the desire to quit.

I would next thank Dr. M.O. Thirunarayanan, a very precious person, guided me with such grace and dignity. Dr. Thiru, you will never know the confidence you instilled in me in our very first meeting. You also gave me the encouragement and gentle pushes I needed to keep me going when my spirits got down. Your demeanor had the calming but encouraging effect that I needed as I journeyed through this process. Thank you for your affection, support and patience you have shown over these years without expecting anything in return. I would also like to thank my committee, Professors Gulati, Farouk, Visweswaran and Aixa Perez for their guidance for their helpful suggestions and comments during my study.

Finally I would like to thank my colleagues Illano and Maley who supported and encouraged me throughout this process. Their support and understanding was always refreshing and reassuring when times got hard. 


\title{
ABSTRACT OF THE DISSERTATION \\ THE IMPACT OF ELIMINATING EXTRANEOUS SOUND AND LIGHT ON STUDENTS' ACHIEVEMENT: AN EMPIRICAL STUDY
}

\author{
by
}

Rajarajeswari Mangipudy

Florida International University, 2010

Miami, Florida

Professor M.O. Thirunarayanan, Major Professor

The impact of eliminating extraneous sound and light on students' achievement was investigated under four conditions: Light and Sound controlled, Sound Only controlled, Light Only controlled and neither Light nor Sound controlled. Group, age and gender were the control variables. Four randomly selected groups of high school freshmen students with different backgrounds were the participants in this study. Academic achievement was the dependent variable measured on a pretest, a posttest and a post-posttest, each separated by an interval of 15 days. ANOVA was used to test the various hypotheses related to the impact of eliminating sound and light on student learning. Independent sample $\mathrm{T}$ tests on the effect of gender indicated a significant effect while age was non- significant. Follow up analysis indicated that sound and light are not potential sources of extraneous load when tested individually.

However, the combined effect of sound and light seems to be a potential source of extrinsic load. The findings revealed that the performance of the Sound and Light controlled group was greater during the posttest and post-posttest. The overall 
performance of boys was greater than that of girls. Results indicated a significant interaction effect between group and gender on treatment subjects. However gender alone was non-significant. Performance of group by age had no significant interaction and age alone was non-significant in the posttest and post-posttest. Based on the results obtained sound and light combined seemed to be the potential sources of extraneous load in this type of learning environment. This finding supports previous research on the effect of sound and light on learning.

The findings of this study show that extraneous sound and light have an impact on learning. These findings can be used to design better learning environments. Such environments can be achieved with different electric lighting and sound systems that provide optimal color rendering, low glare, low flicker, low noise and reverberation. These environments will help people avoid unwanted distraction, drowsiness, and photosensitive behavior. 


\section{TABLE OF CONTENTS}

CHAPTER

PAGE

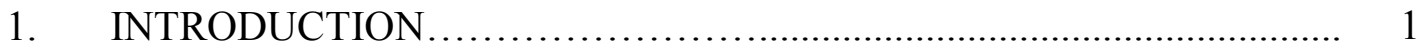

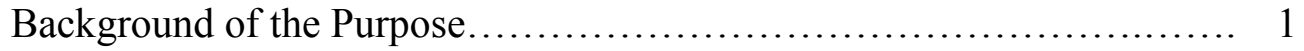

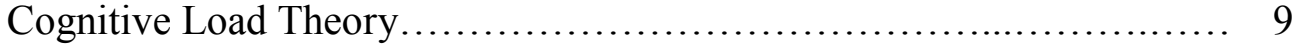

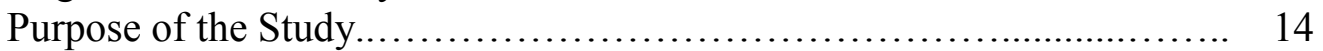

Assumptions...................................................... 15

Research Questions............................................ 16

Significance of the Study ........................................ 17

De-limitations of the Study ........................................ 18

Rationale.......................................................... 18

Organization of the Study ........................................ 19

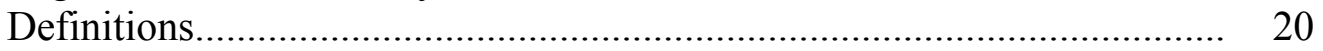

11. LITERATURE REVIEW ................................................................. 21

Theoretical framework........................................... 22

Minimizing extrinsic load........................................ 29

Cognitive load and age .............................................. 31

Cognitive Styles.................................................... 33

Sound / Noise........................................................ 37

Noise and Performance.......................................... 39

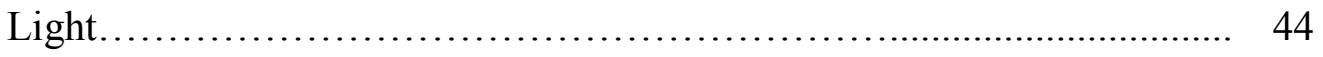

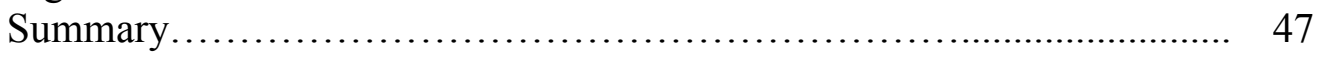

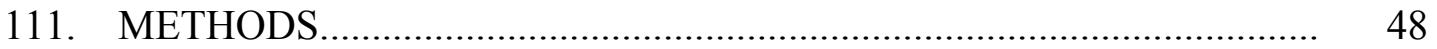

Research Design.................................................. 49

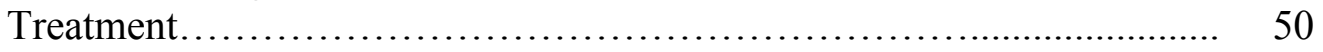

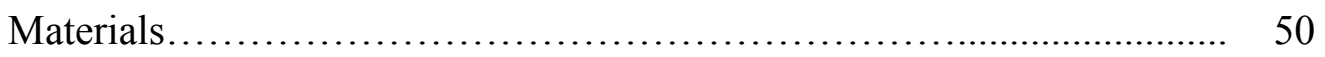

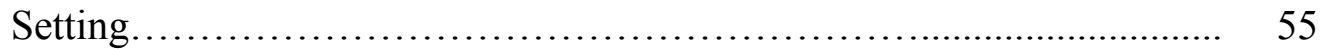

Instrumentation......................................................... 56

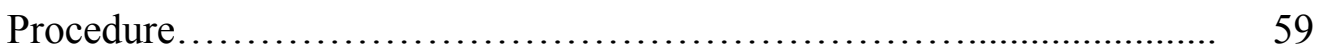

Analysis of Data...................................................... 61

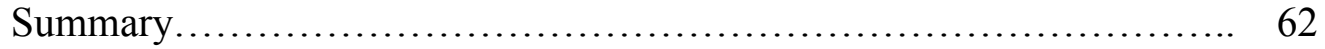

1V. ANALYSIS OF THE DATA................................................................. 64

Statistical analysis of the Pretest....................................... 66

Group Pretest Scores................................................... 70

Gender Pretest scores.............................................. 78

Age Pretest scores.................................................. 85

Posttest - pretest by Group........................................ 90

Group vs gender post-pre scores................................... 97

Posttest - pretest for Age......................................... 104 
Pposttest - Pretest for Group....................................... 109

Ppostest - pretest Gender scores.................................. 114

Ppost-pretest Age scores.......................................... 121

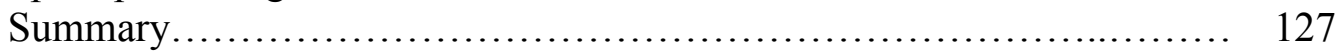

1V. CONCLUSIONS AND DISCUSSION ................................ 128

Pretest results for Group .......................................... 130

Pretest results for Gender........................................ 131

Pretest results by Age.......................................... 132

Post - pre results by Group ......................................... 133

Post-pre results by Gender........................................ 134

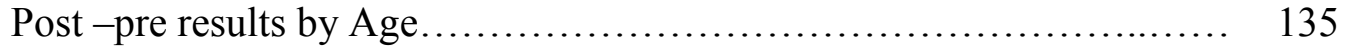

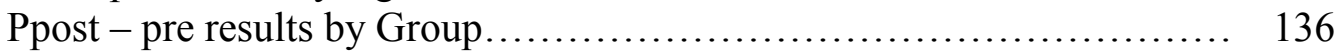

Ppost - pretest by Gender........................................ 137

Ppost-pretest by Age.............................................. 137

Answers to the Research Questions................................ 138

Practical Implications............................................... 141

Limitations and Future Directions................................ 143

Conclusions.......................................................... 144

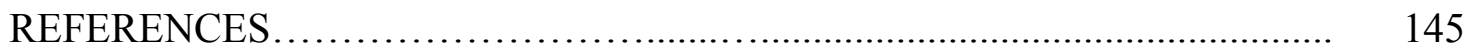

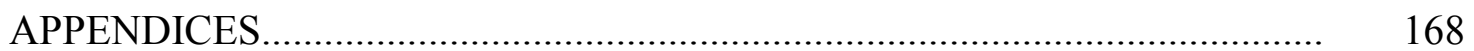

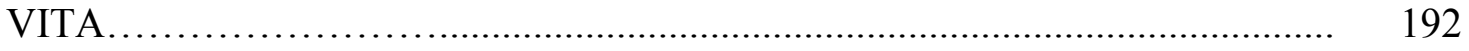




\section{LIST OF TABLES}

TABLES $\quad$ PAGE

1. Frequency Tables.................................................. 1

2. Group pretest Tables............................................. 10

3 Gender pretest Tables.......................................... 16

$4 \quad$ Age pretest Tables............................................ 21

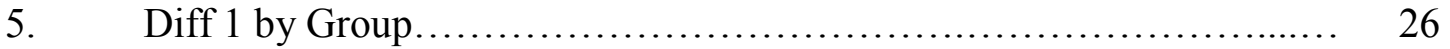

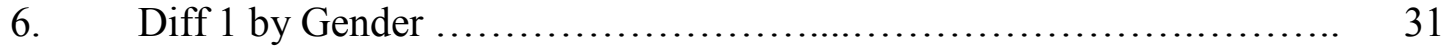

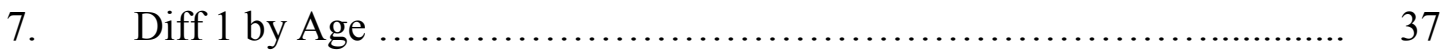

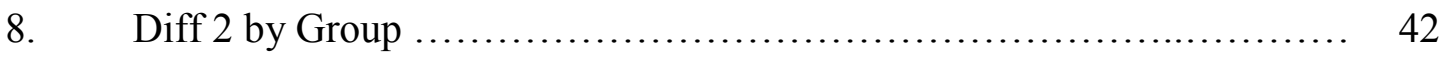

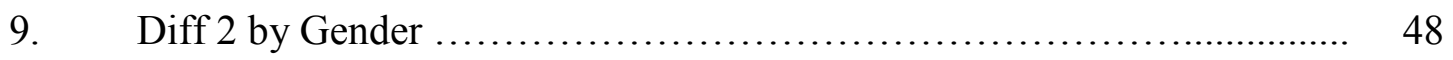

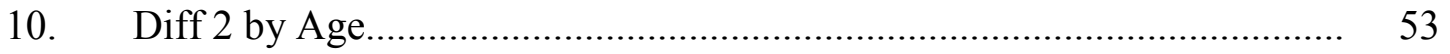




\section{CHAPTER 1}

\section{INTRODUCTION}

This study investigated the impact of eliminating the extraneous cognitive load caused by elements that are not central to the learning material for student achievement. Chapter 1 presents the following sections: background of the problem, statement of the problem, research questions, hypotheses, significance of the study, rationale/assumptions of the study, and delimitations of the study. The chapter concludes with a description of the organization of the dissertation.

\section{Background of the Purpose}

There are two major areas related to the background of the problem that this dissertation addresses. The first part presents the general problem of the impact of sound and light on learning. The second part presents the problems of extrinsic cognitive load and the possible effect on student learning and achievement with special emphasis on multimedia education. The author then presents her interpretation of the relationships between these two areas as a potential source of extrinsic cognitive load.

\section{General Problem}

Children engage in intensive, continuous learning while developing their social, intellectual and communication skills in a variety of situations both within and outside of the classroom. However, classroom experience is an opportunity to focus on these critical skills in a controlled environment and provide the stimuli needed to help a child realize his or her full potential. Classrooms are largely auditory learning environments with listening serving as the cornerstone of the educational system (Flexer, Richards, Buie, \& Brandy, 1994). Most learning takes place through speaking and listening in the 
classroom. Currently, children spend $45 \%$ of the school day engaged in listening activities (Berg, 1987). Most of the teaching encountered in the classroom consists of the teacher talking, students asking questions, and students listening to both the teacher and other students. Multimedia materials used in classrooms also require students listening to a message.

While classroom design and materials have changed little over the past 20 years, there has been a significant change in teaching styles (DiSarno, 2002). Today's classrooms offer many different learning experiences: large and small group instruction, group projects and individual work (American Speech-Language-Hearing Association, 2005). In today's classrooms, instruction is delivered through lectures, instructional videos, and computers (DiSarno, Schowalter, \& Grassa, 2002). One of the side effects of these teaching approaches is increased noise levels in the classroom.

According to the Institute for Enhanced Classroom Learning (2003), children in today's classrooms have difficulty understanding $20 \%$ to $30 \%$ of what is said because of excessive ambient background noise (DiSarno, 2002). Do the disruptions affect the learning process? According to Crandall and Smaldino (2000), many parents and teachers believe they do. Some normal children when put in an average classroom, break down tremendously. In an above-average classroom listening environment, grade-school children with no hearing problems can make out only $71 \%$ of the words a teacher at the front of the room pronounces (Crandall \& Smaldino, 2000). In the worst environments, children can process just $30 \%$ of the sounds in their environment (Crandall \& Smaldino, 1994). Even though the problem is quite severe for children in elementary schools, poor acoustics go largely undetected by adults. Crandall explained that children don't develop 
an adult-like ability to understand speech until they are 15 and these rooms can just devastate them. If a child cannot hear, attentional and/or behavioral problems often occur (Crandall \& Smaldino, 1994). High classroom noise levels from the incessant squeals of chattering children to loud machinery may be affecting children's ability to learn (Bess, Dodd-Murphy, \& Parker, 1998). Classrooms often buzz with noise levels so high they impair a young child's speech perception, reading and spelling ability, behavior, attention and overall academic performance (Ching \& McPherson, 2005).

The ability to hear properly is one of the most important factors in a child's ability to process and learn new information (Kreisman \& Crandall, 2002). However, in the typical classroom, various environmental and student factors interfere with listening and comprehending. Some students struggle to pay attention in class and in other study areas because small background noises interfere with their concentration. However, background noise does not affect all students in the same way. According to Petersson, Forkstam and Ingvar (2004), factors such as learning styles and personality type may determine whether noise is a distraction or not.

\section{Noise Distraction}

One's learning style was defined by Dunn and Dunn (1993) as "the way in which each learner begins to concentrate on, process, and retain new and difficult information" (p. 2). They hypothesized that the interaction of various environmental factors affects each person differently as he or she learns. Several studies have suggested that underachieving students make significant gains in classroom performance when their learning style preferences are accommodated (Andrews, 1990; Gadwa \& Griggs, 1985). Restak (1979) found that $60 \%$ of one's learning style is a biological and developmental 
set of characteristics. This can result in effective instruction for some students, but ineffective instruction for those whose learning styles do not match their school environment. Individual responses to learning modalities, intake of food or drink, time of day, mobility, sound, light, temperature, and seating preferences are biological, while motivation, responsibility (conformity), and need for structure or flexibility are thought to be sociological (Dunn \& Griggs, 1995). On the other hand, researchers disagree about whether persistence (task commitment and completion) is a biological or developmental characteristic (Dunn \& Dunn, 1993).

Three of the most commonly recognized learning styles are visual learning, tactile learning, and auditory learning (Dunn \& Dunn, 1993). Studies have shown that auditory learners are most distracted by background noise. It is not always possible to take learning styles into account even if you know what they are. The Productivity Environmental Preference Survey (PEPS) by Dunn, Dunn, and Price (1979) measures both social (i.e., individual vs. group) and perceptual/ environmental preferences (e.g., bright light vs. low light, noise vs. quiet, warm vs. cold).

The need to create an effective learning environment has led educators to explore different dimensions of teaching, learning and assessment styles. Moreover, it is important to explore factors outside of the classroom that influence the way grades are assigned. In the literature, such factors include: learning style, instructor-student personality match, and inherent skill in self-expression. Keefe (1982) defined learning style as cognitive, affective, and physiological traits that serve as relatively stable indicators of how learners perceive, interact with, and respond to the learning environment. O’Brien et al. (1998) note that cognitive styles hold the greatest potential 
for yielding new knowledge that is critical in the educational experience. The authors posit that cognitive styles are defined as the habit associated with information processing. They represent a learner's typical mode of perceiving, thinking, problem solving, and remembering. While making the same point, Messick (1996), notes that cognitive styles involve both cognitive perception and processing. This sentiment is shared by Abbott et al. (2003), Davidson et al. (1999), and Reinhold (2004). O'Brien et al. (1998) argue that cognitive style is the most relevant variable in academic achievement or mental ability; especially when such constructs are examined through tests or other means of standardized evaluation.

Personality of the individual can vary in a continuum from introversion to extroversion. It is important to know that these types have nothing to do with ability or intelligence; these terms merely describe the way that different people function (Anderson, 2003). Some students are deep thinkers who tend to talk less than others. These are common traits of introverted students (Laney, 2002). One study has shown that noise distraction can be more harmful to introverted students than to extroverted students when it comes to study time. Introverted students can experience more difficulty understanding what they are reading in a noisy environment (Furnham \& Strbac, 2002).

A poor acoustical environment can impact student learning and behavior such as attention, listening, and speech perception. Students identified with potential learning difficulties are young listeners, children learning English as a second language, children with hearing loss, and children with otitis media (Anderson, 2003). Other students impacted by a poor acoustical environment are those with learning disabilities, central 
auditory processing disorders, and developmental delays (DiSarno et al., 2002), as well as students with normal hearing (McSporran, Butterworth, \& Rowson, 1997).

The ability to hear properly is one of the most important factors in a child's ability to process and learn new information. However, in the typical classroom, various environmental and student factors interfere with listening and comprehending (Flexer, 2009).

Previously, many educational audiologists have spent most of their time in assessing the hearing status of students and providing listening solutions to those students with hearing loss. Audiologists are being called on to provide solutions for improving the noisy environment in average classrooms that are full of students with normal hearing and with mild hearing impairment. Although Flexer, Wray and Ireland (1989) and Crandell, Smaldino and Flexer (2005) have provided excellent reviews of classroom listening for the hearing professional, there is a need for a simple description of classroom listening for the educator, administrator, and parent. The present study was developed to assist educational audiologists and classroom teachers to enhance the classroom learning environment. Parents must be made aware of the potential effects of noisy classrooms on learning and help ensure that steps are taken to maximize their child's education.

It is easy to conclude that in order to learn and comprehend well, a child must be able to receive all auditory signals (Rasinski, Flexer, \& Szypulski, 2006). For those students with known hearing loss, special devices that make the sound audible or provide special assistance to transform the audible signal into a visual signal, were used in the classrooms (Nelson, Kohnert \& Sabur, 2005). Unfortunately classrooms can be so noisy 
that most students from kindergarten to high school are likely to experience significant problems hearing the voice of a teacher. It is easy to understand that noise of significant volume can overpower speech from someone in the same room, preventing us from hearing what is being said (Nelson et al., 2005). Environmental noise levels during regular school activities are sometimes 4 to $38 \mathrm{~dB}$ above values currently agreed upon for optimal speech recognition by normal-hearing children, and the situation would be no different for hearing-impaired children taught in special classrooms (Flexer, 2000). Studies have shown that children with hearing problems or for whom English is a second language, have an especially hard time following what a teacher says. These students are more vulnerable to learning and behavioral disabilities (Crandall \& Smaldino, 2000).

For more than two decades, research has established a link between noise and poor academic progress (Lewis, 2000). Continual pleas for quiet, and frequent reminders to students about the volume of noise, have proven to be only a temporary measure for reducing the noise level (Bronzaft \& McCarthy, 2002). Every school teacher is familiar with the phenomenon of noise in the classroom (Emmer, 1995). The general conception is that noise is something the teacher should be wary of, something to be avoided, and something that hinders the realization of educational purposes (Cothran, Kulinna, \& Garrahy, 2003).

\section{Source of Noise in the Classroom}

Studies of the last decade have revealed that many classrooms have poor quality acoustics and that children are not always working in optimal classroom listening conditions (Nelson \& Soli, 2000). Because children primarily learn through listening, noisy classrooms can have serious effects on a child's ability to learn (Moody, Schwartz, 
Gravel, \& Ruben, 1999). The sources of classroom noise can be internal or external. Noise is either being generated inside a classroom or entering from an outside source. Some examples of internal noise sources include: fans, heating systems, ventilating and air conditioning systems, occupants, or even desks and chairs as they get dragged across a hard surface (Dockrell \& Shield, 2006).

Other internal classroom noises vary in many ways (Bronzaft \& McCarthy, 1975; Evans \& Maxwell, 1997; Maxwell \& Evans, 2000). Noises such as students tapping pencils, cell phone ringers, students talking, drumming, clicking their tongues, stamping their feet, singing, humming, or cracking their knuckles can drive the teacher and the students to distraction. Examples of background noises include environmental sounds such as wind and traffic noise, cell phone ringers, alarms and beepers, people talking, various bioacoustical noises, and mechanical noise from devices such as conditioning, fans and blowers, power supplies and motors.

The effects are more pronounced for older children (Darai, 2000). Although one might be able to ignore some extraneous noises, others interfere with the lesson or with the students' ability to concentrate (Laliberte, 2006). External noise sources outside the classroom may include: adjacent heating and cooling systems, adjacent hallways and rooms (other classrooms, gymnasiums, and cafeterias), construction or remodeling, roadways, trains, and airplanes. Attention to classroom acoustics does not only end with the acceptance of an acoustically appropriate design but also requires overall modifications to assess their effect (Nelson \& Soli, 2000). 


\section{Cognitive Load Theory}

Cognitive Load Theory (CLT) was initially proposed in the e early 1980s and now is considered a well-founded theory (Paas, Renkl, \& Sweller, 2003; Van Merriënboer \& Ayres, 2005), associated with learning. CLT is an instructional theory derived from our knowledge of the evolutionary bases of human cognitive architecture and the instructional consequences that flow from that architecture. Cognitive load can be defined as the mental load that performing a task imposes on the cognitive system (Sweller, 1988; Sweller, Van Merriënboer, \& Paas, 1998) caused by causal and assessment factors (Paas \& Van Merriënboer, 1994). Causal factors can be characteristics of the subject (cognitive abilities), the task (task complexity), the environment (noise), and their relations Assessment factors include mental load, mental effort, and performance as the three measurable dimensions of cognitive load (Paas \& Merriënboer, 1994).

According to Sweller and Merriënboer (2005), there are three types of cognitive load: intrinsic, extraneous, and germane. The first, intrinsic cognitive load occurs during the interaction between the nature of the material being learned and the expertise of the learner (Pollock, Chandler, \& Sweller, 2002). The key component being studied in terms of intrinsic cognitive load is element interactivity (Paas et al., 2003). Some types of learning need high levels of element interaction for the information to be processed (Paas et al., 2003; Sweller 1988, 1994). Working memory capacity is considered limited to seven plus or minus two elements or chunks of information (Miller, 1956). Tasks that contain a high number of interacting elements place high demands on working memory and therefore increase cognitive load (Sweller, 1988; Sweller et al., 1998). 
CLT suggested that meaningful learning happens best under conditions that are aligned with human cognitive architecture. This has also been demonstrated through the study of interactive multimedia, hypertext, and interactive software use (Moreno \& Valdez, 2005; Morrison \& Anglin, 2005). The extent to which curriculum materials impose a load on working memory varies widely (Sweller et al., 1998) and this cannot be altered by instructional manipulations. Only a simpler learning task that omits some interacting elements can be chosen to reduce this type of load.

The second type, extraneous cognitive load (ECL), is caused by the manner of presentation, factors such as activities that split attention between multiple sources of information (Kalyuga, Ayres, Chandler, \& Sweller, 2003; Sweller et al., 1998). ECL has been defined as the cognitive load that is imposed by instructional designs that require students to engage in activities "that are not directed at schema acquisition or automation" (Sweller, 1994, p. 299). Sweller and his colleagues, in their empirical research, have made clear that the reduction of extraneous cognitive load, offers a more effective way of learning complex cognitive tasks than conventional problem solving (Chandler \& Sweller, 1991, Sweller, 1999; Sweller \& Cooper, 1985; Tarmizi \& Sweller, 1988). The studies of Mayer and Moreno (1998), Mousavi, Low, and Sweller (1995), and Tindall-Ford, Chandler, and Sweller (1997) showed nine alternative ways of decreasing extraneous load.

By studying worked-out examples and solving goal- free problems CLT (Sweller, 1988) suggests that extraneous load must be as low as possible, so that all available mental resources can be used for the actual learning process (Sweller, 1988; Sweller et 
al., 1998). Unfortunately, this work on the reduction of extraneous cognitive load has often been misinterpreted by assuming that the cognitive load of learners needs to be kept at a minimum during the learning process (Sweller, 1994, 2004). If the load is imposed by mental activities that interfere with the construction or automation of schemas, that is, ineffective or extraneous load, then it will have negative effects on learning (Paas et al., 2003, Paas et al., 2004, Sweller et al., 1998; Van Merriënboer \& Sweller, 2005). If the load is imposed by relevant mental activities, for example, effective or germane load, then it will have positive effects on learning (Sweller, 1999). Reducing cognitive load is not necessarily beneficial, particularly in cases where working memory capacity limits are not exceeded and the load is already manageable (Sweller, 1994, 2004). As long as the load is manageable, it is not the level of load that matters, but rather its source (Sweller 1988, 1999). Although extraneous load does not hamper learning when tasks are low in intrinsic load, it does hamper learning when tasks are high in intrinsic load; hence, reducing extraneous load is imperative for such tasks (Van Merriënboer \& Sweller, 2005).

The third type of cognitive load, germane load, enhances learning, and results in task resources being devoted to schema acquisition and automation (Van Merriënboer \& Sweller, 2005). Germane cognitive load focuses on efforts by the instructional designer to help the learner devote resources to the development of schema and automation through mental effort (Paas et al., 2003). Motivation has been shown to be one key to this process (Van Merriënboer \& Ayres, 2005). Without proper motivation, mental effort remains low, thereby resulting in lower performance than when motivation is high (Paas, Tuovinen, Merriënboer, \& Darabi, 2005). 
Kalyuga et al. (2003) have shown that knowledge of the learner's level of expertise is of importance for instructional designers in order to be able to categorize information and activities as intrinsic, extraneous, or germane, and to predict learning outcomes. A cognitive load that is germane for a novice may be extraneous for an expert. In other words, information that is relevant to the process of schema construction for a beginning learner may hinder this process for a more advanced learner.

Intrinsic, extraneous, and germane cognitive loads are additive in that, together, the total load cannot exceed the working memory resources available if learning is to occur (Sweller \& Chandler, 1994; Sweller et al., 1998). The relations among these three forms of cognitive load are asymmetric. Intrinsic cognitive load is irreducible other than by constructing additional schemas and automating previously acquired schemas. Any available working memory capacity remaining after resources have been allocated to deal with intrinsic cognitive load can be allocated to deal with extraneous and germane load. A reduction in extraneous cognitive load by using a more effective instructional design can free capacity for an increase in germane cognitive load. If learning is improved by an instructional design that reduces extraneous cognitive load, the improvement may have occurred because the additional working memory capacity freed by the reduction in extraneous cognitive load has now been allocated to germane cognitive load. As a consequence of learning through schema acquisition and automation, intrinsic cognitive load is reduced. A reduction in intrinsic cognitive load reduces total cognitive load, thus freeing working memory capacity. The freed working memory capacity allows the 
learner to use the newly learned material in acquiring more advanced schemas. A new cycle commences; over many cycles, very advanced knowledge and skills may be acquired.

In many of the earlier experiments above mentioned, the focus of cognitive load theorists was on devising alternative instructional designs and procedures to reduce extraneous cognitive load compared to conventionally used procedures (Sweller \& Van Merriënboer, 2005). What has not been mentioned so far in cognitive load research but appears to be important in the studies of neuroscience and cognitive psychology that has not dealt with cognitive load, is the impact of external elements in the environment (casual factors of Merriënboer, such as noise and light) that could be the potential source of cognitive load (Hygge \& Knez, 2001; Smith \& Broadbent, 1980; Smith \& Miles, 1987). The goal of the researcher was to address this issue in the current experiment.

This study investigated if extraneous cognitive load is caused by causal factors (elements) in the environment such as sound (noise) and light. Due to obvious lack of this type of data in cognitive load theory research, the researcher attempted to combine the findings of studies in neuroscience and cognitive psychology in this investigation. This experimental approach also differed from earlier research in focusing on eliminating external sources of cognitive load rather than altering the instructional design to manage the cognitive load. Hence, the purpose of the study was to determine how well students learn when extraneous sound and light, that can be the potential sources of cognitive load, are eliminated. An Extraneous Light and Sound Elimination Chamber (ELSEC) was designed and constructed to eliminate the extrinsic effects of light and sound, and tested, before research questions related to student learning were addressed. 
There is a wealth of research indicating that the ergonomics of an environment significantly improve or retard individual and group learning performance (Baron et al., 1992; McCloughan et al., 1998). These elements include light and sound enhancement (Campbell \& Murphy, 1998; Dalgleish et al., 1996). The impact on cognitive performance was measured by memory (short-term memory, long-term memory and recognition), attention (short-term memory-load search) and problem solving (abstract embedded figure search) tasks, previously shown to be sensitive to environmental factors (Hygge \& Knez, 2001; Knez, 2001a; Smith \& Broadbent, 1980; Smith \& Miles, 1987). Since then, although a great body of research has, in general, addressed this issue, the combined impact of noise and light on cognitive and emotional processes have not attracted much attention (Berglund, Lindvall, \& Schwela, 1999; Cohen, Evans, Stokols, \& Krantz, 1986; Evans \& Lepore, 1993). Due to the obvious lack of data on combined effects of noise and light, what follows in this study is a discussion on the elements of "light" and "sound" affecting learning, performance, and achievement. This study also aimed to address the lack of data on the combined impact of noise and light on humans in previous research and to complement findings of irrelevant sound and light effect in memory studies.

\section{Purpose of the Study}

The purpose of the study was to determine how well students learn when extraneous sound and light, potential sources of cognitive load, are eliminated. This study also investigated gender and age as attributes that may be related to student achievement under the controlled conditions of light and sound as they directly co-relate with students achievement. 


\section{Assumptions}

The theory is based on the basic assumption that a person has a limited processing capacity, and proper allocation of cognitive resources is critical to learning (Van Merriënboer \& De Croock, 1992). Any increase in resources required for various processes not directly related to learning (e.g., integration of information separated over distance or time, or processing redundant information) inevitably decreases resources available for learning (Sweller, 1988). According to Mayer and Moreno (1998), CLT is best illustrated by the following three assumptions: (a) that humans possess separate information processing channels for verbal and visual material; (b) that there is a limited amount of processing capability available in each channel; and (c) that learning requires substantial cognitive processing in both channels (Bannert, 2002; Kirschner et al., 2006; Mayer, 2001; Moreno \& Mayer, 2002; Sweller, 1988). Research in the area of cognitive load theory, dual-channel theory (Mayer \& Moreno, 1998; Paivio, 1986), and multimedia instruction(Mayer, 2001; Mayer \& Moreno,2002), has yielded strategies for reducing the cognitive load of instruction thereby allowing students to focus their limited working memory resources on the meaningful information processing. Mayer (2001; Mayer \& Moreno, 1998, 2002) have conducted extensive research on multimedia instructions and have identified at least nine strategies for reducing cognitive load and improving retention and transfer.

One strategy in particular is the off-loading of content from one channel to another (Van Merriënboer \& Sweller, 2005). The dual-channel theory of working memory posits that humans possess two distinct channels for processing information: a visual/pictorial channel and an auditory/verbal channel (Mayer \& Moreno, 2002) Paivio, 
1986). Images, for example, are processed through the visual channel, while spoken narration or lecture are processed through the auditory channel. Written words, however, are processed in both channels as the images of the words are transformed into sounds (Bannert, 2002). Shifting information from one channel to another can reduce the amount

of essential processing required by the learner. Reduced-cognitive-load (RCL) instruction also reduces the potential for the split-attention effect, which occurs when learners are required to divide their attention between multiple inputs (Mayer \& Moreno, 1998). Studies described in the review of literature provide evidence for some of the consequences derived from these assumptions.

\section{Research Questions}

This study aimed to test the impact of noise and light on the performance of high school students. Students viewed a multimedia based instructional unit "Astronomy" for 50 minutes a day, for a period of 8 weeks. The multimedia based instructional unit is user-paced instead of system-paced. This study took place over an 8 week- period during the last 9 weeks of the year on the unit of "Astronomy." This study determined if student learning and retention can be enhanced by eliminating extrinsic cognitive load imposed by sound and light when presenting the content.

Based on the literature review, the effects of noise and sound on learning can also be linked to sex, learning styles, personality type and academic ability (Bradley and Lang, 2000; Kenz \& Enmarker, 1998).

It was hypothesized that there would be a measurable extrinsic effect of sound and light on student performance (Bronzaft \& McCarthy, 1975; Cohen et al., 1986; Hawkins \& Lilley, 1992). 
This study was designed to answer the following questions as they pertain to the performance of high school students.

1. Is the "Extraneous Light and Sound Elimination Chamber" effective in eliminating students' exposure to extrinsic sound and light?

2. Does eliminating extrinsic sound improve students' content learning?

3. Does eliminating extrinsic light improve students' content learning?

4. Does eliminating extrinsic sound and light improve students' content learning?

5. How do Group by Gender interaction affect the learning during during posttest (posttest - pretest)?

6. How do Group by Age interaction affect the learning during posttest (posttest pretest)?

7. How do Group by Gender interaction affect the learning during postpost test (postpost - pretest)?

8. How do Group by Age interaction affect the learning during postpost test (postpost - pretest)?

\section{Significance of the Study}

Research has indicated that noise and light in classrooms is one of many issues that may hamper sound education (Dockrell \& Shield, 2006). The findings of this study showed that extraneous sound and light have an impact on learning. Elimination of both the factors had a positive impact on students' academic achievement. Such findings can be used to design better learning environments. Such environments can be achieved with different electric lighting and sound systems that vary in their ability to provide good color rendering, low glare, low flicker, low noise and reverberation (Benya, Heschong, 
McGowan, Miller, \& Rubenstein, 2003). These environments will help people avoid unwanted distraction, drowsiness, levels of arousal and photosensitive behavior (Dockrell, \& Shield, 2006).

\section{Delimitations of the Study}

This study has the following delimitations:

1. The generalizability of the results is limited to the sample of participants in this study because individual participants were not randomly assigned to the control and treatment groups. Since the population selected to this study is limited to only one school in Miami-Dade County, the results cannot be generalized to all Miami-Dade County Public Schools.

2. The generalizability of the results is limited to multimedia settings as explained in this study. The results cannot be generalized to regular classrooms and laboratory settings where sound and light cannot be eliminated or controlled.

\section{Rationale}

The rationale of this study comes from a combination of professional and personal experiences in the researcher's classroom. This classroom is characterized by a poor acoustic learning environment which became a critical factor in the academic achievement of the students. Many of these students' (freshmen) learning is compromised by noisy or highly reverberant spaces and poor lighting systems. Students listen, learn, and function less in this noisy classroom which is located right next to the courtyard and adjacent to the cafeteria. Research informs us that many students are harmed by bad acoustics (Bronzaft \& McCarthy, 1975; Cohens et al., 1986; Crandall \& Smaldino, 2000; Hawkins \& Lilley, 1992). If the lighting environment is stimulating, the students' mental 
and physiological systems, visual performance, alertness and mood will improve (Isen \& Baron, 1991). To assist local educational audiologists and classroom teachers in obtaining technology to enhance the classroom learning environment, the present study was developed for use with administrators, school board members, and parents. Parents must be educated about the potential effects of extrinsic elements on learning and help ensure that steps are taken to maximize their child's education.

\section{Organization of the Study}

The first chapter provided a statement of the problem and its importance as well as a description of the study, its theoretical framework and the research questions. Chapter 2 provides a review of the literature and relevant research. The third chapter presents the research methodology and design. This includes a description of the participants, instrumentation, data collection, and data analysis procedures. Chapter 4 presents and summarizes the results of the investigation. Chapter 5 provides a summary of the entire investigation, relating the findings to the research questions and literature review, and offers possible conclusions that are evident or supported as a result of the data analysis. Chapter 5 includes implications of the study as well as recommendations for practice and future investigations based on the findings and discussions.

In summary, the purpose of this study was to examine the impact of extraneous sound and light on student achievement. Analysis of variance was employed. Data sources included pretest, posttest, and delayed posttest achievement scores. 


\section{Definitions}

Cognitive Load: - "Cognitive load theory has been designed to provide guidelines intended to assist in the presentation of information in a manner that encourages learner activities that optimize intellectual performance" (Sweller, van Merriënboer, and Paas, 1998, p. 251).

Extraneous Load: - Extraneous cognitive load-also known as ineffective cognitive load - is the result of instructional techniques that require learners to engage in working memory activities that are not directly related to schema construction or automation (Sweller, 1994).

Intrinsic Load: - "Intrinsic cognitive load through element interactivity is determined by an interaction between the nature of the material being learned and the expertise of the learners" (Sweller et al., 1998, p. 262).

Germane Load: - Germane cognitive load - also known as effective cognitive load-is the result of beneficial cognitive processes such as abstractions and elaborations that are promoted by the instructional presentation (Gerjets \& Scheiter, 2003).

Working memory:- Working memory, in which all conscious cognitive processing occurs, can handle only a very limited number — possibly no more than two or three — of novel interacting elements (Sweller, 1988).

Long term memory: - The contents of long term memory are "sophisticated structures that permit us to perceive, think, and solve problems," rather than a group of rote learned facts (Sweller, 1988). 


\section{CHAPTER II}

\section{LITERATURE REVIEW}

This chapter consisted of a review of two bodies of literature: (a) research studies based on cognitive load theory; and (b) studies from the field of cognitive neuroscience. Within the review of cognitive load theory's literature, the emphasis is on studies that deal with reducing or managing of extrinsic cognitive load associated with environmental factors such as sound and light that are detrimental to student learning (Van Merriënboer $\&$ Sweller, 2005). Though much research has been devoted to the effects of extrinsic cognitive load that is not central to the learning material, studies based on cognitive load theory rarely focus on elimination of extraneous sound and light. Hence this review of the literature will also draw upon studies from the field of cognitive neuroscience.

The literature related to cognitive load theory (CLT) with specific references to instructional strategies for minimizing the extrinsic cognitive load effect is limited to content based studies (Paas et al., 2003, 2004). The basic assumption underlying CLT is that the human information processing system is characterized by limited workingmemory capacity (Kalyuga et al., 2003). The theory, focused on managing complex cognitive tasks in which instructional control of cognitive load is critically important for meaningful learning, provides the context for the study. 


\section{Theoretical Framework}

There is a clear distinction between theories and frameworks, as used in this study. Cognitive theories explain all the factors involved in learning and cognition, whereas frameworks guide the researcher in investigating certain aspects of learning, specifically, frameworks are based on, and can possibly extend, an existing theory of learning (Cottrell, 2003). While this study is based on cognitive load theory, the cognitive architecture and principles of multimedia instruction is the framework under which the collection and interpretation of this study's data are made (Cobb \& Steffe, 1983). The central notion of Cognitive Load Theory (CLT) (Paas et al., 2003, 2004; Sweller, 1999, 2004) is that if individuals are to learn effectively in a learning environment, the architecture of their cognitive system, the learning environment, and interactions between both must be understood, accommodated and aligned.

The CLT explains learning outcomes by considering the strengths and limitations of the human cognitive architecture and deriving instructional design guidelines from knowledge about how the human mind works (Paas et al., 2003). This theory was developed in the early 1980s, and provided instruction that differed from the prevailing orthodoxies of the time (Sweller, 1988). Having established a variety of basic instructional designs, an increasing number of cognitive load theorists from all parts of the world considered the interaction of these instructional designs - first, with the characteristics of the information and tasks that learners were dealing with and, second, with the characteristics of the learners themselves (Mayer \& Anderson, 1991). Those interactions were proven unique in their ability to generate a large range of instructional designs in various contexts (Johnson-Laird \& Wason, 1970; Paas et al., 2003). This 
theory and its design guidelines were the first ones to provide insight on basic cognitive processes and their origins rather than merely using known cognitive processes to generate instructional designs (Paivio, 1991; Mayer \& Moreno, 1998; Mayer \& Sims, 1994).

\section{Cognitive Architecture}

Sweller et al. (1998) discussed the main effects predicted by the theory, and reviewed empirical studies providing support for those effects (Kalyuga, Chandler, \& Sweller, 1999; Kalyuga, Chandler, \& Sweller, 2001). The basic assumptions underlying CLT are that the human information processing system (cognitive architecture) is characterized by the limited working-memory capacity, the idea that only a few pieces of information can be actively processed at any one time (Baddeley, 1992, Paas et al., 2003). Working memory is able to deal with information for no more than a few seconds with almost all information lost after about 20 seconds unless it is refreshed by rehearsal (Cowan, 2001). Working memory has no known limitations when dealing with information retrieved from long-term memory (Ericsson \& Kintsch, 1995; Sweller, 2004). In effect, long-term memory alters the characteristics of working memory. Longterm memory holds cognitive schemata that vary in their degree of complexity and automation (Kalyuga et al., 2003).

These schemata organize and store knowledge, but also heavily reduce working memory load because even a highly complex schema can be dealt with as one element in working memory. Hence schemata can act as a central executive, organizing information or knowledge that needs to be processed in working memory. It is under these circumstances that there are no limits to working memory. If knowledge is completely 
unavailable to organize information, it must be organized randomly and the organization then tested for effectiveness (Van Merriënboer et al., 2002). Working memory must inevitably be limited in capacity when dealing with novel, unorganized information because as the number of elements that needs to be organized increases linearly, the number of possible combinations increases exponentially. Random testing of the effectiveness of possible combinations based on many elements becomes impossible effectively due to a combinatorial explosion. This problem of exponential growth can only be accommodated by severely limiting the number of information units that can be processed simultaneously. That problem does not arise when dealing with information from long-term memory that is already organized (Sweller, 2003, 2004).

\section{Learner's Expertise}

A central aspect of CLT and other cognitive models of learning is the ability of the learner to direct and actively monitor their own cognitive processes-executive control (Baker \& Brown, 1984; Garner, 1987). Empirical evidence demonstrates that increased executive control tends to enhance learning (Nist, Simpson, \& Olejnik, 1991; Shapiro \& Niederhauser, 2004). Human expertise comes from knowledge stored in these schemata, not from an ability to engage in reasoning with many elements that have not been organized in long-term memory. Human working memory simply is not able to process many elements. Expertise develops as learners mindfully combine simple ideas into more complex ones.

These schemata organize and store knowledge, but also heavily reduce working memory load because even a highly complex schema can be dealt with as one element in working memory (Gerjets, Scheiter, \& Schorr, 2003). 
By taking into consideration the demands on the limited cognitive resources that are needed for schema acquisition and proceduralisation, CLT allows for predictions and explanations as to how learning can be effectively supported by teaching and instruction. Accordingly, cognitive load researchers have drawn from CLT to explain and predict how students learn from different instructional designs (Sweller, 1988, 1994; Sweller et al., 1998).

The design of powerful learning environments, in which instructional conditions are aligned with the cognitive architecture, requires understanding of the learner characteristics that affect the underlying knowledge structures and their interactions with the learning task. Hence the instructional material selected for the purpose of this study follows six of the nine principles of cognitive load theory in multimedia instruction. These principles will be explained in detail in chapter three.

A learner's expertise has been identified by cognitive load researchers as a key characteristic to consider in the design of instructional techniques (Kalyuga et al., 2003). Kalyuga et al. (2003) have described a phenomenon called the expertise reversal effect, indicating that the effectiveness of instructional techniques depends very much on levels of learner expertise.

Instructional techniques that are effective with inexperienced learners can lose their effectiveness and even have negative consequences when used with more experienced learners (Kalyuga et al., 2003). So, as novice learners gain expertise, their requirements in learning materials change in accordance with their capacity for cognitive load (Sweller et al., 1998). 
According to Kalyuga et al. (2003) constructed schemata may become automated if they are repeatedly applied. As is the case for schema construction, automation can free working memory capacity for other activities because an automated schema, acting as a central executive, directly steers behavior without the need to be processed in working memory(Sweller, 1988). Because automation requires a great deal of practice, automated schemata only develop for those aspects of performance that are consistent across problem situations, such as routines for dealing with standard game positions in chess, for operating machines, and for using software applications. From an instructional design perspective, well-designed instruction should not only encourage schema construction but also schema automation for those aspects of a task that are consistent across problems (Van Merriënboer et al., 2002). Novel information must be processed in working memory in order to construct schemata in long-term memory. The ease with which information may be processed in working memory is a focus of CLT.

CLT argues that the interactions between learner and information characteristics can manifest as intrinsic or extrinsic cognitive load (Paas, Tuovinen, Tabbers, \& Van Gerven, 2003). The first one is extraneous cognitive load (ECL), is the thrust of CLT and also the basis for the original worked example research. ECL has been defined as the cognitive load that is imposed by instructional designs that require students to engage in activities "that are not directed at schema acquisition or automation" (Sweller, 1994, p. 299). CLT was devised primarily to provide reduction principles of ECL, with worked examples to reduce the extraneous load that resulted from presenting students with cognitively demanding traditional problem-solving techniques (Chipperfield, 2006; Sweller, 1988; Sweller \& Cooper, 1985). 
Intrinsic cognitive load (ICL) is the load that depends on the difficulty of the material to be understood. Although originally proposed to be the fixed source of load (Sweller et al., 1998), there is new evidence that learning materials of high complexity are enhanced when the interacting elements are taught first in isolation and the relevant interactions are instructed later, suggesting that intrinsic load can be manipulated by instruction (Pollock, Chandler, \& Sweller, 2002). Moreover, it is the opinion of this researcher that the fixed nature of ICL contradicts the very assumptions of CLT itself. That is, material that is complex for one individual may be very simple for another. It all depends on the schemas that have been acquired by that individual in the past and the degree to which those schemas have become proceduralised in long-term memory (Sweller, 1994).

Finally, CLT introduces the concept of germane cognitive load (GCL) as the load that results from cognitive activities that are relevant to the processes of schema acquisition and automation. Therefore, this type of load is desirable because "it contributes to, rather than interferes with learning" (Sweller et al., 1998, p. 264). For instance, within the worked-example research, some studies have examined techniques to increase example elaboration, that is, methods that prime the learner to draw inferences concerning the structure of the example, the rationale underlying solution procedures, and the goals accomplished by individual steps (Renkl, 1997). Similarly, other researchers have examined techniques that require students to compare worked examples to increase the likelihood that they will abstract, by comparison, the structural features that examples may have in common from superficial features of the examples (Quilici \& Mayer, 1996). 
The use of information characteristics to design powerful learning environments has always been at the heart of cognitive load research. In order to promote understanding (Mousavi et al., 1995), information should be allocated as much as possible to processes that contribute to schema acquisition. In other words, the learner's germane load should be optimized and their extraneous load should be minimized (Sweller et al., 1998; Van Merriënboer \& Sweller, 2005). This important principle is the backbone of many studies conducted ever since the introduction of cognitive load theory (Sweller, 1988).

Extraneous cognitive load is not necessary for learning (i.e., schema construction and automation) and it can be altered by instructional interventions. Instructional strategies to lower extraneous load are well documented (Sweller et al., 1998). Studies of Mayer and Moreno (1998) on multimedia instructions have found that extraneous cognitive load may be imposed, for example, by using weak problem solving methods such as working backward from a goal using means-ends-analysis, integrating information sources that are distributed in place or time, or searching for information that is needed to complete a learning task (Sweller et al., 1998). Overloading one of the processors that constitute working memory also may increase it (Kalyuga et al., 2003). Visual and auditory working memory is partially independent. If multiple sources of information that are required for understanding are all presented in visual form (e.g., a written text and a diagram), they are more likely to overload the visual processor than if the written material is presented in spoken form, thus enabling some of the cognitive load to be shifted to the auditory processor (Mousavi et al., 1995). 


\section{Minimizing Extraneous Load}

In 1998, CLT had been used almost exclusively to study instruction intended to decrease extraneous cognitive load. Because extraneous cognitive load is undesirable in a learning context and is a comparatively easier problem to deal with than intrinsic cognitive load, quite a number of different strategies have been developed to reduce it and have given place to a number of observable effects. CLT states that an instructional presentation that minimizes extraneous cognitive load can facilitate the degree to which learning occurs. Chandler and Sweller (1991) demonstrated that one method for reducing extraneous cognitive load is to eliminate redundant text. Mousavi et al. (1995) and Sweller et al. (1998) argued that cognitive load is reduced by the use of dual mode (visual-auditory) instructional techniques and that the limited capacity of working memory is increased if information is processed using both the visual and auditory channels, based on Sweller et al. (1998) identified the split-attention effect as the situation whereby a statement and a diagram must be integrated using working memory in order to understand an instruction that neither the textual or pictorial components could convey independently.

Split-attention occurs because there are two separate sources of information that can only be examined one at a time. While reading the text, one is unable to look at the diagram, and vice versa. The modality effect describes the utilization of both audio and visual sensory input channels, thus effectively expanding the capacity of a working memory that is only really utilizing one of the two channels (Mousavi et al., 1995). The typical example given is that of the textual component of a split-attention effect being transmitted as a spoken narration instead, freeing the visual sensory channel to focus 
solely on the graphical component. Some of the major effects that yield better schema construction and higher transfer performance and that may be attributed to a decrease in extraneous cognitive load are briefly explained by Sweller et al. (1998) in Table 1(Appendix A).

\section{Prior Knowledge}

Using a large group of ninth-grade students, Olina, Reiser, Huang, Lim, and Park (2006) investigated the influence of different problem formats, problem presentation sequence, and different ability levels, on an achievement and transfer test, and on subjective cognitive load ratings. As expected, the higher ability students outperformed the lower ability students on the criterion measures of achievement and transfer scores. However, the subjective cognitive load ratings during practice did not differ significantly between ability levels, and were rather low. The latter finding is especially surprising because on average the achievement and transfer test scores of both groups were relatively far removed from the maximum score. Moreover, the students showed relatively low achievement gains (about 11\%) from pretest to posttest. According to the authors this finding can be explained by the fact that these students already had relatively high levels of prior knowledge of punctuating sentences, as is corroborated by their pretest achievement scores. These learning gains indicate, therefore, that the experimental treatment had only a limited influence on their existing schemas of sentence punctuation. On the other hand, these findings (i.e., low achievement gains and low subjective load ratings), could also be interpreted as a lack of student motivation. Furthermore, as in the study of Ayres (2006) it would have been interesting if the authors had collected subjective cognitive load measures during the transfer and achievement test. This would 
have enabled the researchers to evaluate whether the experienced load during practice differed significantly from that during the test phases. Following the same line of reasoning, it would have been a good had the researchers registered the time both student groups needed to deal with these problems. It is not necessarily that higher ability students dealt with these problems more rapidly than lower ability students.

Alternatively, if both groups would have received an equal amount of time to deal with these problems, a more distinct difference in performance between these students groups could have emerged. Time factor limitations could have accentuated differences in performance that are not present when there are no strict time limitations. If this is true, it would shed a different light on the test scores and experienced cognitive load of the present study.

\section{Cognitive Load and Age}

The study by Van Gerven, Paas, Van Merriënboer, and Schmidt (2002) has studied the influence of instructional design on younger and older adults. According to Van Gerven et al.'s (2000) study, the cognitive capacity of elderly people is smaller than the cognitive capacity of young people. Any gain in cognitive capacity caused by a lowering of extraneous load is proportionally larger for the elderly than for the young.

In diverse experimental settings and problem domains a complexity effect has been experienced by the elders (Czaja \&Sharit, 1993; Gilinsky \& Judd, 1994; Lorsbach \& Simpson, 1988). This indicated that relative to the young, the performance of the elders was impaired when the complexity of the task is raised (Van Gerven et al., 2000). When the demands of the task are high the cognitive declines associated with aging are apparent, and a relatively heavy burden is imposed on the cognitive system, such as in 
transfer tasks. One can assume that the elderly perform relatively poorly if a transfer problem deviates considerably from previously encountered problems (i.e., far transfer) than if a transfer problem closely resembles earlier problems (i.e., near transfer) (Paas \& Van Merriënboer, 1994; Renkl, Stark, Gruber, \& Mandl, 1998; Van Gerven, Paas et al., 2000). Numerous studies have shown that, in case of complex tasks, worked examples lead to superior performance and transfer relative to conventional problems. These results were obtained with young adults (Paas \& Van Merriënboer, 1994) as well as with children (Pillay, 1994).

All these principles immediately provide us with essential characteristics of a powerful learning environment. First of all, the design of the learning environment itself should be taken into account. Cognitive load theory focuses on two major issues. How are the learning materials or problems presented to the learner? In what way does the learner interact with the environment? Secondly, the background of the users should be taken into consideration. What do they already know? What is their motivation to use this learning environment? But also, and often forgotten, what is their age?

An important problem in cognitive load research is when element interactivity of complex tasks is still too high for learning (Van Merriënboer, Kirschner, \& Kester, 2003) even after removal of all sources of extraneous load? Then, the question that comes to the researcher's mind is "are there any elements in the environment that aren't central to the learning might be a potential source of extraneous cognitive load"? Very limited research has been done in this area; however, findings from the studies of neuroscience research and cognitive psychology have suggested that the environmental elements such as sound and light have a significant effect on cognitive processes especially the ambient noises in 
and outside the learning environment as well as the acoustic characteristics of the learning environment.

Many previous studies within the cognitive load framework have almost exclusively focused on reducing extraneous cognitive load or on inducing germane cognitive load, in order to improve the learners' understanding of the task at hand (Van Merriënboer \& Sweller, 2005). These studies have demonstrated that the detrimental effects of extraneous cognitive load (e.g., redundancy effect, split attention effect, etc.) should be taken into account in instructional designs (Sweller, 1991). Furthermore, these studies have shown us that germane cognitive load can be induced by practice variability, in particular random practice (i.e., all versions of a task are randomly mixed), or by providing feedback and guidance to the learner (Van Gerven et al., 2000). What these studies do not tell us, is how to deal with the elements that aren't central to the learning and might be the potential source of extrinsic load. So, the researcher, in this study examines the impact of eliminating the extraneous sound and light on student learning.

\section{Cognitive Styles}

Cognitive style refers to the way an individual organizes and processes information (Riding \& Rayner, 1998). Cognitive strategies may vary from time to time, and may be learned and developed (Pillay \& Wilss, 1996). Cognitive styles by contrast are static and are relatively in-built feature of the individual (Riding \& Cheema, 1991). According to Miyata and Norman (1986), there are two styles of human information processing: task-driven processing and interrupt-driven processing. In a task-driven state, people become engrossed in the task to which they are paying conscious attention and they do not process other events (Schnotz, \& Rasch, 2005). In an interrupt-driven state, 
people are usually sensitive to extraneous events (noise), and are easily distracted by extraneous thoughts and external signals. Individual differences play a role in deciding whether a person is in a state of task or interrupt driven processing. Some people are more easily controlled by task-driven structures; others are more distractible by extraneous events (noise) or thoughts.

According to Pillay and Wilss (1996), two cognitive style groups consisting of four styles are Wholist-Analytic and Verbal-Imagery dimensions (Riding \& Cheema, 1991). Individuals along the Wholist-Analytic continuum tend to process information in wholes or parts. Those along the Verbal-Imagery dimension tend to represent information verbally or in mental images. These styles are not absolute and indeed, most individuals are bi-modal, intersecting the two (e.g., a Wholist/Verbaliser or Wholist/Imager) (Morrison \& Anglin, 2005).

An understanding of cognitive styles is important to the educators because styles affect the way individuals process and acquire information, make decisions, solve problems and respond to other people in social situations (Riding \& Rayner, 1998). Wholists organize information into chunks to form an overall perspective of the given information (Morrison \& Anglin, 2005). Analytics, by contrast, view information in conceptual groupings focusing on one grouping at a time. Verbalisers process information as words or verbal associations, whereas Imagers relate information better with mental images or pictures (Riding \& Cheema, 1991). Members of each group can make use of other modes by conscious choice; however, this requires additional processing, imposing extraneous cognitive load which may hinder learning (Sweller, 1988). It follows that designing online instruction suited to the learner's cognitive style, 
reduces extraneous cognitive load. Unfortunately, in this study, much of instructional content in the Glencoe's online text book Geology, the Environment and the Universe (Florida edition) is designed on experts' preferred cognitive styles, which may be in contradiction with the learner's preferred style. One of the conclusions drawn by Pillay and Wilss (1996) is that online instruction has increased accessibility to a broader audience; learners may be at a disadvantage in terms of cognitive accessibility. The study provides preliminary information to suggest that there may be an interaction between online instruction and individuals' preferred cognitive style (Pillay \& Wilss, 1996). The conclusions indicate a need for further research in replicating this study and by designing additional studies around online instruction that can be tailored to individual cognitive styles to promote learning through reduced extraneous cognitive load.

Students' ability to increase their own willingness to engage in and complete academic activities is thought to be important for understanding learning and performance because students' motivation to complete academic tasks can change the time it takes to finish those tasks (Barrick \& Mount, 1991). Do personality test and learning motivation predict performance? Many studies already found that personality can be a predictor of work performance Because of its obvious applied significance in educational psychology there has been a vast amount of research into the relationship between them (Eysenck, 1967). However, this study is not directed towards an integration of personality types, learning styles, motivation, and demographic variables in measuring students' learning under light and sound controlled conditions.

Pastor (2004), in his article "Background noise Jumbles brain circuit" quoted that Martin and Bedenbaugh documented how different background noises change the 
readiness of different parts of the auditory forebrain to interact with foreground sounds.

Each type of noise activates some brain areas, while others are idled or suppressed. Noise effectively changes the computations which can be used to perceive a foreground sound. Bedenbaugh stated that noise interference is a fundamental aspect of many impaired populations; Children struggling with language and reading often have problems specifically in the presence of noise (Pastor, 2004)

Background noises do not just cover up conversation, but they may actually scramble brain activity, a discovery that helps explain why even perfectly loud speech can be hard to understand in a noisy room because background noise reconfigures the computations performed by the auditory forebrain (Edward \& Merzenich, 2004).

Researchers explored the effects of background noises by recording brain activity detected by electrodes implanted in the auditory thalamus of the rats (Edward \& Merzenich, 2004). Each of the background noises changed the brain's electrical activity, suggesting brain circuits received a message, but the message was scrambled (Pastor, 2004). Similar interactions occur during human audio reception and noise processing, which kindles the understanding that noise is more than just a nuisance. Noise specifically interferes with the way the brain processes information (Edward \& Merzenich, 2004). Scientists examined how brain cells in alert rats responded to specific sounds while one of three standardized noises played in the background. They discovered that brain activity actually decreased in the presence of background noise (Evans \& Lepore, 1993). Furthermore, background noise did not simply cover up sounds; it interfered with the brain's ability to process or interprets information about a sound, even though the sound was heard (Berglund \& Lindvall, 1999). 
Trimmel and Poelzl (2006) conducted their study on the effect of background noise on brain activity as reflected by the direct coupled (DC) potential. Results suggested reduced cortical resources by widespread inhibitory activation through background noise. It can be concluded that even low intensity background noise is associated with energy consumption and with impaired performance in spatial attention (Trimmel \& Poelzl, 2006). The phenomenon may play a role in auditory processing disorder, a problem first noticed in children in the 1970s (Solan, Shelley-Tremblay, Larson, \& Mounts, 2006). The lack of coordination between the ear and brain that characterizes the disorder is expected to be widespread, although it is difficult to diagnose, according to the American Academy of Audiology (Solan et al., 2006).

\section{Sound/Noise}

Both inside and outside the classroom, children practice intensive, continuous learning and develop their social, intellectual, and communication skills in a variety of situations. However, classroom experience is an opportunity to focus on these critical skills in a controlled environment and provide the stimuli needed to help a child realize his or her full potential. Classrooms are largely auditory learning environments with listening serving as the cornerstone of the educational system (Berglund et al., 1999; Cohen et al., 1986; Evans \& Lepore, 1993). Most of the learning takes place through speaking and listening in the classroom. Actually, children spend $45 \%$ of the school day engaged in listening activities (Berg, 1987, Kjellberg \& Landström, 1994). Most of the teaching is done by talking, students asking questions, and students listening to both the teacher and other students. Multimedia materials also depend on students listening to a message. 
While classroom design and materials have changed little over the past 20 years, there has been a significant change in teaching styles. Today's classrooms offer many different learning experiences: large and small group instruction, group projects and individual work. In today's classroom, instruction remains primarily through teacher lectures, instructional videos, and computers remain the primary mode of classroom instruction (DiSarno et al., 2002). One of the side effects of child-centered learning approaches is increased noise levels in the classroom. Bronzaft and McCarthy (1975), Cohen et al. (1986) and Hawkins and Lilley (1992) contended that students' concentration levels are affected by sounds that come from inside and outside the classrooms.

According to the Institute for Enhanced Classroom Learning, children in today's classrooms have difficulty understanding $20 \%$ to $30 \%$ of what their teacher said because of excessive ambient background noise. Do these disruptions affect the learning process? Many educators and parents do believe so. Some normal children, when put in an average classroom, break down tremendously, Crandall (2005). In an above-average classroom listening environment, grade-school children with no hearing problems can make out only $71 \%$ of the words a teacher at the front of the room pronounces, says Crandall (2005). According to Crandall (2005), in the worst noisy environments, children can process just $30 \%$ of the sounds. This problem is severe for children in elementary schools, but poor acoustics go largely undetected by adults. High classroom noise levels from the incessant squeals of chattering children to loud machinery may be affecting children's ability to learn (DiSarno et al., 2002). In addition, Jones, Miles, and Page (1990) reported that classrooms often buzz with noise levels so high they impair a young 
child's speech perception, reading and spelling ability, behavior, attention, and over-all academic performance.

The ability to hear properly is one of the most important factors in a child's ability to process and learn new information (Bronzaft \& McCarthy, 2002). However, in the typical classroom, various environmental and student factors interfere with listening and comprehending (Evans \& Maxwell, 1997). Some students struggle to pay attention in class and other study areas because small background noises interfere with their concentration (Berg, 1987). However, background noise does not affect all students in the same way. Factors such as learning styles and personality type may determine whether noise is a distraction or not (DiSarno et al., 2002).

\section{Noise and Performance}

Noise is unwanted or meaningless sound that may distract attention from cues that are important for task performance (Salas et al, 1996). Significant background noise may negatively affect performance in a number of ways (Smith, 1989). In some cases the noise may directly affect one's ability to perform a task but there are also many ways in which noise can disturb task performance indirectly (Tremblay, Billings, Friesen, \& Souza, 2006).

For instance, noise may disrupt sleep patterns, disturb normal social behavior or increase subjective feelings of stress, all of which could ultimately lead to poor performance in cognitive tasks (Jones et al., 1990).

Loud background noise (above $90 \mathrm{dBA}$ ) typically reduces the quality of performance. A number of studies have demonstrated that noise hinders performance on cognitive tasks involving vigilance, decision-making, and memory (Banbury et al., 2001; 
Broadbent, 1971; Salas et al, 1996; Smith, 1989). In an experiment more relevant to the school setting, it has been shown that reducing noise levels in a factory setting improves work performance by reducing the number of work errors (Broadbent, 1971). According to Broadbent's, now classic theoretical treatment of the effects of noise on performance, loud noise leads to over-arousal, which narrows attention, restricting ones focus to a limited range of cues. This inability to attend to less salient cues ultimately leads to deterioration of performance (Broadbent, 1971).

The negative effects of noise are not only limited to cognitive performance but also demonstrated that noise disrupts both social behavior and indices of subjective stress (Salas et al., 1996). These effects may have important consequences for group situations like collaborative learning. The subjective impression of stress, especially in combination with poor social functioning may lead to situations where the subject is emotionally upset and thus may affect performance (Banbury et al., 2001; Broadbent, 1971; Salas et al., 1996; Smith, 1989). Even if the effects on cognitive performance are small, they may compound in the long term, leading to a slow degradation in performance over time. (Ohrstrom, 2000, 2002; Thiessen, 1978). However, in the majority of the classic studies on noise subjects were exposed to high intensity (90 dBA and higher), and sometimes, variable noise. Hence it is certain that these effects would generalize to the noise experienced by the public school students (Ohrstrom, 2003).

Three of the most commonly recognized learning styles are visual learning, tactile learning, and auditory learning. Studies have shown that auditory learners are most distracted by background noise (Banbury, Tremblay, Macken, \& Jones, 2001). The irrelevant sound effect in short-term memory is commonly believed to entail a number of 
direct consequences for cognitive performance in the office and other workplaces. Instances of such performances include reading, arithmetic or (in laboratory experiments) silently reading a list of numbers and reporting back that series after a brief delay (Banbury, Tremblay, Macken, \& Jones, 2001). Petersson and Ingvar (2004) revealed that for auditory distraction to disrupt working-memory performance requires the activation of the dorso-lateral prefrontal cortex of the brain (Tremblay et al., 2006a).

Underachievement by America's children is a frustrating phenomenon for both educators and parents. However, underachievement seems especially troubling when it is manifested by our brightest students (Gowan, 1955, p. 247) and has been described as one of the greatest social wastes of our culture (Seeley, 1993). However, examination of learning style profiles revealed some differences between achievers and underachievers in preferences for quiet or sound, flexibility or structure in assignments, bright light or dim, and level of need for mobility (Rayneri, Gerber, \& Wiley, 2003). Many low achievers showed a strong need for tactile and kinesthetic modalities; sound in the learning environment; informal seating design; and bright lighting (Rayneri, Gerber, \& Wiley, 2003). There is no universally accepted definition for underachievement. When attempting to discuss the phenomenon, some researchers focus on standardized instruments alone to define it (Supplee, 1990), whereas others place more emphasis on student actions in the classroom (Baum, Renzulli, \& Hebert, 1995). However, most researchers agree that underachievement is a discrepancy between expected performance based on some standardized measure of ability and actual performance (Emerick, 1992; Peterson \& Colangelo, 1996; Whitmore, 1980). 
What causes these bright students to fall short of reaching their potential? Baker, Bridges, and Evans (1998) found that factors included family, environment, school, and the individual. Other researchers (Rayneri et al., 2003) have noted that underachievement is linked to a mismatch between the learning styles of high-ability students and the instructional approaches used in the classroom (Baum et al., 1995 \& Whitmore, 1986).

One's learning style was defined by Dunn and Dunn (1993) as "the way in which each learner begins to concentrate on, process, and retain new and difficult information" (p. 2). They hypothesized that the interaction of various environmental factors affects each person differently as he or she learns. Several studies have suggested that underachieving students make significant gains in classroom performance when their learning style preferences are accommodated (Andrews, 1990; Gadwa \& Griggs, 1985).

Restak (1979) found that $60 \%$ of one's learning style is a biological and developmental set of characteristics. This can result in effective instruction for some students, but ineffective instruction for those whose learning styles do not match their school environment. Individual responses to learning modalities, mobility, sound, light, temperature, and seating preferences are biological, while motivation, responsibility (conformity), and need for structure or flexibility are thought to be sociological (Dunn, 1990; Dunn \& Griggs, 1995 Gemake, Jalali, Zenhausern, Quinn, \& Spiridakis, 1990).

In Vastfjall's (2002) study of annoyance and sensitivity to noise, noise distraction was shown to be more harmful to introverted students than to extroverted students when it comes to study time. Introverted students can experience more difficulty understanding what they are reading in a noisy environment (Dornic \& Ekehammar, 1990). 
Audiologists Fligor and Ives (2006) have found that loud sounds stress and could damage the delicate hair cells in the inner ear that convert mechanical vibrations in the air (sound) into the electrical signals that the brain interprets as sound. If exposed to loud noises for a long time, the hair cells can become permanently damaged and no longer work, producing hearing loss.

Some past research has suggested that certain individual differences can affect sensitivity to noise stressors, and, in turn, performance in noisy environments (Smith, 1989). For example, locus of control, or beliefs about the degree to which an individual's actions will affect outcomes, have been shown to be related to performance under noise conditions. Related work has demonstrated that individuals scoring high on anxiety measures such as neuroticism perform more poorly under noise stress, relative to individuals who are less anxious (Nurmi \& von Wright 1983; von Wright \& Vauras, 1980). Finally, some research in the psychological resiliency area has demonstrated a relationship between other individual differences and the tendency to perform well under a variety of stressful conditions. This relation has not been yet demonstrated for noise stress specifically. Since this is not a central focus of this study, personality factors and learning style preferences in performance measures were not included in this research.

\section{Light}

Another physical factor in the workplace and learning environments that may affect humans is artificial light. Human factors research on lighting has to a great extent addressed the visual aspects of light, investigating the phenomena of visual discomfort (e.g., Vos, 1984) and visual performance (e.g., Rea, 1987). Recently, however, evidence for non-visual, biological (e.g., Campbell \& Murphy, 1998; Dalgleish et al., 1996) and 
psychological (e.g. Baron et al., 1992; McCloughan et al., 1999) effects of light have been indicated. In line with the latter findings, Knez (1997) and Knez and Enmarker (1998) reported effects of indoor lighting on positive and negative moods. In particular, the type of lamp (color, temperature, such as warm-white lighting, more reddish versus cool-white lighting, more bluish) was shown to influence subjects' moods, an effect which varied with gender. Contrasting mood reactions of younger and older subjects to type of lamp were also found by Knez and Kers (2000), as well as gender differences in problem solving and memory task performances in different type of light settings. Hence, artificial light and especially its color parameter have been shown to evoke moods in females and males, as well as to influence their cognitive performances (Knez \& Kers 2000).

Studies of Hathaway (1995) concluded that lighting systems have important nonvisual effects on students who are exposed to long periods of time. Research shows that learning benefits (Fielding, 2006; Zamkova \& Krivitskaya, 1966), under the higherintensity bluish light than under the reddish-white light (Raloff, 2006), suggesting that schools should consider installing fluorescent lights that emit more blue.

If the lighting environment is stimulating, the students' mental and physiological systems, visual performance, alertness, and mood will be improved (Isen \& Baron, 1991). Whether the impact of indoor lighting on cognition is direct or mediated by effect is, however, still an open question (Knez, \& Kers, 2000).

However, cognitive researchers have found that the impact of these external elements cause bodily stress, anxiety, hyper-activity, attention problems, and other distress leading to poor learning. 
Lack of attention is associated with significant school failure (Gathercole \& Pickering, 2000) and is one of the most common childhood school problems (Carrol, Bain, \& Houghton, 1994). Lack of attention leads to avoiding specific types of tasks or response requirements in favor of alternative environmental objects or internal thoughts (Cohen et al., 1986; Evans \& Maxwell, L (1997); Evans \& Lepore, 1993). A possible explanation for this avoidance is a mismatch between task requirements (intrinsic) (Smith, 1989), and the student's learned skills or natural abilities (extrinsic) (Salamé \& Baddeley, 1982, 1986; Tremblay et al., 2006a). Once tasks are appropriate to the skills and abilities of the child in their requirements (input, response, and cognitive processing), we can expect the child to demonstrate attention and performance to that task (germane). When problems remain after accommodation for these skill differences, the difficulty lies in the interaction between the requirements of the task (elements) and the cognitive processing of the child (Tremblay et al., 2006a).

Previously; many educational audiologists were being called on to provide solutions for improving the noisy environment in average classrooms that are full of students with normal hearing and with mild hearing impairment. Although Flexer, Wray, and Ireland (1989) and Crandell et al. (2005) have provided excellent reviews of classroom listening for the hearing professional, there is a need for a simple description of classroom listening for the educator, administrator, and parent.

With so many schools located near noisy highways, railroads, and airports, principals/teachers need to become advocates for lessening the noises from these outside/inside sources (Anderson, 2004). Corrective actions may include reducing background noise, increasing (amplifying) the instructor's/teacher's level of speech, 
improve the instructor's/teacher's teaching/learning strategies, or improving the classrooms acoustical design. Each of these means of addressing the problem has its own pros and cons (Hygge, 2003). There have been many obstacles to improving noisy classrooms. Improving the overall acoustics of a classroom can be a very complex and costly task in the current situation where the administrators/school board members project budget crisis. It is not just the costs to build and operate the schools but also the cost to the students and society if they do not learn what is being taught (Bronzaft \& McCarthy, 1975).

While amplification of instructor's/teacher's voice may be an inexpensive option, this solution does not help the situation where students respond to questions and to each other. Cohen et al. (1986) reported a marginal improvement in reading ability and mathematical skills after a reduction of background noise of $7 \mathrm{dBA}$. Reducing background noise may appear to be the optimal choice but it may be the most costly or simply not possible (Evans \& Lepore, 1993). For example, if the gymnasium, cafeteria, band room or music class causes the background noise, it would be very unlikely that classrooms would be moved (Cohen et al., 1986). Since lowered chronic noise levels improved children's reading and comprehension, it seems reasonable to assume that minimizing the noise exposure to below threshold level experimentally, that is, by reducing the extrinsic load effect, could improve students' achievement. However, no such studies are reported in the literature. 


\section{Chapter Summary}

This chapter consisted of a review of the literature on the principles of cognitive load theory in reference to multimedia instruction and strategies to minimize the cognitive load effect when presenting the content. First, the chapter presented information on managing the cognitive load which supports this study. It then examined the neuroscience and cognitive psychology literature on the effect of sound and light on cognition, thus providing the context for the study. Subsequently, the chapter presented the role of extrinsic effect on students' achievement. The following chapter presents the methodology for the study, including a description of the setting, participants, instrumentation, research design, procedures, and data analysis. 


\section{CHAPTER III}

\section{METHODOLOGY}

This chapter includes the methodology used in this study. The first section includes the description of the population that was studied and a description of the research design employed. As this study utilized a quantitative component, the instrumentation and materials used for data analysis in this component are presented under the quantitative section.

\section{Participants}

The target population for this study was 148 ninth-grade subjects who are enrolled in the researcher's Earth and Space Science class. These participants were enrolled in a public school, a senior high school in a mid-sized southeastern city in Florida. The school is from Miami-Dade school district. The demographics were 92.2\% $(\mathrm{n}=3540)$ Hispanic; 02.2\% $(\mathrm{n}=84)$ African American; 04.6\% $(\mathrm{n}=176)$ Caucasian; and 01.0\% $(\mathrm{n}=39)$ other racial backgrounds. Of the 148 students, $41.89 \%(n=62)$ were female students and $58.11 \%(\mathrm{n}=86)$ were male students. All participants in this study were from regular education. About 3\% of the students were labeled as English as Second Language (ESL) students. Out of these 148 students, $52.7 \%$ are boys and $47.3 \%$ are girls. 43 students (0.4\%) belong to Caucasian, 18 students (01.7\%) are African Americans, 991 students (93.3\%) are Hispanics and 10 students (00.9\%) belong to the other. About $3 \%$ of these students were labeled as English as Second Language students. The study took place over a 3-week period in the latter part of the school year, that is, in the fourth 9-week period. Middle school credentials indicated that these students were familiar with the Internet and 
basic computer applications such as Microsoft Word and PowerPoint. The school operated on a traditional 50-minute, seven-bell schedule. This sample meets the sampling size criteria established by Krejcie and Morgan (1970) needed to generalize experimental results to the larger population.

\section{Variables}

The data needed for this study were details regarding student achievement so the cultural differences, personality differences, learning styles, linguistic levels, and the building acoustical conditions would not be considered as variables in this study. Age, Gender, and Groups are the control variables while the achievement scores are the dependent variables in this study.

\section{Research Design}

This study utilized Campbell and Stanley's (1963) nonequivalent control group design. According to Stanley and Campbell this is "one of the most widespread experimental designs in educational research" and is an effective design when the "control and experimental groups do not have pre-experimental sampling equivalence" (p. 47). Campbell and Stanley indicated that this condition exists in school classrooms, as they are "naturally assembled collectives" (p. 47). Data are often analyzed using ANOVA techniques. For the purpose of this study, students in intact classes enrolled in the earth and science subject $(\mathrm{n}=115)$ were used as the experimental group while randomly selected intact subjects $(n=33)$ served as the control group. Period numbers were placed in a hat and students in those periods were randomly assigned to these groups by picking the period numbers out of the hat. Use of the nonequivalent control group design 
adequately controls for the effects of history, testing, instrumentation, and maturation on internal validity (Fisher 1959; Stanley \& Campbell, 1963).

\section{Treatment}

The focus of the experimental treatment centered on the extrinsic effect of Light and Sound and its impact on student achievement and attitude. The curriculum and accompanying software is a technology-based approach by which students utilized Glencoe's "Interactive Chalkboard," a CD-based hypermedia for concept review, and "ECLIPSES Science Explorer Astronomy," the online Educational 3D simulation software to solve real world problems using their knowledge of the concepts in a selfpaced, learn-on-your own environment.

\section{Materials}

The materials used for this study were noise cancellation headphones, cardboard partitions, Styrofoam sheets, computers, Glencoe's "Interactive Chalkboard," a CD-based hypermedia for concept review, and "ECLIPSES Science Explorer Astronomy," the online Educational 3D simulation. ForgeFX presents interactive 3D simulations created for Prentice Hall's secondary grades science program, Science Explorer` 2005. These projects represent interactive simulations and visualizations built to accompany the Science Explorer digital curriculum on inquiry and problem-based learning environment. Guided by the theories and research on problem-based learning in its design, the goal is to engage earth science students in solving a complex problem that require them to gain specific knowledge about both laws that govern the motion of our solar system, and the tools and procedures scientists use to study it. 
The Glencoe's Earth Science geology, the Environment, and the Universe student online edition (2006) was downloaded onto the computers for students' use instead of the regular text book for references.

\section{Noise Cancellation Headphones}

The researcher decided to use Bose noise-cancellation headphones instead of the regular headphones for the simple reason that the regular headphones depend upon the traditional noise suppression techniques (such as their ear cups) to prevent higherfrequency noise from reaching the interior of the headphone. Bose noise cancellation headphones have a large ear cup that is filled with sound absorbing material. When the sound vibrations from the air reach them, these sound absorbing materials do not move as much as the sound molecules move in the air. This dampens the frequency of the sound and as the wave travels through layers of sound absorbent material, it is blocked immediately. Harris, in "How Noise-canceling Headphones Work," illustrated well in Figure 1 that the incoming wave from the noise-canceling headphone and the wave associated with the ambient noise have the same amplitude and frequency, and troughs are arranged so that the crests of one wave line up with the troughs of the other wave and vice versa. Both these waves cancel each other out in a phenomenon known as destructive interference, enabling the listener can focus on the desirable sounds. According to Tokhi and Leitch (1992), noise-cancelling headphones reduce unwanted ambient sounds (i.e., acoustic noise) by means of active noise control (Nixon, McKinley, $\&$ Steuver, 1992). Noise cancellation is a method to reduce or completely cancel out undesirable sound, such that a person cannot hear it (Kurtus, 2009), as shown in Figure 1. 


\section{Inside noise-canceling headphones}

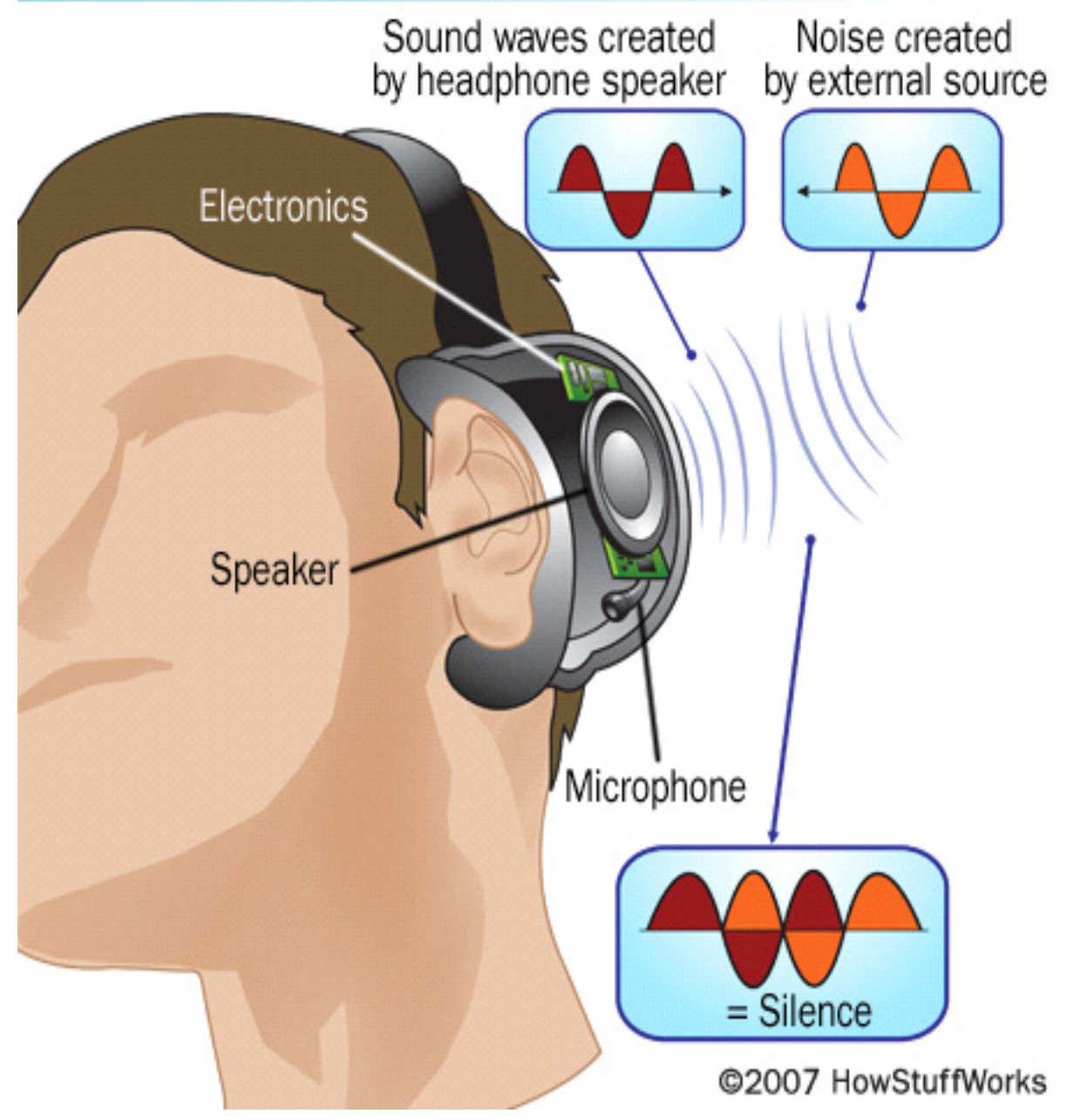

Figure 1 How noise cancellation headphones work

The phenomenon is often known as Active Noise Cancellation because the electronics involved actively cause the noise cancellation in real time. In the case of a single sound frequency, the same frequency $180^{\circ}$ out of phase can be added to cancel the sound. If the sound waves were $180^{\circ}$ or one-half a wavelength out of phase, the sum of the waveforms would be zero. They would cancel each other out, and there would be no sound (Banbury et al., 2001, Broadbent, 1971; Salas et al., 1996; Smith, 1989). 


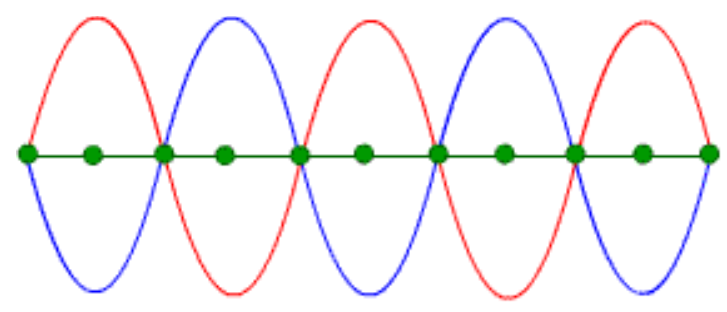

Figure 2 Sound cancellation waves

The most common electronic noise cancellation device consists of special earphones. Essentially, this involves using a microphone, placed near the ear, and electronic circuitry which generates an "antinoise" sound wave with the opposite polarity of the sound wave arriving at the microphone (Kuo \& Morgan, 1996). This results in destructive interference, which cancels out the noise within the enclosed volume of the headphone. Adding two sound waves would result in no sound because it is the addition of positive and negative pressure, which then equals zero.

Kurtus (2007) in his article, "Beat Frequencies in Sound," explained sound cancellation mechanism — sound is created when an object vibrates in a medium (air, liquid or solid). It is a compression wave in air or other media. That means the wave first compresses to an amount greater than normal air pressure. This is the positive part of the wave graphic (Kuo \& Morgan, 1996).). Then the air expands to a pressure less than normal air pressure. This is the negative part of the wave, the part below the zero centerline. Adding the positive pressure and negative pressure will result in normal air pressure.

According to Jacobson (2004), noise cancellation almost always requires the sound to be cancelled at a source, such as from a loud speaker. That is why the effect works well with headsets, since the person can contain the original sound and the 
canceling sound in an area near the ear (Manning \& Harris, 2003). "How Noise-canceling Headphones Work" students can wear these headsets to cancel out unwanted noise, while being able to listen to the computer module or listen to their own music while they study. In applications where the sound comes from many areas, such as in a room, it is difficult to cancel the sound from each area (Jacobson 2004). But, scientists and engineers are working on solutions. In this type of a headphone, there are three elements that make noise cancellation possible. There is a microphone pointing away from the ears, so that it can receive the low frequency sounds that have managed to penetrate the passive noise cancellation techniques (Campanella, 2006). It then sends this sound to an electronic circuit embedded inside the headphone which analyzes the sound and calculates its frequency and amplitude so that it can create a wave. Once it has successfully analyzed the wave pattern of the incoming low frequency sounds, it sends signals to the speaker (in the headphone) to create a sound wave which is exactly opposite (or 180 degrees out of phase) to these low frequency sounds (Herman, \& Bowlby, 1998). Since these waves get superimposed and are exact opposites of one another, it leads to the complete cancellation of that wave to achieve silence. The circuit can be programmed to analyze the complete signal coming inside the headphone and then create anti-sound only for those sounds that a normal human would consider as noise and leave alone important sounds such as police sirens, human voices, and similar sounds (Kolmansberger, 2005). The same concept is applied for noise cancellation in cars, conference rooms, and even space shuttles. A microphone listens for unwanted sound, sends it to the analytical chip that decodes the wave pattern and produces a wave, which is 180 degrees out of phase or the exact opposite (meaning that where there are crests in the original wave, the new one will have 
troughs) of the unwanted sound that gets cancelled out automatically (Manning \& Harris,2003).

\section{Setting}

Prior to the intervention, the researcher issued the parental consent form (Appendix A) and the student's consent form (see Appendix B) to make sure that both the parents and students were fully aware of the study before giving the permission to participate. As a precautionary measure, students were not informed in advance about the group in which they would be placed. Students were informed that they will be using the same class textbook but the Online Edition for 45 minutes in their daily 1-hour science class. This book along with the Glencoe Interactive Chalkboard was aligned with the National Science Content Standards on scientific investigation and problem-solving methods, Sunshine State standards, and FCAT benchmarks on concept understanding. Students worked in the computer lab and had access to computers for their own use. The teacher had discussed the procedure of the study with the students and explained that they would be placed randomly in one of four different groups: Light controlled group (LS); Sound controlled group (SC); Light and Sound controlled group (L\&S); or the control group.

The pretest (Appendix C) was administered to all the subjects of the four groups on the March, 24th, 2008, the last Monday of the third, nine-week period. After that week, students had spring vacation for a week from March 31st to April $6^{\text {th }}, 2008$. Soon after the vacation, on day 1 , as soon as the students entered the computer lab, the teacher 
and the students had a recapitulation session about their primary task. For the rest of the 18 days, the teacher/researcher allowed the students to decide what their learning tasks were for each day and how to approach the problem. Students were asked to write down the questions that come up during the intervention time and discuss them with the teacher in the class as whole at the end of each session. Though the teacher had her own ways of facilitation, for this study each day, the teacher began the lesson with a mini-discussion for 5 minutes on what the students did in the previous day and addressed questions that came up. Students' questions were often answered by more questions from the teacher or answered by other students. Then, the students were allowed to work on the computer for exactly 45 minutes. The teacher monitored the students' participation, checked their progress, and ensured that they were on task. Most days, the lesson ended with another short discussion about what the students accomplished that day, any questions that surfaced, and what the learning goal should be for the next day. Because all the necessary tools for students to work on the problem were provided via technology in this study, it was possible for the researcher to spend most of the class time monitoring the students individually. Even though the teacher's role was minimal in the explaining the content during the intervention, she facilitated her students' learning through daily questioning, answering, and discussion before and after the intervention time.

\section{Instrumentation}

Students' understanding of the science concepts introduced in the unit "Beyond Earth" was measured through a 30-item multiple-choice test "Astronomy Unit Test", selected from Glencoe's Exam View CD-Rom. Glencoe's Exam View CD-Rom has been used districtwise and also in several studies with similar samples to measure earth science 
content achievement and to assess knowledge, comprehensive, and application level objectives of the cognitive domain.

In Florida, students are assessed based on the content that has been selected to match the benchmarks outlined in the Sunshine State Standards. Content validity for this test is estimated from the multiple choice test developed by Glencoe/McGraw-Hill. The researcher along with six other earth science teachers read the materials and the reviews to determine whether the publisher had made a compelling case that the test is valid and appropriate for the intended use. In order for a teacher to make sound decisions based on students' achievement results, the teacher must be willing to consider the possible threats to the validity of the test score. These experts checked the correspondence between the treatment and test item contents, and determined that the nature of the test items was strongly related to the important concepts introduced in the instruction (see Appendix D).

Based on the review of her colleagues, the researcher concluded that the questions in Exam View are written based on the content in the chapters and that content is tied directly to state and national content standards. These experts also checked the correspondence between the treatment and test item contents, and determined that the nature of the test items was strongly related to the important concepts introduced in the instruction. However, according to the publisher, the questions are reviewed by specific content specialists, but they are not analyzed for psychometrics as Exam View is not a norm-referenced test. Mr. Smith, the sales representative of Glencoe Publications Florida, had informed the researcher that every item on the test was measured against the Sunshine State Standards' curriculum and is aligned with the FCAT benchmarks (Personal Communication, Mr. Smith, (2009). The Exam-Pro test has been designed 
specifically to meet the needs of today's teachers and students. Materials at the developmental stage are field tested and revised based upon the input from both teachers and students.

Focus groups and teacher advisory boards were appointed for creating materials to meet the ever-changing needs of today's classroom. Experts in content areas and special needs, including specialists in such areas as inclusion, cognitive development, and ELL, review and revise lesson manuscript - all of this taking place prior to publication to ensure that the content, aligned to national and state standards and assessment, is developmentally appropriate, pedagogically correct, and adaptable for all students.

Based on the researcher's conversation with the sales representative, it seems to the researcher that, because customers have requested that this product be fully editable and customizable for use in their specific classrooms, the publisher has no way of ensuring the validity of each test generated. It appeared that the publisher strives to offer a variety of questions at a variety of different cognitive levels to best meet the customers' diverse needs and to rely on teachers' expertise to create exams that suit the content they have covered.

The instrument was further classified into three categories (factual, comprehensive, and integrated items) which correspond to Bloom's Taxonomy (1956) of knowledge (factual), comprehension, and application (integrated) levels (Forehand,2005). The same panel of earth and space science experts, who were knowledgeable about the criteria of these categories, classified these items into three categories with high agreement of $97 \%$. 
To evaluate for validity and reliability, the researcher used the questions from the "Exam View" and administered them to the subjects who had already taken the earth and space science course earlier. These subjects participating in the pilot study were different from the subjects participating in the final research.

The questionnaire measures the learning outcome on three main concepts:

questions 1-8 measure students' knowledge of "Tools of Astronomy"; questions 9-24 measure students' knowledge of "The Surface of the Moon"; and questions 25-30 measure the students' knowledge of "The Solar System."

Since no direct teaching was noted in using all the instructional materials (online edition book, interactive chalkboard, and the Internet), a good score on the test would indicate the student has acquired a good understanding of the scientific topics introduced in the topic through his or her self-directed learning, classroom discussions, and/or peer interaction. This test was given both prior to and after intervention. To measure students' retention of the knowledge, it was also given to the students 2 weeks after the completion of the unit "Beyond Earth." Given that there were at least 15-days between the pretest and posttest, the pretest should not have served as a cue to the students. Students were not told about the retention test.

\section{Procedure}

In the beginning, students were asked to read Unit 8, "Beyond Earth," which deals with astronomy, using the student online edition along with the PowerPoint presentations of the interactive chalkboard CD. In this unit, the students explained how telescopes worked and how eclipses are formed, described space exploration, theories of the moon formation and its phases, understood the electromagnetic spectrum and wave properties, 
explained the behavior of light and shadow formation, and finally identified the relative positions and motions of Earth, the Sun, and the Moon. At the end of each instructional goal, students were asked to manipulate the positions of the Sun, Moon, and the Earth in order to form the geometry of eclipses and lunar phases. In order to do so, students must first gain the knowledge of properties of light and image formation. To capture the image with relative position of light, students must engage in a variety of problem-solving activities. This real-time 3-D simulation of the Sun, Earth, and Moon explains lunar and solar eclipses, as well as the defined moon phases. The student can manipulate the Sun, the Earth, and the Moon into all of their phases as well as view the phases from a variety of different perspectives. This 3-D simulation allowed the student to control and interact with solar eclipses, lunar eclipses, and the different phases of the moon. Eclipses depend on the moon's revolution around Earth. The moon's orbit is tilted with respect to Earth's orbit. So the moon rarely goes directly between Earth and the Sun or directly behind Earth. When the moon does move into one of these positions, an eclipse occurs. This simulation allows the student to control the position of the Earth, Sun and Moon while viewing the scene from a number of different angles using telescope simulations and perspectives to fully understand the concepts being taught. Each instruction group experienced the same topics and instructional time.

To assist students in their problem-solving, a set of cognitive tools performing various functions was provided via technology as hyperlinks. Based upon Lajoie's categorization of cognitive tools (1993, p. 134), these tools can share cognitive load, support cognitive processes, support cognitive activities that would be out of reach otherwise, and allow hypotheses generation and testing. Computer-based cognitive tools 
are tools that are intended to engage and facilitate cognitive processing (Kommers, Jonassen, \& Mayes, 1992).

Examples of tools that share cognitive load in the concept databases are provided as links in the student online edition. These are carefully constructed and well-organized knowledge databases enhanced with graphics, animations, and 3-D videos. If students want to search the laws of reflection and refractions, the shadow formation, arrangement and electromagnetic spectrum, the relative motion of sun moon and the earth, they can access such information readily in the solar database. If they come across unfamiliar concept, they can look it up in the concept database that provides visually illustrated tutorials on various science topics. Such tools help reduce the memory burden for the students and put the multimedia-enriched information at students' fingertips. Examples of tools supporting cognitive processes are the concept mapping tools that are spatial representations of concepts and their interrelationships that simulate the knowledge structures that humans store in their minds (Jonassen, Beissner, \& Yacci, 1993). Presented in the short video format, the expert tool is available at critical points to model an expert process in solving the central problem.

\section{Analysis of the Data}

To analyze Hypotheses 2, 3, and 4, univariate analysis of variance was performed on the knowledge test on "Beyond Earth." Univariate ANOVA allowed us to control for other influences such as gender and age and examine interaction effects. ANOVA generated pair wise comparisons between groups. Independent sample T tests compared the outcomes between groups. 
The between subjects factors were Sound (with and without) and Light (with and without). The within subjects factor was time (pre, post). For significant effects, pair-wise comparisons were performed using Bonferroni's procedure at a 0.05 significance level.

To analyze Hypothesis 5, 6, 7, and 8, 2 x 4 analyses of ANOVA were conducted with gender and age interaction effects as additional factors. The between subjects factors were Sound (with and without) and Light (with and without). The within subjects factor is time (pre, post, ppost). For significant effects, pair-wise comparisons using performed using Bonferroni's procedure since there could be smaller sample size due to attrition.

Thus $2 \times 4$ Analysis of Variance was conducted on the interaction effects. The between subjects factors are Sound (with and without) Light (with and without). The within subjects factor is time (pre, post and postpost). In each of the analyses, the independent between-groups variables were Age Group, with levels of age 1 and age 2 and Gender with levels boys and girls. There were four treatment groups. This yielded a 4 (between groups $) \times($ within groups) design. Simple effects were analyzed as a follow up test after a significant interaction obtained. Significant interaction between group and gender in ANOVA was followed by post hoc tests in which all the 8 groups were subjected to independent sample t-tests to look into the gender effect.

\section{Chapter Summary}

The study examined the impact of eliminating the extraneous effects of sound and light on students' performance. Participants were freshmen from one public school who volunteered to participate in this study. A 30-item multiple-choice test selected from Glencoe's Exam View CD-Rom was used as an instrument to measure the performance scores at different intervals of time. Reliability and validity of the instrument were not 
considered findings as the teacher is compelled to use the state prescribed test bank questions. Analysis procedures were described for each research question. 


\section{CHAPTER 1V}

\section{DATA ANALYSIS}

This chapter presents the results of a study that examined the impact of eliminating extraneous sound and light during student learning. Quantitative data regarding participants' achievement scores were gathered using “The Earth Science Achievement Test." The same instrument was administered to all the participants of all the groups during pre-, post-, and post-post time. The learning outcome variables of interest are the scores on posttest and follow up test (post-posttest). Age and genderrelated performances were measured using univariate analysis and also their interaction effects were measured by factorial analysis. Demographic data regarding the participants were gathered through this instrument as well. In accordance with analysis of variance repeated measures, the data were analyzed statistically.

This study evaluated the relationship of gender and achievement (scores), age and achievement (scores) at different treatment conditions and different time levels. The factors were Gender, Age, Group, and Time. The dependent variable was the achievement scores (a within-subjects variable) has three levels, pretest, posttest, and post-posttest consisting of 30 items (achievement test) administered at 3 different times with a difference of 2 weeks in between each test. Treatment (between-subjects variable) has four levels (groups): Light and Sound controlled (group 1), Sound only controlled (group 2), Light only controlled (group 3), and Neither light nor sound control (group 4). The control variable, Gender (between-subjects variable), has two levels: girls and boys. Another control variable, Age, has two levels (between subject variable): 14years (age 1), 15 and 16 (age 2) years. 
A two-way design ANOVA (with independent measures on gender and repeated measures on time) is the appropriate test in these circumstances (Campbell \& Stanley, 1963). These analyses yielded a 2 x 4 factorial design. There were eight cells and 148 subjects in the experiment shown in Table 2 and in Table 3 . The values of the first variable, CELLS, give information about the cell number for the one-way design. A value of 1 for CELLS corresponds to the A1B1 cell, 2 to the A1B2 cell and so on. The values for CELLS for MSE and DFE will be missing since this information corresponds to the analysis as a whole, not any particular cell. The means inside the boxes are called cell means, the means in the margins are called marginal means, and the bottom right-hand corner is called the grand mean.

Table 2

Factorial ANOVA Cells for Group by Gender

\begin{tabular}{lllll}
\hline Treatment & & & & \\
\hline Gender & Group1 & Group 2 & Group 3 & Group 4 \\
Female & Cell 1 & Cell 2 & Cell 3 & Cell 4 \\
Male & Cell 5 & Cell 6 & Cell 7 & Cell 8 \\
\hline
\end{tabular}


Table 3

Factorial ANOVA for Group by Age

Treatment

\begin{tabular}{lllll}
\hline Age(categories) & Group1 & Group 2 & Group 3 & Group 4 \\
Age 1 & Cell 1 & Cell 2 & Cell 3 & Cell 4 \\
Age 2 & Cell 5 & Cell 6 & Cell 7 & Cell 8 \\
\hline
\end{tabular}

\section{Statistical Analysis for Pretest}

Test data were analyzed using a number of techniques including descriptive statistics and/univariate analysis (Palomba \& Banta, 1999). Descriptive statistics techniques (frequency, maximum, mean, median, minimum, and mode) described the characteristics of the data. Univariate analysis was used for preliminary testing and background characteristics of participants to predict test scores (questions 2, 3, and 4). Two-way analyses were used to find the interaction effects of gender and age on the test scores (questions 5, 6, 7, and 8). Interpretation of the data begins with describing and analyzing the group, gender, age, and their achievement scores in pretest, posttest-pretest (diff1) and post posttest-pretest (diff 2), for the convenience of the readers. 
Table 4

Values in Each Variable

\begin{tabular}{llllll}
\hline $\mathrm{N}$ & Gender & $\begin{array}{l}\text { Light } \\
\text { Control }\end{array}$ & $\begin{array}{l}\text { Sound } \\
\text { Control }\end{array}$ & Group & Age \\
\hline 148 & $\begin{array}{l}\text { Boys } \\
\text { vs }\end{array}$ & 74 & 74 & 4 & 2 \\
& Girls & & & & \\
\hline
\end{tabular}

Table 4 reveals lists of values (categories) within each selected variables and the number of times each category occurs. The participants number $(\mathrm{N}=148)$, variables included in the study (gender, age, and group type), with no missing valid numbers $(100 \%)$.

Table 5

Gender Frequency Distribution

\begin{tabular}{rllll}
\hline Gender & Frequency & Percent & Valid Percent & Cumulative Percent \\
\hline 1 girl & 62 & 41.9 & 41.9 & 41.9 \\
2 boy & 86 & 58.1 & 58.1 & 100.0 \\
Total & 148 & 100.0 & 100.0 & \\
\hline
\end{tabular}

Table 5 is the simple frequency distribution for the variable gender (1: female, 2 : male). The frequency columns display the frequency of each score. There are 62 girls $(41.9 \%)$ and 86 boys (58.1\%). There are no valid missing values indicated. 
Table 6

Light Control Frequency Distribution

\begin{tabular}{cllll}
\hline $\begin{array}{l}\text { Light } \\
\text { Controlled }\end{array}$ & Frequency & Percent & $\begin{array}{l}\text { Valid } \\
\text { Percent }\end{array}$ & $\begin{array}{l}\text { Cumulative } \\
\text { Percent }\end{array}$ \\
\hline 1 Yes & 74 & 50.0 & 50.0 & 50.0 \\
2 No & 74 & 50.0 & 50.0 & 100.0 \\
Total & 148 & 100.0 & 100.0 & \\
\hline
\end{tabular}

Table 6 is the simple frequency distribution for the variable light controlled (1:

yes, 2: no). There are 74 students in each frequency column indicating 50\% of each cell. Cumulative percentage includes scores that are equal to the current value.

Table 7

Sound Control Frequency Distribution

\begin{tabular}{rllll}
\hline $\begin{array}{l}\text { Sound } \\
\text { Controlled }\end{array}$ & Frequency & Percent & $\begin{array}{l}\text { Valid } \\
\text { Percent }\end{array}$ & $\begin{array}{l}\text { Cumulative } \\
\text { Percent }\end{array}$ \\
\hline 1Yes & 77 & 52.0 & 52.0 & 52.0 \\
2 No & 71 & 48.0 & 48.0 & 100.0 \\
Total & 148 & 100.0 & 100.0 & \\
\hline
\end{tabular}

Frequency Table 7 is the simple distribution for the variable sound controlled (1: yes, 2: no). There were 77 students in the "yes" frequency column (52\%) and 71 students (48\%) in "no" frequency column. The Valid Percent shows the same values indicating no missing data. Cumulative percentage scores are equal to than the current value. 
Table 8

Treatment Group Type Frequency Distribution

\begin{tabular}{lllll}
\hline Treatment groups & Frequency & Percent & $\begin{array}{l}\text { Valid } \\
\text { Percent }\end{array}$ & $\begin{array}{l}\text { Cumulative } \\
\text { Percent }\end{array}$ \\
\hline $\begin{array}{l}\text { 1 Light and sound } \\
\text { controlled }\end{array}$ & 38 & 25.7 & 25.7 & 25.7 \\
2 Sound controlled & 39 & 26.4 & 26.4 & 52.0 \\
3 Light controlled & 36 & 24.3 & 24.3 & 76.4 \\
4 Neither light nor & 35 & 23.6 & 23.6 & 100.0 \\
sound controlled & & & & \\
Total & 148 & 100.0 & 100.0 & \\
\hline
\end{tabular}

Table 8 is the simple frequency distribution for the variable (Group 1) Light and sound controlled, (Group 2) Sound only controlled, (Group 3) Light only controlled, and (Group 4) Neither light nor sound controlled). There were 38 (25.7\%), 39 (26.4\%), 36 $(24.3 \%)$, and $35(23.6 \%)$ students in the frequency columns. Cumulative percentage includes scores that are equal to the current value.

Table 9

Age Factor Frequency Distribution

\begin{tabular}{llllll}
\hline & & & & Valid & Cumulative \\
No & Age & Frequency & Percent & Percent & Percent \\
\hline 1 & 14yrs & 83 & 56.1 & 56.1 & 56.1 \\
2 & $15 \mathrm{yrs}$ & 51 & 34.5 & 34.5 & 90.5 \\
& and 16yrs & 14 & 9.5 & 9.5 & 100.0 \\
Total & & 148 & 100.0 & 100.0 & \\
\hline
\end{tabular}

Table 9 is the simple frequency distribution for the variable age (14years; 15years and 16years). Students of age 14 were 83 in number (56.1\%), students of age 15 years were 51 in number $(34.5 \%)$, and students 16 years of age were 14 in number $(9.5 \%)$. 
Students aged 15 and 16 years were $65(43.9 \%)$ in number. The Valid Percent column shows the same values. Cumulative percentage includes scores that are equal to than the current value.

The basic assumptions used in ANOVA were: (a) The populations are normally distributed, and (b) Each value is sampled independently from every other value.

The researcher's goal for performing univariate analysis was to find the central tendency, variability or dispersion, and to find the shape of the overall distribution. In the next part of the chapter, the data analysis was organized first by pretest scores of all the three variables, followed by the analysis of difference in posttest-pretest scores of all the three variables, and finally by the analysis of difference in post posttest-pretest scores of all the three variables.

\section{Group Pretest Scores}

Table 10

Dependent Variable Pretest Achievement Test Score

\begin{tabular}{llll}
\hline Group type & Mean & Std. Dev & $\mathrm{N}$ \\
\hline 1 Light and sound controlled & 10.84 & 1.952 & 38 \\
2 Sound controlled & 10.85 & 2.312 & 39 \\
3 Light controlled & 10.33 & 1.882 & 36 \\
4 Neither light nor sound controlled & 8.46 & 2.477 & 35 \\
Total & 10.16 & 2.355 & 148 \\
\hline
\end{tabular}

Descriptive statistics Table 10 for pretest achievement scores indicated that (Group 1) Light and sound controlled $(M=10.84, S D=1.952)$ performance was marginally lower than the Sound only controlled (Group 2) $(M=10.85, S D=2.312)$. 
(Group 3) Light only controlled performance $(M=10.33, S D=1.882)$ was greater than neither light nor sound controlled performance (Group 4) $(M=8.46, S D 2.477)$. Before interpreting these means, one must first examine the results of the ANOVA displayed in the Tests of Between-Subjects Effects table.

Table 11

Testing for Homogeneity of Variance for Group Pretest Scores

\begin{tabular}{llll}
\hline $\mathrm{F}$ & $\mathrm{df1}$ & $\mathrm{df2}$ & Sig. \\
\hline 1.252 & 3 & 144 & .293
\end{tabular}

We first calculated homogeneity of variance since it is an important factor in AVOVA. Table 11 is Levene's Test for Equality of Variances on pretest scores that was used for testing the Type I error with alpha at .05.

The Levene test hypothesized as:

$\mathrm{H}_{\mathrm{o}}$ : The variances of the groups are equal.

$\mathrm{H}_{\mathrm{a}}$ : The variances of the groups are different at least by one pair.

The homogeneity test on the pretest achievement scores (Table 11) indicated $F=1.252$ $(d f=3)$ "Sig." value $.293(p>.05)$, which is clearly not significant. Hence, the researcher failed to reject the null hypothesis and there is no reason to doubt the assumption of homogeneity of variance.

\section{Normality Tests}

All statistical methods are based on the four main assumptions. Distributional assumptions for ANOVA are: (a) Linearity_-The relationship between the dependent variable and the fixed variables is a linear relationship, (b) Constant Variance of the Error Term-Equal variances (homoscedasticity), (c) Independence of the Error Terms-Each 
predicted value is not related to any other prediction, and (d) Normality of the Error Term Distribution. The independent and dependent variables are both normally distributed. Before applying statistical methods that assume normality, it was necessary for the researcher to perform a normality test on the data (with some of the above methods, we checked residuals for normality). Hence, the researcher performed all the above tests on time (pposttest-pretest) diff 1 and (ppost-pretest) diff2.

Table 12

Standardized Residual for Pretest

\begin{tabular}{lll}
\hline \multicolumn{2}{l}{ Shapiro-Wilk } & \\
Statistic & df & Sig. \\
\hline .989 & 148 & .331 \\
\hline
\end{tabular}

Table 12 revealed the Shapiro-Wilk normality test to determine whether or not a random sample of values follows a normal distribution. The hypothesis for this test is as below:-

$\mathrm{H}_{0}$ : The residuals are normally distributed.

$\mathrm{H}_{\mathrm{a}}$ : The data distribution is non-normal.

The test for normality table indicated the sample size N (148), with no missing values. Since the $p$ value in Shapiro-Wilk is $0.331(p>0.05)$. Since the $p$ value is greater than 0.05 , the null hypothesis has not been rejected and concluded that the samples are drawn from the normal distribution.

The histogram in Figure 3 indicated the overall means of the four groups which is 4.09 E_ 16 which is very close to zero, and $0.99 \mathrm{SD}$, with a width of one for each group. In Figure 3 the histogram showed a rough bell-shaped distribution. The normal 
probability plot (zresid normal p-p plot) is another test of normally distributed residual error.

Figure 3 Standardized residuals for pretest histogram.

Frequency

\section{Histogram}

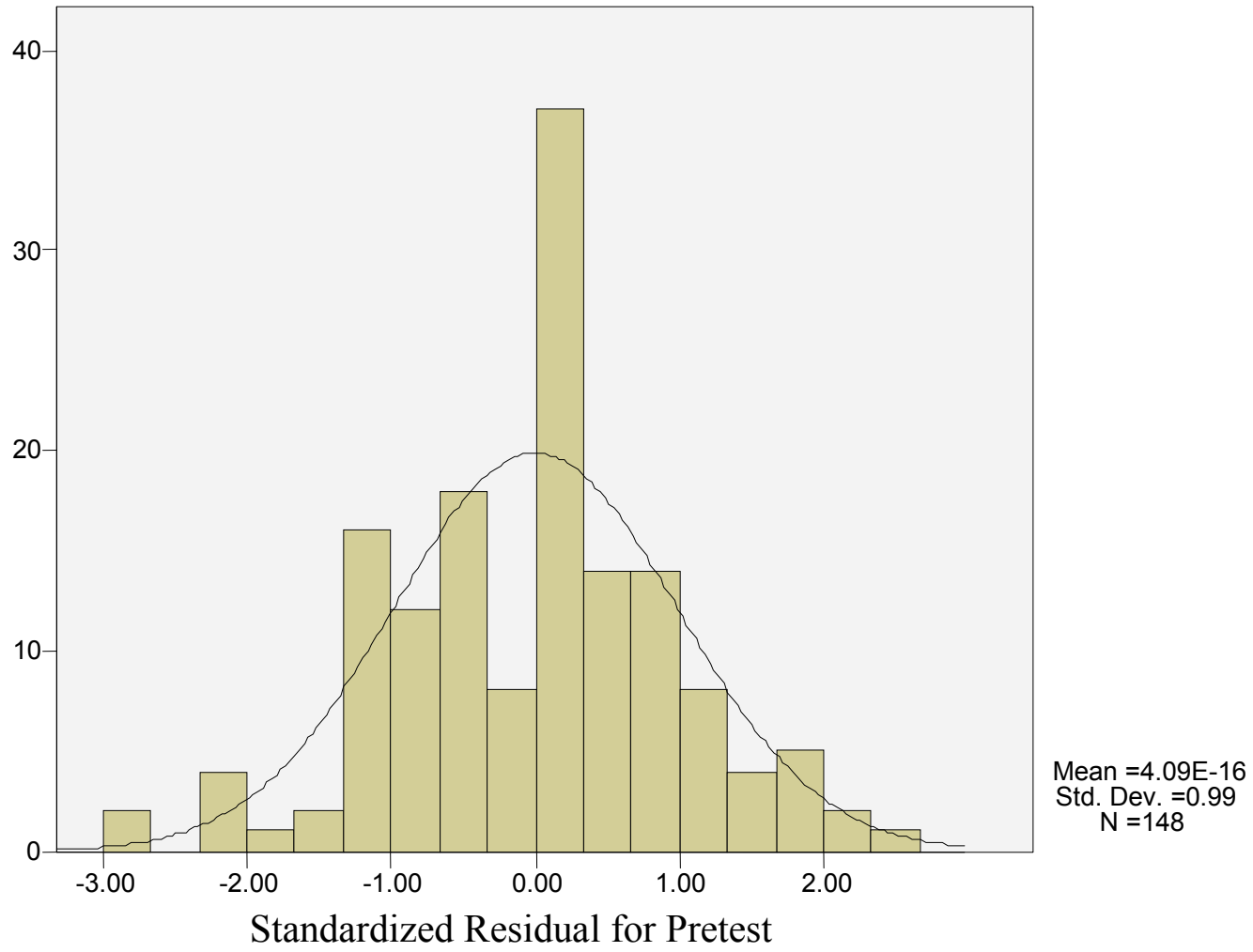

. For this example, the shape of the curve is close enough for exploratory conclusions that the assumption of normally distributed residual error is met. 


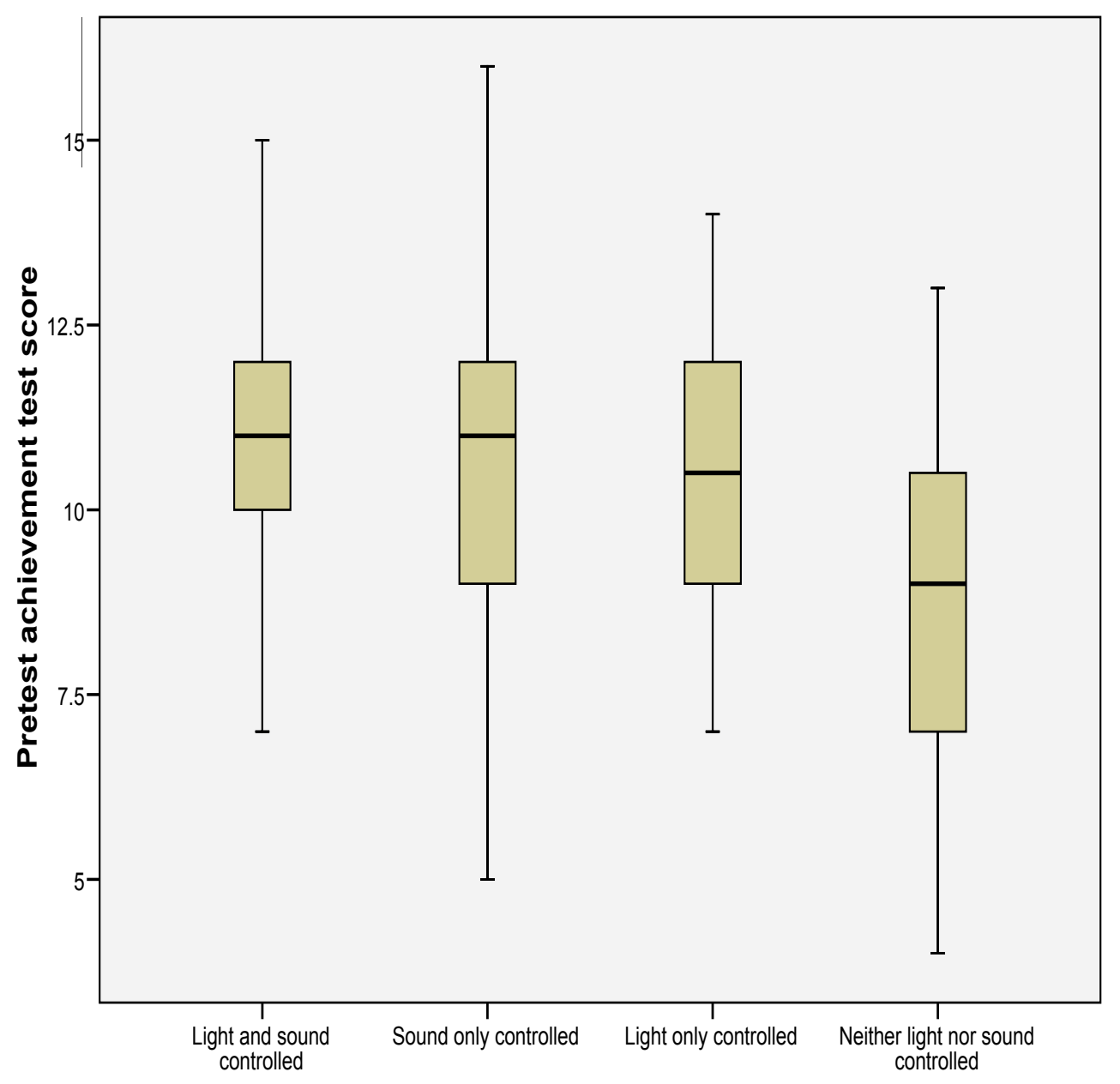

Figure 4 is the box plot based on the ANOVA summary revealed the pretest scores of the four treatment groups, the means and their standard deviations. Inside the graph for each X category is a rectangle indicating the spread of the dependent's values for that category. If these rectangles are roughly at the same $\mathrm{Y}$ elevation for all categories, this indicates little difference among groups. Within each rectangle is a horizontal dark line, indicating the median. If most of the rectangle is on one side or the other of the median line, this indicates the dependent is skewed (not normal) for that group. The mean of Light and sound controlled is 10.84 , Median is 11.00 , Std. Deviation 
1.952 range is 10 , and interquatile is 2 . The mean of Sound only controlled is 10.85 , Median is 11.00 , Std. Deviation 2.312, range is 11 and interquatile is 3 . The mean of Light only controlled is 10.33 , Median is 10.50 , Std. Deviation 1.882, range is 7 and interquatile is 3 . The mean of neither light nor sound controlled is 8.46 , Median is 9.00 , Std. Deviation 2.477, range is 11 and interquatile is 4 . The mean of the neither light nor sound controlled group (8.46) is significantly different than the other three experimental groups. Sound only controlled group's mean (10.85) is marginally different than light and sound controlled.

\section{Univariate Analysis by Group}

A one-way analysis of variance in Table 13 evaluated the relationship between the independent variable (group) and the dependent variable (pretest scores). The independent variable included 4 levels (Group 1) Light and sound controlled $(\mathrm{n}=38)$, (Group 2) Sound only controlled ( $\mathrm{n}=39)$, (Group 3) Light only controlled $(\mathrm{n}=36)$, and (Group 4) with Neither light nor sound controlled $(n=35)$.

Table 13

ANOVA Pretest Achievement Test Score

\begin{tabular}{lllllll}
\hline Source & $\begin{array}{l}\text { Type III Sum } \\
\text { of Squares }\end{array}$ & df & $\begin{array}{l}\text { Mean } \\
\text { Square }\end{array}$ & F & Sig. & $\begin{array}{l}\text { Partial Eta } \\
\text { Squared }\end{array}$ \\
\hline $\begin{array}{l}\text { Corrected } \\
\text { Model }\end{array}$ & $138.610(\mathrm{a})$ & 3 & 46.203 & 9.830 & .00 & .170 \\
Intercept & 15128.688 & 1 & 15128.688 & 3218.79 & .00 & .957 \\
group & 138.610 & 3 & 46.203 & 9.830 & .00 & .170 \\
Error & 676.815 & 144 & 4.700 & & & \\
Total & 16079.000 & 148 & & & & \\
Corrected & 815.426 & 147 & & & & \\
Total & & & & & & \\
\hline
\end{tabular}


The null hypothesis tested by ANOVA is that the population means for all conditions are the same which is expressed as follows:

$\mathrm{H}_{0}$ : There is no significant difference in the means.

$\mathrm{H}_{\mathrm{a} \text { : }}$ At least 2 means are different.

The summary of the ANOVA Table 12 indicated a significant effect for group, $F$ $(3,144)=9.830$ and the $p$-value is less than $.05,(p=.000)$. It can be concluded that at least one of the population means is different from other population means. However, to know exactly which means are significantly different the researcher interpreted pair-wise comparisons in the later part of the description.

The next part of analysis was the effect size which is the difference between two means (e.g., treatment minus control) divided by the standard deviation of the two conditions.

\section{Effect Size}

An effect size allows the researcher to compare the magnitude of experimental treatments from one experiment to another.

$$
\text { Partial } \eta^{2}=\frac{S S_{\text {treatment }}}{S S_{\text {treatment }}+S S_{\text {error }}}
$$

However, SPSS does not provide the recommended eta-squared as a measure of effect size for ANOVA effects. In 1-way ANOVA, eta-squared and partial eta-squared are the same. Hence partial eta squared was reported (.170).

\section{Estimated Marginal Means}

Predicted marginal means for the main effect treatment condition with associated standard errors and upper/lower bounds are shown in Table 14. The levels of treatment group are labeled as 1, 2, 3 and 4 . The researcher would have $95 \%$ confidence that the 
interval ranging from 10.147 to 11.537 covers the true population mean for Group 1, $(M$ $=10.842, S E=.352$ ), the interval ranging from 10.160 to 11.532 .

The true population mean for Group 2, $(M=10.846, S E=.347), 9.619$ to 11.048 covers the true population mean for at Group 3, $(M=10.333, S E=.361)$, and 7.733 to 9.181 covers the true population mean for Group 4, $(M=8.457, S E=.366)$. The performance of Group 4 is significantly lower than the other three groups as indicated in table 14.

Table 14

Estimates (Group) Pretest Achievement Test Score

\begin{tabular}{|c|c|c|c|c|}
\hline \multirow[t]{2}{*}{ Treatment Type } & \multirow[t]{2}{*}{ Mean } & \multirow[t]{2}{*}{ Std. Error } & \multicolumn{2}{|l|}{$95 \%$ C I } \\
\hline & & & Lower Bound & Upper Bound \\
\hline 1 Light and sound controlled & 10.842 & .352 & 10.147 & 11.537 \\
\hline 2 Sound controlled & 10.846 & .347 & 10.160 & 11.532 \\
\hline 3 Light controlled & 10.333 & .361 & 9.619 & 11.048 \\
\hline 4 Neither light nor sound controlled & 8.457 & .366 & 7.733 & 9.181 \\
\hline
\end{tabular}

Since ANOVA results indicated that the group is significant, the researcher conducted pairwise comparisons and found that Group 4 was statistically significant with the other groups and was summarized in table 15.

Table 15

Pairwise Comparisons by Group Pretest Scores

\begin{tabular}{llllll}
\hline (I) type & (J) type & $\begin{array}{l}\text { Mean Diff } \\
\text { (I-J) }\end{array}$ & Sig & $\begin{array}{l}95 \% \text { Confidence Interval for } \\
\text { Difference(a) } \\
\text { Upper Bound }\end{array}$ & Lower Bound \\
\hline $\begin{array}{l}\text { 4 Neither } \\
\text { light nor } \\
\text { sound }\end{array}$ & $\begin{array}{l}\text { 1 Light and } \\
\text { sound controlled }\end{array}$ & $-2.385\left(^{*}\right)$ & .000 & -3.744 & -1.026 \\
& & & & \\
& 2 Sound control & $-2.389\left(^{*}\right)$ & .000 & -3.739 & -1.039 \\
& 3 Light control & $-1.876\left(^{*}\right)$ & .002 & -3.253 & -.499 \\
\hline
\end{tabular}


Using the Bonferroni correction for four comparisons, the $p$ value has to be below $0.05 / 6=0.00833$ for an effect to be significant at the 0.05 level. For these data, all $p$ values for Group 1 and Group 4, Group 2 and Group 4, Group 3 and Group 4 are far below that, and therefore these comparisons revealed that the means of Neither sound nor sound controlled group means are statistically significant from the means of all the other three treatment groups. Now that the researcher found significant group effect, the researcher proceeded to look into the gender effect on group. The next section of the analysis is a $2 \times 4$ factorial ANOVA conducted to look at the interaction effect of gender on group.

\section{Gender Pretest Scores}

Table 16 is the descriptive statistics of the gender and group pretest scores, means and standard deviations. The hypothesis for gender effect is as follows:-

$\mathrm{H}_{0}$ : There is no significant difference among the group means.

$\mathrm{H}_{\mathrm{a}}$ : There is a significant difference at least in one pair group means. Variations in the means and standard deviations in Group 1 girls $(\mathrm{M}=12.75, S D=1.832)$, Group 2 girls $(M=10.54, S D=2.519)$, Group $3(M=10.13, S D=1.928)$ girls and Group 4 girls $(M=10.00, S D=1.922)$ are noted.

Variations in means and standard deviations are also noted in Group 2 boys $(M=$ 11.33, $S D=1.915)$, Group 3 boys $(M=10.50, S D=1.878)$, Group 1 boys $(M=10.33$, $S D=1.915)$ and in Group 4 boys $(M=7.43, S D=2.293)$. 
Table 16

Group versus Gender Pretest Achievement Test Scores

\begin{tabular}{lllll}
\hline \multirow{2}{*}{ Group type } & gender & Mean & $\begin{array}{l}\text { Std. } \\
\text { Deviation }\end{array}$ & $\mathrm{N}$ \\
\hline 1 Light and sound & 1 Female & 12.75 & 1.832 & 8 \\
controlled & & 10.33 & 1.668 & 30 \\
& 2 Male & 10.84 & 1.952 & 38 \\
& Total & 10.54 & 2.519 & 24 \\
2 Sound controlled & 1 Female & 11.33 & 1.915 & 15 \\
& 2 Male & 10.85 & 2.312 & 39 \\
& Total & 10.13 & 1.928 & 16 \\
3 Light controlled & 1 Female & 10.50 & 1.878 & 20 \\
& 2 Male & 10.33 & 1.882 & 36 \\
4 Neither light nor & Total & 10.00 & 1.922 & 14 \\
Sound controlled & Female & 7.43 & 2.293 & 21 \\
& 2 Male & 8.46 & 2.477 & 35 \\
Total & Total & 10.60 & 2.287 & 62 \\
& 1 Female & 9.84 & 2.366 & 86 \\
& 2 Male & 10.16 & 2.355 & 148 \\
\hline
\end{tabular}

Prior to the Anova test, Levene's Test for Equality of Variances is performed. A

homogeneity-of-variance test that is less dependent on the assumption of normality than most tests. For each case, it computes the absolute difference between the value of that case and its cell mean and performs a one-way analysis of variance on those differences.

Table 17

Levene's Test of Equality of Error Variances Pretest achievement scores

\begin{tabular}{llll}
\hline F & df1 & df2 & Sig. \\
\hline 1.053 & 7 & 140 & .398 \\
\hline
\end{tabular}

$\mathrm{H}_{\mathrm{o}}$ : The variances are equal.

$\mathrm{H}_{\mathrm{a}}$ : The variances are different at least by two groups. 
Table 17 indicated $F=1.053(7,140)$ "Sig." value $.398(p>.05)$ which is clearly not significant. So the researcher concluded that the variances were not significantly different across the groups. But this difference may also be the result of certain other factors which are attributed to chance termed as "error." Thus, estimates of the amount of variation due to assignable causes (or variance between the samples) as well as due to chance causes (or variance within the samples) are obtained separately and compared using an F-test and conclusions are drawn using the value of F. The most common method of looking at interaction effects is to interpret the graphs.

Figure 5

\section{Estimated Marginal Means of Pretest achievement test score}

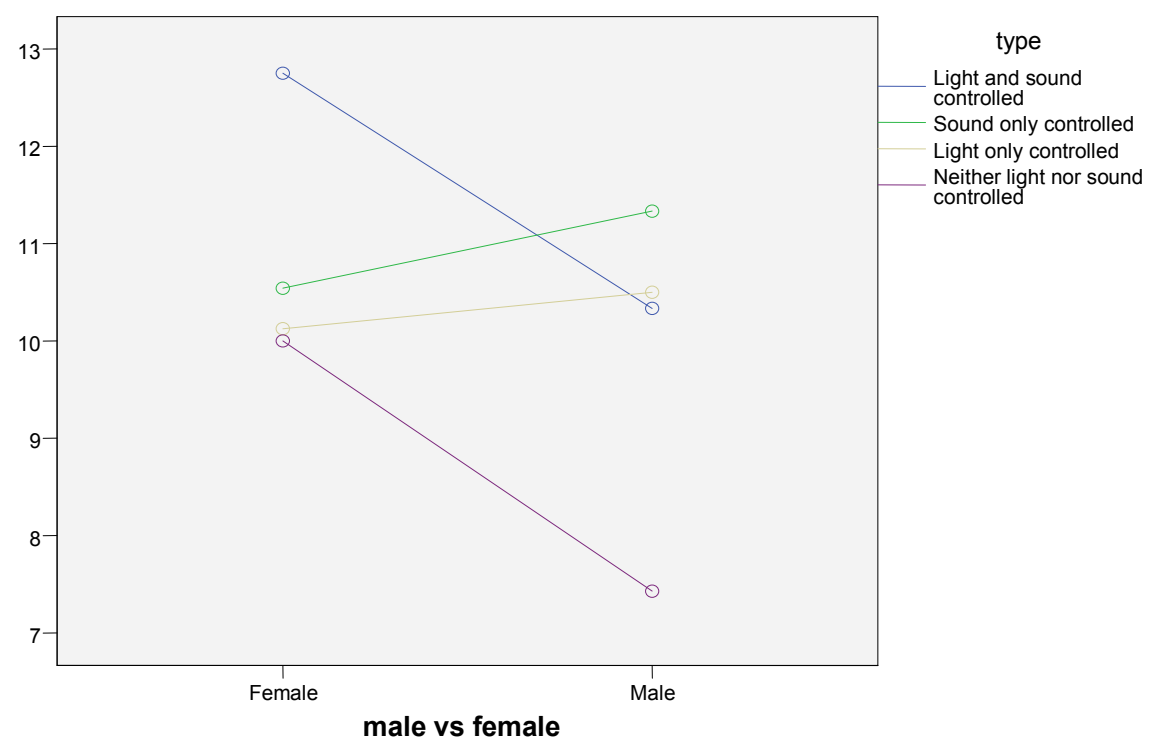

The graph in Figure 5 presented the groups (IV) selected on the X-axis and the achievement was selected on the Y-axis. The graph in Figure 5 indicated the gender differences among the four treatment groups. The performance of Group 1 females was 
higher than the Group 1 males. Since the lines are not parallel, there is an evidence of interaction between the group and the gender. Graphs of the cell means were analyzed to get an idea of what the interaction looks like. Since the lines cross with each other a two way $(2 \mathrm{x} 4)$ ANOVA was conducted for further analysis.

\section{Pretest ANOVA (Gender)}

A two-way analysis of variance in Table 18 evaluated a significant $\mathrm{A} * \mathrm{~B}$ interaction effect indicating $F(3,148)=6.347$ and a sig value ".000" $(p<0.05)$. Since $\mathrm{p}$ $<$ than alpha, the researcher rejects the null hypothesis and favored that there exists a relationship between the two variables group by gender.

Table 18

Two way ANOVA for pretest scores

\begin{tabular}{lllllll}
\hline Source & $\begin{array}{l}\text { Type III Sum of } \\
\text { Squares }\end{array}$ & df & $\begin{array}{l}\text { Mean } \\
\text { Square }\end{array}$ & F & Sig. & $\begin{array}{l}\text { Partial Eta } \\
\text { Square }\end{array}$ \\
\hline $\begin{array}{l}\text { Corrected } \\
\text { Model }\end{array}$ & $238.074(\mathrm{a})$ & 7 & 34.011 & 8.247 & .000 & .292 \\
Intercept & 13831.350 & 1 & 13831.350 & & .000 & .960 \\
& & & & 3353.91 & & \\
group & 138.415 & 3 & 46.138 & 11.188 & .000 & .193 \\
gender & 29.311 & 1 & 29.311 & 7.108 & .009 & .048 \\
group * & 78.523 & 3 & 26.174 & 6.347 & .000 & .120 \\
gender & & & & & & \\
$\begin{array}{l}\text { Error } \\
\text { Total }\end{array}$ & 577.351 & 140 & 4.124 & & & \\
$\begin{array}{l}\text { Corrected } \\
\text { Total }\end{array}$ & 16079.000 & 148 & & & & \\
\hline
\end{tabular}

\section{Effect Size}

Effect size or the $\eta 2$ was calculated from $2 \times 4$ ANOVA table by using the formula 
$\eta 2=$ SSbetween / SStotal where SST $=138.415+29.311+78.523+577.351+823.6$

$\eta 2$ for Group $=138.415 / 823.6=0.17$

$\eta 2$ for Gender $=29.311 / 823.6=0.04$

$\eta 2$ for interaction $=78.523 / 823.6=0.09$

$\eta 2$ for error $=577.351 / 823.6=0.70$. The sum of the $\eta 2$ is 1 . In this example, the IVs

explains $21 \%$ of the variance and Gender explains $4 \%$.

\section{Estimated Marginal Means for Group by Gender}

Table 19 revealed the predicted marginal means for the main effect of type with associated standard errors and upper/lower bounds. The researcher would have 95\% confidence that the interval ranging from 11.331 to 14.169 in case of females that covers the true population mean for the measure at Light and sound controlled, $(M=12.750, S E$ $=.718)$, and for boys in Light and sound controlled, $(M=10.333, S E=.371)$ the interval ranging from 9.600 to 11.066 covers the true population mean for the measure at for Light and sound controlled.

Table 19

Group by Gender Pretest Achievement Test Score

\begin{tabular}{llllll}
\hline Group Type & Boy vs Girl & Mean & Std. Error & 95\% C I & \\
\cline { 5 - 6 } & & & & L Bound & Up Bound \\
\hline 1 Light and sound & 1 Female & 12.750 & .718 & 11.331 & 14.169 \\
& 2 Male & 10.333 & .371 & 9.600 & 11.066 \\
2 Sound control & 1 Female & 10.542 & .415 & 9.722 & 11.361 \\
& 2 Male & 11.333 & .524 & 10.297 & 12.370 \\
3 Light control & 1 Female & 10.125 & .508 & 9.121 & 11.129 \\
& 2 Male & 10.500 & .454 & 9.602 & 11.398 \\
4 Neither light nor sound & 1 Female & 10.000 & .543 & 8.927 & 11.073 \\
& 2 Male & 7.429 & .443 & 6.552 & 8.305 \\
\hline
\end{tabular}


In the case of Sound only controlled girls $(M=10.542, S E=.415), 95 \%$ confidence that the interval ranging from 9.722 to 11.361 covers the true population and for Sound only controlled males $M=11.333, S E=.524), 10.297$ to 12.370 covers the true population. The mean for Light only controlled girls, $(M=10.125, S E=.508)$, and $95 \%$ confidence that the interval ranging from 8.927 to 11.073 , and for Light only controlled boys $(M=10.500, S E=.454)$, and $95 \%$ confidence that the interval ranging from 6.552 to 8.305 covers the true population. The mean for Neither light nor sound controlled girls, $(M=10.000, S E=.543)$ for Neither light nor sound controlled boys $(M=7.429, S E$ $=.443$ ), and $95 \%$ confidence that the interval ranging from 6.552 to 8.305 covers the true population. Since there was a significant interaction, the researcher performed 4 independent sample $\mathrm{T}$ tests for gender within each group to analyze the effect of gender for each pair. All 8 groups were compared in Table 20 using Independent sample T test to look at the gender effect within each group.

The independent samples t-test is used to test the hypothesis that the difference between the means of two samples is equal to 0 . The difference between the sample mean Light and sound control female and male was 2.167 with a $95 \%$ confidence interval, the $t$ test statistic was 3.570, with 36 degrees of freedom and an associated $\mathrm{P}$ value of $\mathrm{P}=0.007$. The p-value is less than the conventional 0.05 , so the null hypothesis is rejected and the conclusion is that the two means do indeed differ significantly. 
Table 20

Independent Sample T tests for groups

\begin{tabular}{|c|c|c|c|c|c|c|}
\hline \multirow[b]{3}{*}{ type } & \multirow{3}{*}{$\begin{array}{l}\text { (I) male vs } \\
\text { female }\end{array}$} & \multirow{3}{*}{$\begin{array}{l}\text { (J) male vs } \\
\text { female }\end{array}$} & \multirow{3}{*}{$\begin{array}{l}\text { Mean Diff } \\
(\mathrm{I}-\mathrm{J})\end{array}$} & \multirow{3}{*}{$\begin{array}{l}\operatorname{Sig}(2- \\
\text { tailed })\end{array}$} & \multirow{2}{*}{\multicolumn{2}{|c|}{$\begin{array}{l}\text { t-test for Equality of } \\
\text { Means } \\
95 \% \text { C I for Diff }\end{array}$}} \\
\hline & & & & & & \\
\hline & & & & & Lower & Upper \\
\hline $\begin{array}{l}1 \text { Light and sound } \\
\text { controlled }\end{array}$ & Female & Male & $2.167^{*}$ & .007 & .601 & 3.733 \\
\hline $\begin{array}{l}2 \text { Sound only } \\
\text { controlled }\end{array}$ & Female & Male & -.864 & .187 & -2.153 & .425 \\
\hline $\begin{array}{l}3 \text { Light only } \\
\text { controlled }\end{array}$ & Female & Male & -.472 & .479 & -1.786 & .842 \\
\hline $\begin{array}{l}4 \text { Neither light nor } \\
\text { sound controlled }\end{array}$ & Female & Male & $2.479^{*}$ & .000 & 1.128 & 3.831 \\
\hline
\end{tabular}

The difference between the sample mean Neither light and sound control female and male was 2.479 with a $95 \%$ confidence interval, the t test statistic was 3.460 , with 33 degrees of freedom and an associated $p$ value of $p=0.000$. The $p$-value is less than the conventional 0.05 , so the null hypothesis is rejected and the conclusion is that the two means do indeed differ significantly.

The $\mathrm{p}$ values for Sound only group (pair) and Light only group (pair) was higher than alpha, so the researcher failed to reject the null and concluded that the means of each group pairs are equal. 


\section{Age Pretest Scores}

Descriptive statistics in Table 21 revealed the means and standard deviations of the independent variables "Group," and "Age." Age 2 subjects (15 and 16 years) in all groups have performed moderately higher than the Age 1(14years) subjects in all groups.

Table 21

Descriptive Statistics Age Pretest Achievement Test Score

\begin{tabular}{lllll}
\hline \multirow{2}{*}{ Group type } & Age & & & \\
\hline 1 Light and sound & (2 categories $)$ & Mean & Std. Dev & N \\
controlled & 14 & 10.23 & 1.343 & 22 \\
& Total & 11.69 & 2.358 & 16 \\
2 Sound only & 14 & 10.84 & 1.952 & 38 \\
controlled & 15 and 16 & 11.55 & 1.932 & 20 \\
& Total & 10.85 & 2.312 & 39 \\
3 Light only & 14 & 10.10 & 2.024 & 20 \\
controlled & 15 and 16 & 10.63 & 1.708 & 16 \\
& Total & 10.33 & 1.882 & 36 \\
4 Neither light nor & 14 & 8.14 & 2.054 & 22 \\
sound controlled & 15 and 16 & 9.00 & 3.082 & 13 \\
& Total & 8.46 & 2.477 & 35 \\
Total & 14 & 9.61 & 2.157 & 83 \\
& 15 and 16 & 10.85 & 2.432 & 65 \\
& Total & 10.16 & 2.355 & 148 \\
\hline
\end{tabular}

The first row of the table revealed that the subjects $(n=22)$ in Group 1 (light and sound controlled $)$ were of age $1(M=10.23, S D=1.343)$ and the subjects $(\mathrm{n}=16)$ were of age $2(M=11.69, S D=2.358)$. The second row revealed that the subjects $(\mathrm{n}=19)$ in 
Group 2 (sound only controlled) were of age $1(M=10.11, S D=2.492)$ and the subjects $(\mathrm{n}=16)$ were of age $2(M=11.55, S D=1.932)$.

The third row revealed that the subjects $(\mathrm{n}=20)$ in Group 3 (light only controlled) were of age $1(M=10.10, S D=2.024)$ and the subjects $(\mathrm{n}=16)$ were of age $2(M=10.63$, $S D=1.708)$.

The fourth row revealed that the subjects $(\mathrm{n}=22)$ in Group 4 (neither light nor sound controlled $)$ were of age $1(M=8.14, S D=2.054)$ and the subjects $(\mathrm{n}=13)$ were of age $2(M=9.00, S D=3.082)$.

Overall means and standard deviations indicated that the age 2 performed better than the age 1 . There is a marginal difference in Group 2 and Group 3 age 1 means $(M=$ 10.11, $S D 2.492, M=10.10, \mathrm{SD}=2.024)$.

Table 22

Levene's Test Pretest Achievement Test Scores

\begin{tabular}{llll}
\hline F & df1 & df2 & Sig. \\
\hline 2.437 & 7 & 140 & .022 \\
\hline
\end{tabular}

The homogeneity test in Table 22 showed $F=2.437(7,140)$ "Sig." value $.022(p$ $<.05)$ which is clearly significant, so the assumption of homogeneity of variance is not met. Hence, the null hypothesis was rejected and concluded that the data among the group by age, variances were significantly different across groups.

A two-way analysis of variance was conducted to evaluate the interaction effect of age on groups. 
The null hypothesis tested by ANOVA in is that the population means for interaction are the same which is expressed as follows:

$\mathrm{H}_{0}$ : There is no significant interaction among the groups and the age means.

$\mathrm{H}_{\mathrm{a}}$ : There is a significant interaction at least in two of the groups and the age means.

Table 23

Pretest Achievement Test Score (DV) for Age

\begin{tabular}{lllllll}
\hline Source & $\begin{array}{l}\text { Type III Sum } \\
\text { of Squares }\end{array}$ & df & $\begin{array}{l}\text { Mean } \\
\text { Square }\end{array}$ & F & Sig. & $\begin{array}{l}\text { Partial } \\
\text { Eta } \\
\text { Squared }\end{array}$ \\
\hline $\begin{array}{l}\text { Corrected } \\
\text { Model }\end{array}$ & $187.244(\mathrm{a})$ & 7 & 26.749 & 5.961 & .000 & .230 \\
Intercept & 14885.774 & 1 & 14885.774 & 3317.52 & .000 & .960 \\
group & 124.412 & 3 & 41.471 & 9.242 & .000 & .165 \\
age2 & 41.384 & 1 & 41.384 & 9.223 & .003 & .062 \\
group * & 5.752 & 3 & 1.917 & .427 & .734 & .009 \\
age2 & & & & & & \\
Error & 628.182 & 140 & 4.487 & & & \\
Total & 16079.000 & 148 & & & & \\
Corrected & 815.426 & 147 & & & & \\
Total & & & & & & \\
\hline
\end{tabular}

The summary of the ANOVA Table 23 indicated no significant interaction between the group and the age. The $\mathrm{F}$ statistics indicated $F(3,140)=.427$ and $\mathrm{p}$-value is .734 greater than alpha $(p>.05)$. Hence the researcher failed to reject the null hypothesis and concluded that there is no significant interaction between the group by age means.

A significant main effect was obtained for group, $F(3,140)=9.242$ and the $\mathrm{p}-$ value is less than alpha. Since the $p<.05,(.000)$ the researcher concluded that the main 
effect for group is significant. It can be concluded that at least one of the population means is different from at least one other population means. A significant main effect was also obtained for age, $F(1,140)=9.223$, and the $p$ value is less $.000(p<.05)$. However, it is not clear that this effect is due to which age category or due to the group effect. Hence, follow up test for analyzing the simple effects were conducted in the later part of the analysis.

\section{Effect Size}

Effect size or the $\eta 2$ was calculated from $2 \times 4$ ANOVA table which has two IVs and one DV: Group (1, 2, 3, and 4) and Age (Age1/Age2) and the DV is Achievement scores.

$\eta 2=$ SSbetween / SStotal

$\mathrm{SST}=124.412+41.384+5.752+628.18=799.23$

$\eta 2$ for Group $=124.412 / 799.23=0.16$

$\eta 2$ for Age $=41.384 / 799.23=0.05$

$\eta 2$ for interaction $=5.752 / 628.18=0.07$

$\eta 2$ for error $=628.18 / 799.23=0.78$. The sum of the $\eta 2$ is 1 . In this example, the IVs explain $21 \%$ of the variance and Gender explains $5 \%$.

\section{Estimated Marginal Means}

This section of the output revealed the predicted marginal means for the main effect of the factor (type) with associated standard errors. The marginal means for the age groups, their standard errors and upper/lower bounds for the main effect group are shown in Table 24. 
Table 24

Age (2 Categories) Pretest Achievement Test Score

\begin{tabular}{lllll}
\hline Age & Mean & Std. & \multicolumn{2}{l}{$95 \%$ Confidence Interval } \\
\cline { 3 - 5 } & & Error & Lower & Upper \\
& & Bound & Bound \\
\hline 14 years & 9.642 & .233 & 9.182 & 10.103 \\
15 and 16 & 10.716 & .266 & 10.190 & 11.241 \\
\hline
\end{tabular}

Thus, the appropriate interpretation is that there was a significant difference in pretest scores between age 1 and age 2 subjects. Even though the interaction is non significant, simple effects and pairwise comparisons for all 8 groups were conducted to analyze the group effect on this pretest scores.

\section{Pairwise Comparisons}

To determine which group is significant pairwise comparisons for pretest scores were examined in Table 25. Using the Bonferroni correction for four comparisons, the $p$ value has to be below $0.05 / 6=0.00833$ for an effect to be significant at the 0.05 level. Asterisks in the "Mean difference" column indicated groups that are significant at the 0.05 alpha level. However the unadjusted $p$ value is greater than the adjusted $p$ value hence the null hypothesis was not rejected and concluded that there is no significant difference among the groups and the age. 
Table 25

Pairwise comparisons pretest achievement scores

\begin{tabular}{|c|c|c|c|c|c|c|}
\hline \multirow[b]{2}{*}{ type } & \multirow[b]{2}{*}{$\begin{array}{l}\text { (I) Age ( } 2 \\
\text { categories) }\end{array}$} & \multirow[b]{2}{*}{$\begin{array}{l}(\mathrm{J}) \text { Age }(2 \\
\text { categories })\end{array}$} & \multirow[b]{2}{*}{$\begin{array}{l}\text { Mean } \\
\text { Diff (I-J) }\end{array}$} & \multicolumn{3}{|c|}{$\begin{array}{l}95 \% \text { C I for } \\
\text { Difference }^{a}\end{array}$} \\
\hline & & & & Sig. ${ }^{a}$ & $\begin{array}{l}\text { Lower } \\
\text { Bound }\end{array}$ & $\begin{array}{l}\text { Upper } \\
\text { Bound }\end{array}$ \\
\hline $\begin{array}{l}1 \text { Light and sound } \\
\text { controlled }\end{array}$ & 14 years & 15 and 16 & $-1.618^{*}$ & .026 & -3.040 & -.195 \\
\hline $\begin{array}{l}2 \text { Sound only } \\
\text { controlled }\end{array}$ & 14 years & 15 and 16 & -1.278 & .061 & -2.617 & .060 \\
\hline $\begin{array}{l}3 \text { Light only } \\
\text { controlled }\end{array}$ & 14 years & 15 and 16 & -.506 & .474 & -1.898 & .887 \\
\hline $\begin{array}{l}4 \text { Neither light nor } \\
\text { sound controlled }\end{array}$ & 14 years & 15 and 16 & -.884 & .232 & -2.340 & .572 \\
\hline
\end{tabular}

In the next section of the analysis, the outcome variable which is the differences in performance at different times is measured (posttest and post-posttest).

\section{Diff 1 (Posttest-pretest) by Group}

Descriptive analysis Table 26 indicated the mean difference between the posttest and pretest by groups, standard deviations of the treatment type and the number of subjects in each type. Group 1 (light and sound controlled) mean $(M=14.92, S D=2.603)$ was higher than the other treatment types.

Group 2 (Sound only controlled) mean $(M=8.05, S D=2.910)$ is lower than Group 3 (light only controlled) mean $(M=8.08, S D=2.951)$ the mean of Group 4 (neither light nor sound controlled) is lower than the rest of the groups $(M=7.20, S D=2.978)$. 
Sound only controlled group's mean (8.05) is lower from the mean of light and sound controlled group (8.08). The mean difference of posttest and pretest of Group 2, Group 3 and Group 4 was lower than the pretest scores clearly indicated lower achievement scores in posttest.

Table 26

Group Post-Pre (diff1) Descriptive Statistics

\begin{tabular}{llll}
\hline Group Type & Mean & Std. Dev & $\mathrm{N}$ \\
\hline 1 Light and sound controlled & 14.92 & 2.603 & 38 \\
2 Sound controlled & 8.05 & 2.910 & 39 \\
3 Light controlled & 8.08 & 2.951 & 36 \\
4 Neither light nor sound & 7.20 & 2.978 & 35 \\
Total & 9.62 & 4.232 & 148 \\
\hline
\end{tabular}

The above data, indicated that Light and sound controlled group performance was higher $(M=14.92, S D=2.603)$ than the other groups. The next step of the analysis is the analysis variances in order to derive conclusions about means. Hypotheses for equal variances of the subjects in "diff 1" were tested using Levene's test.

Table 27

Between Subject Factor Group Post-Pre (DV)

\begin{tabular}{llll}
\hline $\mathrm{F}$ & df1 & df2 & Sig. \\
\hline .474 & 3 & 144 & .701 \\
\hline
\end{tabular}

Table 27 indicated the homogeneity test on the four groups of data that the variances are not significant across the groups. The hypothesis for this test is: 
Ho: There are no significant differences between the variances of the four groups.

Ha: There is a significant difference at least in one of the variances of the groups. The Sig. value $701(p>.05)$, is clearly not significant so the researcher failed to reject the null hypothesis concluded that variances of the groups are not significant. Figure 6 Normality tests boxplot.

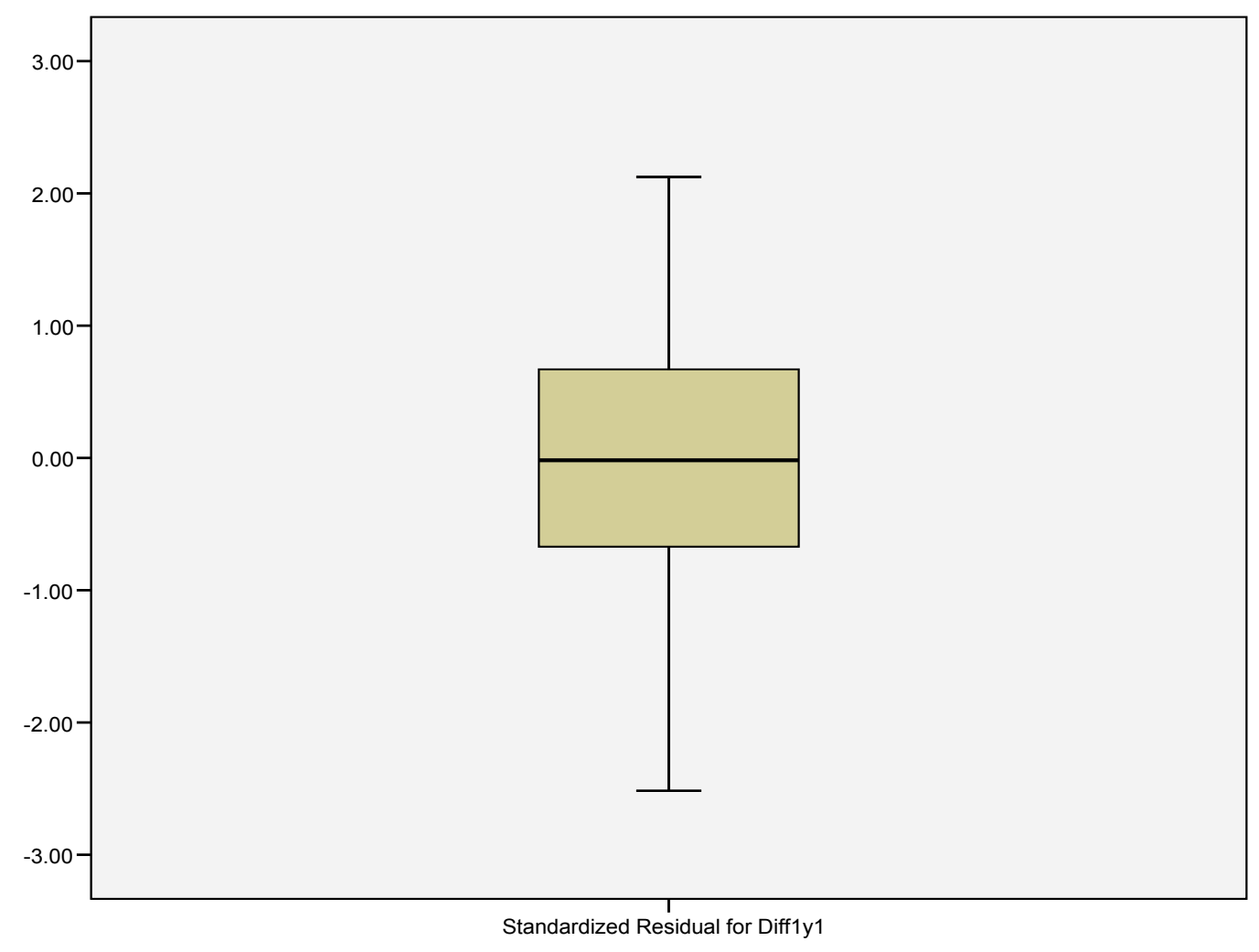

The boxplot in Figure 6 shows posttest-pretest scores (diff 1) with variable on the $\mathrm{X}$ axis and with the $\mathrm{Y}$ axis representing its spread of values. Inside the graph, for the given variable, the height of the rectangle indicates the spread of the values for the variable. The horizontal dark line within the rectangle indicates the median. Light and sound controlled is 14.92, Median is 14.86, Std. Deviation 2.603 range is 11 and interquatile is 3 . The mean of Sound only controlled is 8.03 , Median is 8.00 , Std. 
Deviation 2.910, range is 12 and interquatile is 5 . The mean of Light only controlled is 8.08, Median is 9.00, Std. Deviation 2.951, range is 12 and interquatile is 5. The mean of neither light nor sound controlled is 7.20, Median is 7.00, Std. Deviation 2.978, range is 13 and interquatile is 4 . The mean of the neither light nor sound controlled group i.e. 7.20 is lower than the other three experimental groups. The mean of Light and sound controlled is 14.92 is significantly higher than the rest of the groups. Sound only controlled group's mean i.e. 8.05 is marginally lesser than light and sound controlled group i.e. 8.08. Before interpreting these means, we examined the results of the ANOVA in table 27. The histogram in figure 7 indicated a rough bell shaped distribution. Figure 7 Histogram comparing group for posttest-pretest scores (diff 1)

\section{Frequency Histogram}

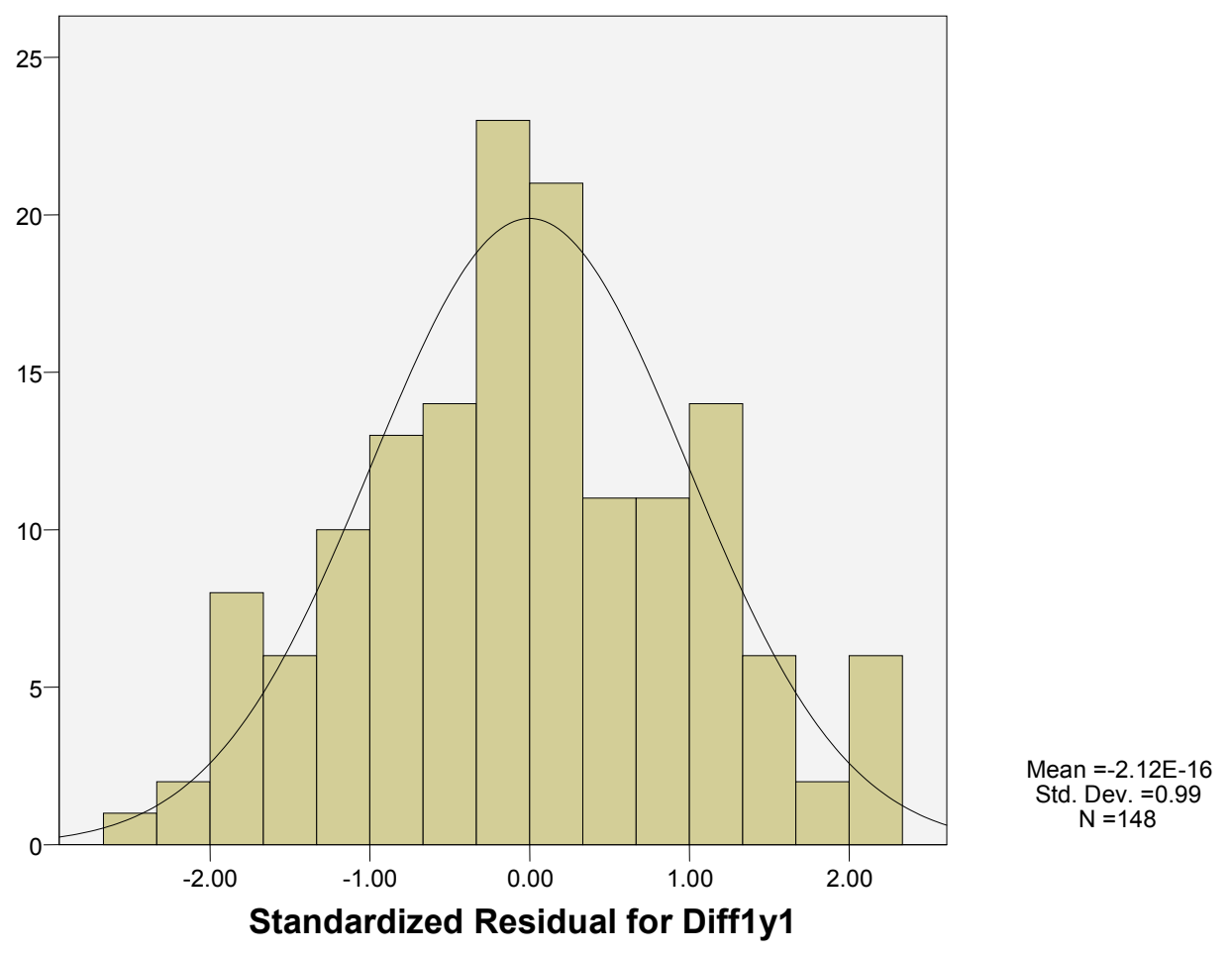


Table 28 revealed the results of ANOVA (one-factor between-subjects design (group). The dependent variable is the difference between post test and pre-test scores (diff 1). The null hypothesis tested by ANOVA is that the population means for all conditions are the same.

Table 28

ANOVA Post-Pre (diff 1)

\begin{tabular}{lllllll}
\hline Source & $\begin{array}{l}\text { Type III Sum } \\
\text { of Squares }\end{array}$ & df & $\begin{array}{l}\text { Mean } \\
\text { Square }\end{array}$ & F & Sig. & $\begin{array}{l}\text { Partial } \\
\text { Eta } \\
\text { Squared }\end{array}$ \\
\hline $\begin{array}{l}\text { Corrected } \\
\text { Model }\end{array}$ & $1453.800(\mathrm{a})$ & 3 & 484.600 & 59.187 & .000 & .552 \\
Intercept & 13512.602 & 1 & 13512.602 & 1650.37 & .000 & .920 \\
group & 1453.800 & 3 & 484.600 & 59.187 & .000 & .552 \\
Error & 1179.011 & 144 & 8.188 & & & \\
Total & 16334.000 & 148 & & & & \\
$\begin{array}{l}\text { Corrected } \\
\text { Total }\end{array}$ & 2632.811 & 147 & & & & \\
\hline
\end{tabular}

This can be expressed as follows:

$\mathrm{H}_{0}$ : There is no significant difference in the group means.

Ha: At least 2 group means are different.

The summary of the ANOVA Table 28 indicated a significant effect for group, $F$ $=59.187$ and the $p$ value is less than $.05, p<.05$. The researcher concluded that the group is significant. However, the researcher does not yet know exactly which group means are significantly different. For this multiple comparisons were conducted for all groups. 
Table 29

Estimated Marginal Means Dependent Variable Diff1 Post-Pre

\begin{tabular}{|c|c|c|c|c|}
\hline \multirow[t]{2}{*}{ type } & \multirow[t]{2}{*}{ Mean } & \multirow[t]{2}{*}{ Std. Err } & \multicolumn{2}{|l|}{$95 \%$ C I } \\
\hline & & & L Bound & Upp Bound \\
\hline 1 Light and sound & 14.921 & .464 & 14.004 & 15.839 \\
\hline 2 Sound controlled & 8.051 & .458 & 7.146 & 8.957 \\
\hline 3 Light controlled & 8.083 & .477 & 7.141 & 9.026 \\
\hline $\begin{array}{l}4 \text { Neither light nor } \\
\text { sound controlled }\end{array}$ & 7.200 & .484 & 6.244 & 8.156 \\
\hline
\end{tabular}

Table 29 is the estimated marginal means, the predicted means, not observed, and is based on the specified linear model. Standard errors of all independent variables (Light and sound controlled, Sound only controlled, Light only controlled and Neither sound nor light controlled) are also provided. The mean of Light and sound controlled $(M=14.921$, $S e=.464)$ is greater the Light only controlled group $(M=8.083, S e=.447)$. The mean of Sound only controlled $(M=8.051, \mathrm{Se}=.458)$ is greater than the mean of Neither light nor sound controlled $(M=7.200, S e=.484)$.

\section{Multiple comparisons}

To determine which group is significant among the other groups pair-wise comparisons were examined in the Table 30. In order to control the familywise error rate for these comparisons, an adjustment to the criterion alpha level suggested by Bonferroni was used. 
Table 30

Pairwise Comparisons (Dependent Variable): Diff1 Post-Pre

\begin{tabular}{llllll}
\hline & & Mean & & \\
Diff (I- & 95\% Con I for \\
& (I) type & & Sig.(a) & $\begin{array}{l}\text { Diff(a) } \\
\text { Upper } \\
\text { Bound }\end{array}$ & $\begin{array}{l}\text { Lower } \\
\text { Bound }\end{array}$ \\
\hline $\begin{array}{l}\text { 1 Light and } \\
\text { sound }\end{array}$ & $\begin{array}{l}\text { 2 Sound } \\
\text { controlled } \\
3 \text { Light } \\
\text { controlled } \\
4 \text { Neither light } \\
\text { nor sound } \\
\text { controlled }\end{array}$ & $6.870\left(^{*}\right)$ & .000 & 5.125 & 8.615 \\
& $7.721\left(^{*}\right)$ & .000 & 5.928 & 9.514 \\
\hline
\end{tabular}

Table 30 presents the comparisons of the mean performance scores of Light and sound controlled group to the means of Sound only controlled group, Light only controlled group and Neither sound nor light controlled group. The differences that have asterisks indicated significant at the .05 level or better. Group 1 was compared to Group 2, Group 3 and Group 4.

All the $\mathrm{p}$ values are lower than the adjusted $\mathrm{p}$ values i.e. 0.00833 hence the researcher concluded that performance at treatment type Light and sound controlled (group 1) was significantly higher from that at Sound only controlled, Light only controlled and Neither sound nor light controlled 


\section{Diff 1 by Gender}

The next section is a two way analysis to find the interaction effect of group by gender during the posttest. Descriptive statistics Table 31 (Diff 1) for gender and group revealed means and their standard deviations of the two factors in this study. Data indicated that Light and sound controlled performance was greater the other three groups.

Table 31

Group by Gender (Diff1) Post-Pre Scores

\begin{tabular}{lllll}
\hline Group type & Male vs. Female & Mean & Std. Dev & N \\
\hline 1 Light and sound & 1 Female & 13.25 & 2.121 & 8 \\
controlled & & 15.37 & 2.566 & 30 \\
& 2 Male & 14.92 & 2.603 & 38 \\
\multirow{3}{*}{ Sound controlled } & 1 Fetal & 8.83 & 2.353 & 24 \\
& 2 Male & 6.80 & 3.342 & 15 \\
& Total & 8.05 & 2.910 & 39 \\
3 Light controlled & 1 Female & 8.38 & 3.096 & 16 \\
& 2 Male & 7.85 & 2.889 & 20 \\
4 Neither light nor & Total & 8.08 & 2.951 & 36 \\
sound controlled & 1 Female & 6.21 & 3.068 & 14 \\
& 2 Male & 7.86 & 2.798 & 21 \\
Total & Total & 7.20 & 2.978 & 35 \\
& 1 Female & 8.69 & 3.337 & 62 \\
& 2 Male & 10.29 & 4.680 & 86 \\
\hline
\end{tabular}

Analysis of gender posttest-pretest scores (diff 1) in Table 31 achievement scores indicated that group 1 females $(M=13.25, S D=2.121)$, performance was greater over group 2 females $(M=8.883, S D=2.253)$, Group $3(M=8.38, S D=3.096)$ females and group 4 females $(M=6.21, S D=3.068)$. Group 1 male $(M=15.37, S D=2.566)$, 
performed greater over Group 2 males $(M=6.80 ; S D=3.342)$; group 3 males $(M=$ 7.85, $S D=2.889)$, group 4 males $(M=7.86, S D=2.798))$. The overall scores on the Diff 1 indicated that the male performance was greater $(M=10.29, S D=4.680)$, than the female performance $(M=8.69, S D=3.337)$. Overall scores indicated that the performance of males is higher to the performance of females. The above data indicated that the females in Light and sound controlled group performed greater than the females of sound only controlled, Light only controlled and Neither sound nor light controlled groups.

Table 32

Levene's Test of Equality of Error Variances (a) Post-Pre

\begin{tabular}{llll}
\hline F & df1 & df2 & Sig. \\
\hline .702 & 7 & 140 & .670 \\
\hline
\end{tabular}

Table 32 is the homogeneity test on the group by gender diff 1 scores indicated $F$ $=.670(7,140)$ "Sig." value being.670 $(p>.05)$ is clearly not significant so the researcher concluded that the data among the groups, variances are not significantly different. The next section of the analysis is a $2 \mathrm{x} 4$ ANOVA for group by gender interaction effects. The hypothesis of this test was as below:-

$\mathrm{H}_{0}$ : There is a significant interaction between group and gender.

Ha: There is no significant interaction between group and gender.

The summary of the ANOVA Table 33 indicated a significant $A * B$ interaction effect for group by gender is significant at $F(1,140)=3.912$ indicating a "sig" value of .010 $(\mathrm{p}<.05)$. 
The $F(3,140)=39.517$ statistics for the main effect group is shown to be significant at alpha $.05(\mathrm{p}<.05)$.

There is a non significant effect for gender, $F(1,140)=.373$ indicated a "sig" value of $.01(\mathrm{p}>.05)$

Table 33

Two way ANOVA Post-Pre

\begin{tabular}{lllllll}
\hline & $\begin{array}{l}\text { Type III } \\
\text { Sum of } \\
\text { Squares }\end{array}$ & df & $\begin{array}{l}\text { Mean } \\
\text { Square }\end{array}$ & F & Sig. & $\begin{array}{l}\text { Partial Eta } \\
\text { Squared }\end{array}$ \\
\hline Corrected & $1545.382 \mathrm{a}$ & 7 & 220.769 & 28.423 & .000 & .587 \\
Model & 11154.176 & 1 & 11154.17 & 1436.03 & .000 & .911 \\
Intercept & 920.838 & 3 & 306.94 & 39.517 & .000 & .459 \\
group & 2.896 & 1 & 2.896 & .373 & .542 & .003 \\
gender & 91.158 & 3 & 30.386 & 3.912 & .010 & .077 \\
group * & 1087.429 & 140 & 7.767 & & & \\
gender & 16334.000 & 148 & & & & \\
Error & Total & & & & & \\
Corrected & 2632.811 & 147 & & & & \\
Total & & & & & & \\
\hline
\end{tabular}

\section{Effect Size}

Effect size or the $\eta 2$ can be calculated from 2 x 4 ANOVA table which has two IVs and one DV: Group $(1,2,3$, and 4) and Gender (Male/Female) and the DV is achievement scores.

$\eta 2=$ SSbetween / SStotal

$\mathrm{SST}=920.836+2.896+91.158+1087.429=2102.321$

$\eta 2$ for Group $=920.836 / 2102.321=0.44$ 
$\eta 2$ for Gender $=91.158 / 2102.321=0.04$

$\eta 2$ for interaction $=2.896 / 2102.321=0.01$

$\eta 2$ for error $=1087.429 / 2102.321=0.52$.

The sum of the $\eta 2$ is 1 . In this example, the IVs explain $48 \%$ of the variance while the Gender explains $4 \%$.

\section{Graphs of Means}

Figure 8 is a graph presenting gender of the groups on $\mathrm{X}$ axis and the estimated marginal means on $\mathrm{Y}$ axis. The male mean scores of sound only controlled performance was greater than the males of other groups as well as the females of the other groups.

Figure 8 Post-pretest marginal means for groups.

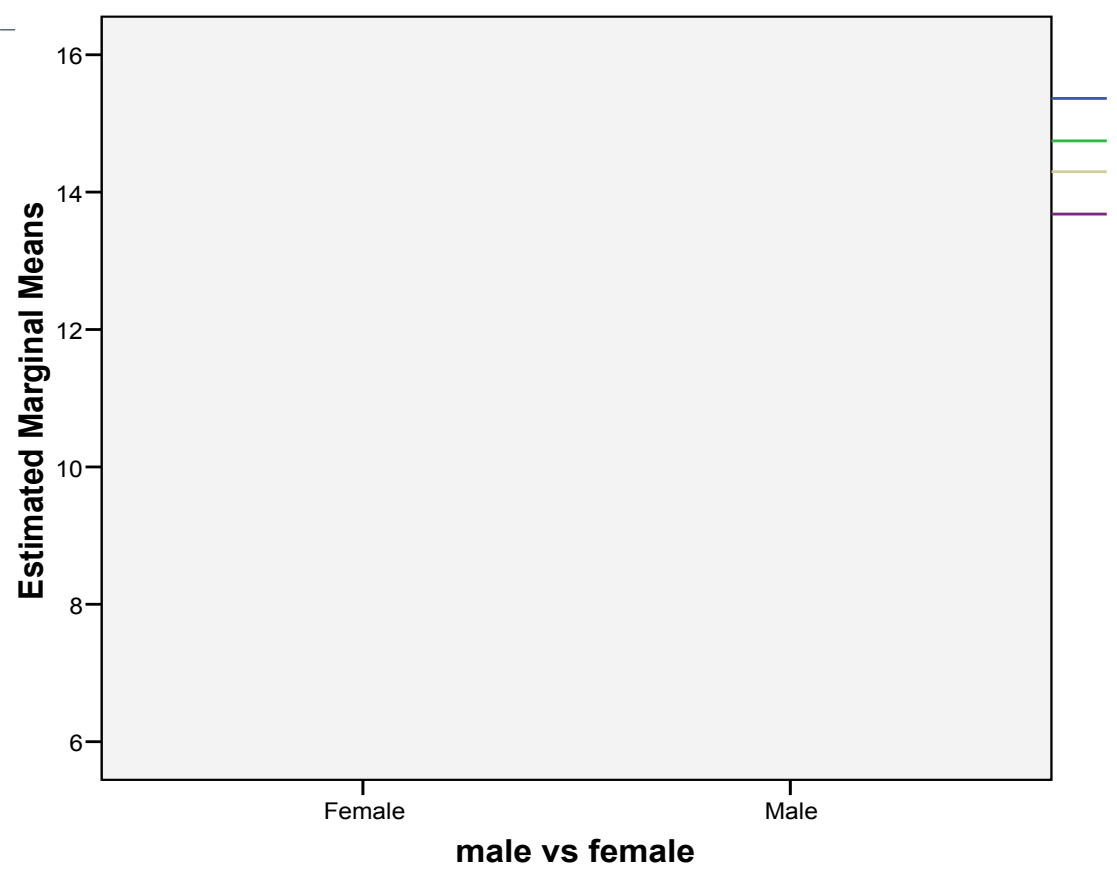


The graph indicated a significant interaction in consistent with the results of ANOVA. There is a very sharp decline in the line as indicated in the graph shows a decline in performance.

\section{Estimated Marginal Means}

The next section of the results is the Estimated Marginal Means, presents information which is partially redundant with the means displayed in Table 34 . This section organizes the means into two tables, one for the marginal means of group and a second table which displays the cell means for individual groups and gender.

Table 34

Group and Dependent Variable Diff1 Post-Pretest Estimates

\begin{tabular}{lllll}
\hline Group & Mean & Std. Error & \multicolumn{2}{l}{$95 \%$ C I } \\
\cline { 4 - 5 } & & & L Bound & Upp bound \\
\hline 1 Light and sound controlled & 14.308 & .554 & 13.212 & 15.405 \\
2 Sound controlled & 7.817 & .459 & 6.910 & 8.723 \\
3 Light controlled & 8.113 & .467 & 7.188 & 9.037 \\
4 Neither light nor sound controlled & 7.036 & .481 & 6.085 & 7.986 \\
\hline
\end{tabular}

The marginal means for the main effect of group type are shown in Table 33. The mean of Light and sound controlled $(M=14.308, S e=.554)$ is greater the Light only controlled group $(M=8.113, S e=.467$. The mean of Sound only controlled $(M=7.817$, $S e=.554)$ is marginally different from the mean of Neither light nor sound controlled (M $=7.036, \mathrm{Se}=.481)$. 
Table 35

Group* Male Versus Female (Diff1) Post-Pre Scores

\begin{tabular}{llllll}
\hline Group & $\begin{array}{l}\text { Male vs. } \\
\text { Female }\end{array}$ & Mean & Std. Err & $\begin{array}{l}\text { 95\% C I } \\
\text { L Bound }\end{array}$ & Upp Bound \\
\hline 1 Light and sound & 1 Female & 13.250 & .985 & 11.302 & 15.198 \\
controlled & 2 Male & 15.367 & .509 & 14.361 & 16.373 \\
2 Sound controlled & 1 Female & 8.833 & .569 & 7.709 & 9.958 \\
& 2 Male & 6.800 & .720 & 5.377 & 8.223 \\
3 Light controlled & 1 Female & 8.375 & .697 & 6.997 & 9.753 \\
& 2 Male & 7.850 & .623 & 6.618 & 9.082 \\
4 Neither light nor & 1 Female & 6.214 & .745 & 4.742 & 7.687 \\
sound controlled & 2 Male & 7.857 & .608 & 6.655 & 9.060 \\
\hline
\end{tabular}

The marginal means for the main effect of group type and its interaction with the group and gender are shown in Table 35. The mean of Light and sound controlled female $(M=13.250, S e=.985)$ is lower than the mean of Light and sound controlled male $(M=$ 15.367, $\mathrm{Se}=.509)$.

The light only controlled group females $(M=8.375$, $S e=.697)$ is greater than the light only controlled group males $(M=7.850, S e=.623)$. The mean of sound only controlled female $(M=8.833, \mathrm{Se}=.569)$ is greater than the mean of sound only controlled male $(M=6.800, S e=.720)$. The mean of neither light nor sound controlled females $(M=6.214, S e=.745)$ is lower than the mean of neither light nor sound controlled males $(M=7857, \mathrm{Se}=.745)$. As mentioned earlier, the main effect for group is significant $(p<.05)$ while the main effect for gender is non-significant $(p>0.05)$. So, even though the mean scores for females appear to be greater than the males in Group 2 and Group 3, this is not statistically significant. Since the main effect for the group is 
significant, the researcher performed pair-wise comparisons for gender as well as for groups to analyze the nature of the effect. Since there was a significant interaction between the group and gender, simple effects were analyzed in the next section of the analysis. Since the researcher observed a significant interaction effect between group and gender as shown in ANOVA summary, the researcher performed 4 independent sample T tests for gender within each group to analyze the effect of gender for each pair. All 8 groups were compared using Independent sample $\mathrm{T}$ test to look at the gender effect within each group. Table 36 provided the means of all the 8 treatment groups. Asterisks on the mean difference column indicated a significant difference $(p<.05)$ in the diff 1 mean scores Sound only controlled group females and males.

Table 36

Independent sample T tests for 8 groups for Diff 1 scores

\begin{tabular}{|c|c|c|c|c|c|c|}
\hline \multirow[b]{2}{*}{ type } & \multirow{2}{*}{$\begin{array}{l}\text { (I) male vs. } \\
\text { female }\end{array}$} & \multirow{2}{*}{$\begin{array}{l}\text { (J) male vs } \\
\text { female }\end{array}$} & \multirow{2}{*}{$\begin{array}{l}\text { Mean } \\
\text { Diff (I-J) }\end{array}$} & \multirow[b]{2}{*}{ Sig. ${ }^{a}$} & \multicolumn{2}{|c|}{$\begin{array}{l}\mathrm{t} \text {-test for Equality of } \\
\text { Means } \\
95 \% \text { C Ifor Diff }\end{array}$} \\
\hline & & & & & Lower & Upper \\
\hline $\begin{array}{l}1 \text { Light and } \\
\text { sound controlled }\end{array}$ & 1 Female & 2 Male & -2.045 & .070 & -4.256 & .166 \\
\hline $\begin{array}{l}2 \text { Sound only } \\
\text { controlled }\end{array}$ & 1 Female & 2 Male & $2.054^{*}$ & .027 & .235 & 3.873 \\
\hline $\begin{array}{l}3 \text { Light only } \\
\text { controlled }\end{array}$ & 1 Female & 2 Male & .553 & .557 & -1.302 & 2.408 \\
\hline $\begin{array}{l}4 \text { Neither light } \\
\text { nor sound } \\
\text { controlled }\end{array}$ & 1 Female & 2 Male & -1.617 & .096 & -3.524 & .291 \\
\hline
\end{tabular}

The independent samples t-test is used to test the hypothesis that the difference between the means of two samples is equal to 0 . The difference between the sample mean 
Sound only controlled female and male was 2.054 with a $95 \%$ confidence interval, the $t$ test statistic was 2.231 , with 37 degrees of freedom and an associated $p$ value of $\mathrm{p}=0.007$. The $\mathrm{p}$-value is less than the conventional 0.05 , so the null hypothesis is rejected and the conclusion is that the two means do indeed differ significantly.

The p values for Light and sound controlled (pair) Sound only group (pair) and Light only group (pair) was higher than alpha, so the researcher failed to reject the null and concluded that the means of each group pairs are equal.

\section{Posttest-Pretest (diff 1) by Age}

Table 37 is the descriptive analysis of the interaction effect of group and age during the posttest and pretest scores. The first row revealed that the subjects $(n=22)$ in Group 1 (light and sound controlled) were of age 1(14 years, $M=15.68, S D=2.255)$ and the subjects $(\mathrm{n}=16)$ were of age $2(15$ and 16years $M=13.88, S D=2.754)$.

\section{Table 37}

Between-Subjects Factors Group by Age (DV) Post-Pretest

\begin{tabular}{lllll}
\hline Group type & Age (2 categories) & Mean & Std. Dev & N \\
\hline 1 Light and sound & 14 & 15.68 & 2.255 & 22 \\
control & 15 and 16 & 13.88 & 2.754 & 16 \\
& Total & 14.92 & 2.603 & 38 \\
2 Sound control & 14 & 8.58 & 3.305 & 19 \\
& 15 and 16 & 7.55 & 2.460 & 20 \\
\multirow{5}{*}{ Light control } & Total & 8.05 & 2.910 & 39 \\
& 14 & 7.60 & 2.854 & 20 \\
& 15 and 16 & 8.69 & 3.049 & 16 \\
4 Neither light nor & Total & 8.08 & 2.951 & 36 \\
sound control & 14 & 7.00 & 2.289 & 22 \\
& 15 and 16 & 7.54 & 3.971 & 13 \\
Total & Total & 7.20 & 2.978 & 35 \\
& 14 & 9.81 & 4.454 & 83 \\
& 15 and 16 & 9.38 & 3.952 & 65 \\
& Total & 9.62 & 4.232 & 148 \\
\hline
\end{tabular}


The second row revealed that the subjects $(n=19)$ in Group 2 (sound only controlled) were of age $1(14$ years, $M=8.58, S D=3.304)$ and the subjects $(\mathrm{n}=16)$ were of age $2(15$ and 16years, $M=7.55, S D=2.460)$.

The third row revealed that the subjects $(n=20)$ in Group 3 (light only controlled) were

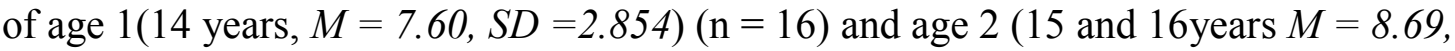
$S D=3.049)$

The last row revealed that the subjects $(n=22)$ in Group 4 (neither light nor sound controlled) were of age $1(14$ years, $M=7.00, S D=2.289)$ and the subjects $(\mathrm{n}=13)$ were of age $2(15$ and 16years $M=7.54, S D=3.971)$.

Overall means and standard deviations indicated that the age 1 group 1 performed better than the age 2 Group 2. However, there is a significant decrease in performance compared to pretest scores in case of Group 2, Group 3 and Group 4 in both the age categories.

Table 38

Levene's Test of Equality of Error Variances (a) Diff1 (Post-Pre) for Age

\begin{tabular}{lrrrr}
\hline F & f1 & df2 & Sig. \\
\hline 1.738 & 7 & & 140 & .105 \\
\hline
\end{tabular}

Levene's Test for Equality of Variances for the difference in posttest and pretest scores of age in Table 38 indicated $F(7,140)=1.738$, and a sig value $.105(p>0.05)$ is clearly not significant. Hence the researcher failed to reject the null hypothesis and concluded that the data among the groups, variances are not significantly different. 
In the next part of the analysis the researcher conducted two way ANOVA to find out the interaction effect of age on group performance in diff 1 scores (post-pre). Table 38 revealed the results of ANOVA interaction between the group and age.

The null hypothesis tested by ANOVA states that all conditions are the same.

$\mathrm{H}_{0}$ : There is no significant interaction between groups and age in diff 1 scores.

$\mathrm{H}_{\mathrm{a}}$. There is a significant interaction at least in two of the groups and age in diff 1 scores.

Table 39

Two way ANOVA Post-Pre (age)

\begin{tabular}{lllllll}
\hline Source & $\begin{array}{l}\text { Type III Sum } \\
\text { of Squares }\end{array}$ & df & $\begin{array}{l}\text { Mean } \\
\text { Square }\end{array}$ & F & Sig. & $\begin{array}{l}\text { Partial Eta } \\
\text { Squared }\end{array}$ \\
\hline Corrected & $1507.238(\mathrm{a})$ & 7 & 215.320 & 26.782 & .000 & .572 \\
Model & & & & & & \\
Intercept & 13141.461 & 1 & 13141.461 & 1634.55 & .000 & .921 \\
group & 1338.347 & 3 & 446.116 & 55.488 & .000 & .543 \\
age2 & 3.286 & 1 & 3.286 & .409 & .524 & .003 \\
group * age2 & 48.969 & 3 & 16.323 & 2.030 & .112 & .042 \\
Error & 1125.573 & 140 & 8.040 & & & \\
Total & 16334.000 & 148 & & & & \\
Corrected & 2632.811 & 147 & & & & \\
Total & & & & & & \\
\hline
\end{tabular}

A non significant interaction effect was obtained for group by age, $F=2.030$ and the p-value is $.112, p>.05$. Since the probability (.112) is greater than .05 , the researcher concluded that there is no interaction effect. 
A significant main effect was obtained for group $F=55.488$ and the p-value is .000 ( $p<$ $.05)$. Since the probability is lesser than .05 , the researcher concluded that the main effect for group is significant.

A non significant main effect was obtained for age $F=.409$ and the p-value is $.524(p>.05)$. Since the probability $(.524)$ is greater than .05 , the researcher concluded that the main effect for age is non significant.

\section{Effect Size}

Effect size or the $\eta 2$ can be calculated from 2 x 4 ANOVA table which has two IVs and one DV: Group (1, 2,3, and 4) and Age (Age1/Age2) and the DV is Achievement scores. Effect size or the $\eta 2$ can be calculated from $2 \times 4$ ANOVA table which has two IVs and one DV: Group (1, 2, 3, and 4) and Age (Age1/Age2) and the DV is Achievement scores. The formula for effect size is:-

$\eta 2=$ SSbetween / SStotal.

$\mathrm{SST}=1338.347+3.286+48.969+1125.573=2516.175$

$\eta 2$ for Group $=1338.347 / 2516.175=0.53$

$\eta 2$ for $\mathrm{Age}=3.286 / 2516.175=.001$

$\eta 2$ for interaction $=48.969 / 2516.175=.02$

$\eta 2$ for error $=1125.573 / 2516.175=.48$. The sum of the $\eta 2$ is 1.03 . In this example, the IVs explain 53.139of the variance and Age explains $0.1 \%$. 


\section{Estimated Marginal Means}

Table 40

Diff1 Post-Pre for Age (2 categories)

\begin{tabular}{lllll}
\hline \multirow{2}{*}{ Age } & Mean & $\begin{array}{l}\text { Std. } \\
\text { Error }\end{array}$ & & \\
\cline { 3 - 5 } & & & 95\% C I & \\
\hline 1 1 14 years & 9.715 & .312 & 9.099 & 10.332 \\
215 and 16 & 9.413 & .356 & 8.709 & 10.116 \\
\hline
\end{tabular}

Estimated Marginal Means for the main effect of age are shown in Table 40 and in Table 41. Recall that the main effect of age was not significant $(p>.05)$. So even though the diff 1 scores for age (9.715) appears to be greater than that for age $2(9.413)$, this is not a statistically significant difference. Thus, the appropriate interpretation is that there was not a significant difference in performance between age 1 and age 2 . Table 40 is the estimates of marginal means for the interaction effect of group versus age. As informed in the test of between subjects, the main effect for group was significant $(p<.05)$ and the main effect for age is not significant $(P>.05)$.

Group 1 age 1 and Group 2 age 1 means are greater than Group 3 age 1 and Group 4 age 1 mean scores. Group 3 age 2 and Group 4 age 2 means are greater than Group 3 age 1 and Group 4 age 1. Recall that there is no significant interaction between the group and age. It is appropriate to conclude that age has no significant effect on group. The next part of the analysis is the diff 2 achievement score by different variables. 
Table 41

Group *Age (2 Categories) Dependent Variable Post-Pre

\begin{tabular}{llllll}
\hline Type & Age & Mean & $\begin{array}{l}\text { Std. } \\
\text { Error }\end{array}$ & 95\% C I & \\
& & & & $\begin{array}{l}\text { Lower } \\
\text { Bound }\end{array}$ & $\begin{array}{l}\text { Upper } \\
\text { Bound }\end{array}$ \\
\hline $\begin{array}{l}\text { 1 Light and sound } \\
\text { controlled }\end{array}$ & 14 & 15.682 & .605 & 14.487 & 16.877 \\
& 15 and 16 & 13.875 & .709 & 12.474 & 15.276 \\
2 Sound controlled & 14 & 8.579 & .650 & 7.293 & 9.865 \\
& 15 and 16 & 7.550 & .634 & 6.296 & 8.804 \\
3 Light controlled & 14 & 7.600 & .634 & 6.346 & 8.854 \\
& 15 and 16 & 8.688 & .709 & 7.286 & 10.089 \\
4 Neither light nor & 14 & 7.000 & .605 & 5.805 & 8.195 \\
sound controlled & & & & & \\
& 15 and 16 & 7.538 & .786 & 5.984 & 9.093 \\
\hline
\end{tabular}

\section{Diff 2(Post-Posttest-Pretest) by Group}

To answer question number 7 , diff 2 were compared across the groups. The dependent variable is the diff 2 scores while the independent variable is the group (treatment type).

Descriptive analysis in Table 42 revealed that the mean of Light and sound controlled ( $M$ $=15.29, S D=2.740)$ is greater than the mean of Sound only controlled is $(M=2.38, S D$ $=3.991)$, the mean of Light only controlled $(M=2.03, S D=3.291)$, the mean of neither light nor sound controlled $(M=5.63, S D=3.291)$. 
Table 42

Descriptive Statistics Dependent Variable Diff2 (Ppost-Pre)

\begin{tabular}{llll}
\hline Group Type & Mean & Std. Deviation & $\mathrm{N}$ \\
\hline $\begin{array}{l}\text { 1 Light and sound } \\
\text { controlled }\end{array}$ & 15.29 & 2.740 & 38 \\
2 Sound controlled & 2.38 & 3.991 & 39 \\
3 Light controlled & 2.03 & 3.291 & 36 \\
4 Neither light nor & 5.63 & 3.291 & 35 \\
sound controlled & 6.38 & 6.373 & 148 \\
Total & & & \\
\hline
\end{tabular}

It was noted that the mean of sound only controlled group that is, 2.38 , is slightly higher than the light only controlled group i.e. 2.03. The mean of control group (neither light nor sound controlled, $M=5.63)$ ) performed somewhat better than the other three groups.

Table 43

Levene's Test of Equality of Error Variances (a) Dependent Variable Ppost-Pre

\begin{tabular}{llll}
\hline $\mathrm{F}$ & $\mathrm{df1}$ & $\mathrm{df} 2$ & Sig. \\
\hline 1.133 & 3 & 144 & .338 \\
\hline
\end{tabular}

Table 43 indicated the results of Levene's Test of Equality of Error Variances for postpost-pretest scores $F(3,144)=1.133$ and Sig. value .338 which is not significant hence the null hypothesis was not rejected and concluded that the data among the groups, variances are equal across the groups.

\section{Test of Normality}

This section of the output describes ZRE_4, the Standardized Residual for Diff2. The case summary indicated subjects $(\mathrm{N}=148)$ with no missing values. SPSS performs the Shapiro-Wilk test. 
Table 44

ZRE_4 Standardized Residual for Diff2

Shapiro-Wilk

\begin{tabular}{lll} 
Statistic & df & Sig. \\
\hline .994 & 148 & .803
\end{tabular}

Analysis of normality provided in Table 44 Shapiro-Wilk normality test to determine whether or not a random sample of values follows a normal distribution. Since the $p$ value is greater than $0.05,(.803)$ the null hypothesis cannot be rejected.

Figure 9 Diff 2 (postpost-pretest) gender scores.

Normal

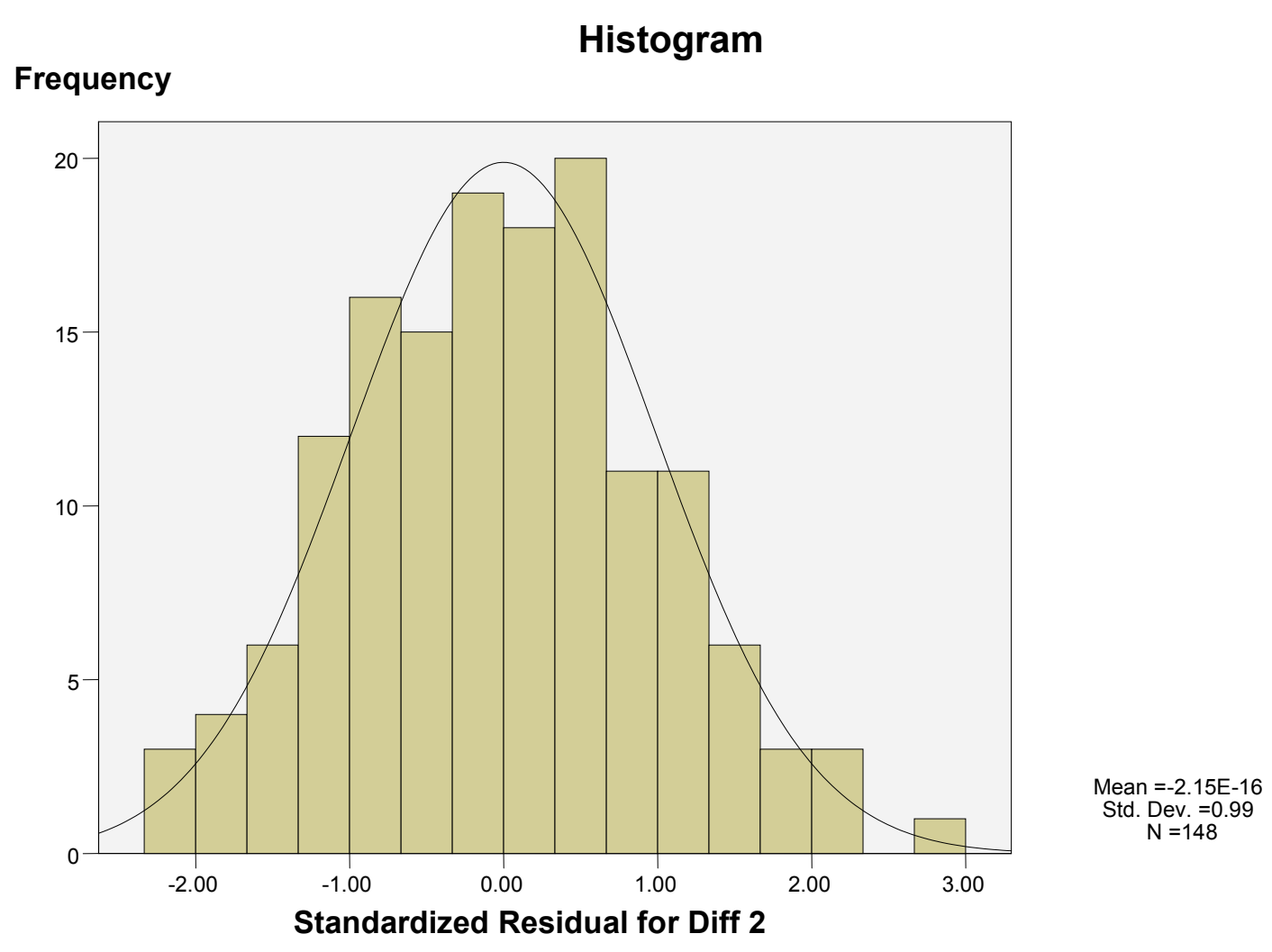


Figure 9 is the histogram showing the relative frequency of the pretest score on $\mathrm{Y}$ axis and the overall mean of response variable on $\mathrm{x}$ axis (pretest). The overall mean of the four groups is $-2.16 \mathrm{E} \_16$ which is very close to zero, and $0.99 \mathrm{SD}$, with a width of one for each group. The histogram shows a rough bell shaped distribution.

Table 45 revealed the results of ANOVA analysis. The dependent variable is the diff 2 scores. The null hypothesis tested by ANOVA is that the population means for all conditions are the same. This can be expressed as follows:

H0: There is no significant difference in the group means.

Ha: There is a significant difference in at least two group means.

Table 45

ANOVA Ppost-Pre

\begin{tabular}{lllllll}
\hline Source & $\begin{array}{l}\text { Type III } \\
\text { Sum of } \\
\text { Squares }\end{array}$ & df & $\begin{array}{l}\text { Mean } \\
\text { Square }\end{array}$ & F & Sig. & $\begin{array}{l}\text { Partial } \\
\text { Eta } \\
\text { Squared }\end{array}$ \\
\hline $\begin{array}{l}\text { Corrected } \\
\text { Model }\end{array}$ & $4340.621(\mathrm{a}$ & 3 & 1446.874 & 127.807 & .000 & .727 \\
Intercept & 5924.242 & 1 & 5924.242 & 523.308 & .000 & .784 \\
group & 4340.621 & 3 & 1446.874 & 127.807 & .000 & .727 \\
Error & 1630.190 & 144 & 11.321 & & & \\
Total & 11992.000 & 148 & & & & \\
Corrected & 5970.811 & 147 & & & & \\
Total & & & & & & \\
\hline
\end{tabular}

The summary of the ANOVA Table 45 indicated a significant effect for group, $F(3,144)$ $=127.807$ and the $p<.05$. Hence the researcher concluded that the main effect for group is significant. However, the researcher does not yet know exactly which means are 
significantly different to which other means. For this we need pairwise comparisons for all the groups.

\section{Estimated Marginals}

Table 46 described the means and standard error of the groups in the outcome variable (diff 2) ppost-pretest. The first column is the four treatment types (group) and their means in the second column.

Table 46

Group Estimates Dependent Variable Ppost-Pre

\begin{tabular}{lcclc}
\hline Group & Mean & $\begin{array}{l}\text { Std. } \\
\text { Error }\end{array}$ & \multicolumn{2}{l}{ 95\% Confidence Interval } \\
\cline { 4 - 5 } & & & $\begin{array}{l}\text { Lower } \\
\text { Bound }\end{array}$ & $\begin{array}{l}\text { Upper } \\
\text { Bound }\end{array}$ \\
\hline $\begin{array}{l}\text { 1 Light and sound } \\
\text { controlled }\end{array}$ & 15.289 & .546 & 14.211 & 16.368 \\
2 Sound controlled & 2.385 & .539 & 1.320 & 3.450 \\
3 Light controlled & 2.028 & .561 & .919 & 3.136 \\
$\begin{array}{l}\text { 4 Neither light nor } \\
\text { sound controlled }\end{array}$ & 5.629 & .569 & 4.504 & 6.753 \\
\hline
\end{tabular}

The third column indicated the standard error. Group 1 mean $(M=15.289, \mathrm{Se}=$ $.546)$ is higher to Group 4 mean $(M=5.629, S e=.569)$. Group 2 mean $(M=2.385, S e=$ $.539)$ is higher to Group 3 mean $(M=2.028, S e=.561)$. However, the overall one-way ANOVA results are significant, so we concluded the not all the population means are equal. 
Table 47

Diff2 Ppost-Pre Group Pairwise Comparisons

\begin{tabular}{|c|c|c|c|c|c|}
\hline (I) type & (J) type & $(\mathrm{I}-\mathrm{J})$ & Sig.(a) & $\begin{array}{l}95 \% \mathrm{C} \\
\text { Interva } \\
\text { Differe }\end{array}$ & $\begin{array}{l}\text { ence } \\
\text { ) }\end{array}$ \\
\hline \multirow{5}{*}{$\begin{array}{l}1 \text { Light and sound } \\
\text { controlled }\end{array}$} & \multirow{5}{*}{$\begin{array}{l}2 \text { Sound } \\
\text { controlled } \\
3 \text { Light only } \\
\text { controlled } \\
4 \text { Neither light nor } \\
\text { sound controlled }\end{array}$} & & & Upper & Lower \\
\hline & & & & Bound & Bound \\
\hline & & $12.905^{*}$ & .000 & 10.853 & 14.957 \\
\hline & & $13.262^{*}$ & .000 & 11.168 & 15.355 \\
\hline & & $9.661^{*}$ & .000 & 7.552 & 11.770 \\
\hline
\end{tabular}

Pair-wise comparisons are needed to be examined in Table 47 to determine the significant effect of group. Bonferroni corrected p-value and 95\% confidence interval of the differences are reported. All the $p$ values are far below than the adjusted $p$ value hence the null hypothesis was rejected and concluded that the performance at type (Group 1) was statistically significant with the all the other groups at alpha $\mathrm{p}<.05(.000)$ as indicated by an asterisks in the mean difference value.

\section{Diff 2 by Gender}

This section of the analysis is done to answer the question 6. Table 48 revealed that factor A (group) has 4 levels while factor B (gender) has two levels along with means and standard deviations of the independent variables group, and gender. The number of participants in each group remained the same throughout the study. 
Table 48

Descriptive Statistics Dependent Variable Ppost-Pre

\begin{tabular}{lllll}
\hline Group Type & Male vs. Female & Mean & $\begin{array}{l}\text { Std. } \\
\text { Deviation }\end{array}$ & $\mathrm{N}$ \\
\hline 1 Light and sound & 1 Female & 13.38 & 2.326 & 8 \\
controlled & 2 Male & 15.80 & 2.644 & 30 \\
& Total & 15.29 & 2.740 & 38 \\
2 Sound controlled & 1 Female & 3.04 & 4.389 & 24 \\
& 2 Male & 1.33 & 3.109 & 15 \\
& Total & 2.38 & 3.991 & 39 \\
3 Light controlled & 1 Female & 2.00 & 3.327 & 16 \\
& 2 Male & 2.05 & 3.348 & 20 \\
& Total & 2.03 & 3.291 & 36 \\
4 Neither light nor & 1 Female & 4.43 & 3.345 & 14 \\
sound controlled & 2 Male & 6.43 & 3.075 & 21 \\
& Total & 5.63 & 3.291 & 35 \\
Total & 1 Female & 4.42 & 5.078 & 62 \\
& 2 Male & 7.79 & 6.850 & 86 \\
& Total & 6.38 & 6.373 & 148 \\
\hline
\end{tabular}

The first row of Table 48 revealed that the subjects $(n=8)$ in Group 1 (light and sound controlled) were females $(M=13.38, S D=2.236)$ and subjects $(\mathrm{n}=30)$ were of males $(M=15.80, S D=2.644)$.

The second row revealed that the subjects $(n=19)$ in Group 2 (sound only controlled) were of females $(M=3.04, S D=4.389)$ and the subjects $(\mathrm{n}=16)$ were males $2(M=$ 1.33, $S D=1.309$ ).

The third row revealed that the subjects $(\mathrm{n}=16)$ in Group 3 (light only controlled) were female $(M=2.00, S D=3.327)$ and the subjects $(\mathrm{n}=20)$ were males $(M=2.05, S D=$ $3.348)$. 
The last row revealed that the subjects $(n=14)$ in Group 4 (neither light nor sound controlled) were females $(M=4.43, S D=3.345)$ and the subjects $(\mathrm{n}=21)$ were males $(M=7.54, S D=3.075)$.

Overall means and standard deviations indicated that the males of group 1 performed better than the males of Group 4. However, there is a significant decrease in performance compared to pretest scores in case of Group 2, Group 3 and Group 4 in all categories. Table 49

Levene's Test of Equality of Error Variances (a) Ppost-Pre

\begin{tabular}{llll}
\hline $\mathrm{F}$ & $\mathrm{df1}$ & $\mathrm{df} 2$ & Sig. \\
\hline 1.104 & 7 & 140 & .364 \\
\hline
\end{tabular}

The homogeneity test in Table 49 on the effect of group by gender data shows $F$ $(7,140)=1.104$ and Sig. value .364 which is clearly not significant $(p>.05)$, so we have no reason to doubt the assumption of homogeneity of variance. The researcher failed to reject the null hypothesis and concluded that the data among the groups, variances are equal across the groups.

The information in Figure 10 revealed a significant interaction between group and gender since the lines are not parallel to each other. This is clearly shown in the ANOVA summary Table 50. 
Figure 10 Estimated marginal means of ppost-pre

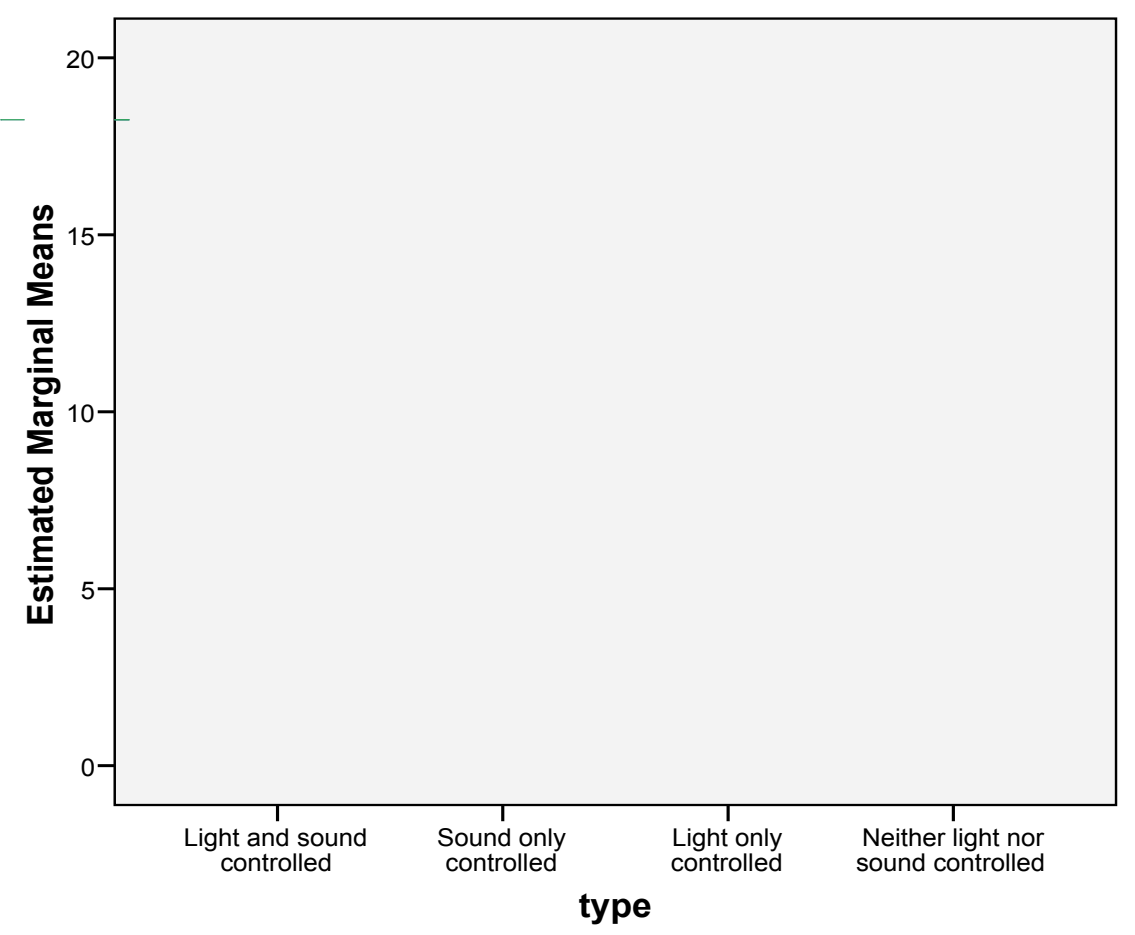

Table 50 revealed the results of ANOVA interaction between the group and gender. The null hypothesis tested by ANOVA is that the population means for all conditions are the same. This can be expressed as follows:

$\mathrm{H}_{0}$ : There is a significant interaction between the group and gender.

$\mathrm{H}_{\mathrm{a}}$. There is no significant interaction between the group and gender. 
Table 50

Two way ANOVA interaction Dependent Variable Ppost-pre

\begin{tabular}{lllllll}
\hline Source & $\begin{array}{l}\text { Type III } \\
\text { Sum of } \\
\text { Squares }\end{array}$ & df & $\begin{array}{l}\text { Mean } \\
\text { Square }\end{array}$ & F & Sig. & $\begin{array}{l}\text { Partial } \\
\text { Eta } \\
\text { Squared }\end{array}$ \\
\hline $\begin{array}{l}\text { Corrected } \\
\text { Model }\end{array}$ & $4438.323(\mathrm{a})$ & 7 & 634.046 & 57.923 & .000 & .743 \\
$\begin{array}{l}\text { Intercept } \\
\text { group }\end{array}$ & 4713.022 & 1 & 4713.022 & 430.557 & .000 & .755 \\
gender & 2918.312 & 3 & 972.771 & 88.867 & .000 & .656 \\
group $*$ & 15.364 & 1 & 15.364 & 1.404 & .238 & .010 \\
gender & 89.116 & 3 & 28.589 & 2.622 & .047 & .055 \\
$\begin{array}{l}\text { Error } \\
\text { Total }\end{array}$ & 1532.488 & 140 & 10.946 & & & \\
Corrected & 11992.000 & 148 & & & & \\
Total & 5970.811 & 147 & & & & \\
\hline
\end{tabular}

A significant interaction effect was obtained for group by gender, $F=2.622$ and the $p$-value is $.047, p>.05$. Since the probability (.047) is lesser than .05 , the researcher concluded there is a significant interaction between group and gender.

\section{Effect Sizes}

Effect size or the $\eta 2$ can be calculated from 2 x 4 ANOVA Table which has two

IVs and one DV: Group (1, 2, 3, and 4) and Gender (male/female) and the DV is achievement scores.

$\eta 2=$ SSbetween / SStotal

$\mathrm{SST}=1338.347+3.286+48.969+1125.573=2516.175$

$\eta 2$ for Group $=1338.347 / 2516.175=0.53$

$\eta 2$ for Gender $=3.286 / 2516.175=.001$ 
$\eta 2$ for interaction $=48.969 / 2516.175=.02$

$\eta 2$ for error $=1125.573 / 2516.175=.48$. The sum of the $\eta 2$ is 1.03 . In this example, the

IVs explain 53.1\% of the variance and Age explains $0.1 \%$.

The next section of the analysis is the estimation of marginal means for the factor type associated with their means and standard errors were reported. This part of the analysis was reported in two tables. The first table 51 (groups) indicates the main effect of treatment type.

\section{Estimated Marginal Means}

In this Table 51 the marginal means with standard error and $95 \%$ Confidence Interval are given for all levels of the two factors.

Table 51

Group * Male Versus Female Dependent Variable Ppost-Pre Interaction

\begin{tabular}{llllll}
\hline & & & & \multicolumn{2}{c}{$95 \%$ Confidence Interval } \\
\cline { 5 - 6 } Group & Male vs. & & Std. & Lower & Upper \\
\hline 1 Light and sound & Female & Mean & Error & Bound & Bound \\
controlled & 2 Male & 13.375 & 1.170 & 11.062 & 15.688 \\
2 Sound controlled & 15.800 & .604 & 14.606 & 16.994 \\
& 1 Female & 3.042 & .675 & 1.706 & 4.377 \\
3 Light controlled & 2 Male & 1.333 & .854 & -.356 & 3.022 \\
& 1 Female & 2.000 & .827 & .365 & 3.635 \\
4 Neither light nor & 2 Male & 2.050 & .740 & .587 & 3.513 \\
sound controlled & 1 Female & 4.429 & .884 & 2.680 & 6.177 \\
\hline
\end{tabular}

Differences between groups and the gender with Standard Errors indicated that the males in group $1(M=15.800, S e=.604)$ and group $4(M=6.429, S e=.722)$ performed better. 
A significant difference is noticed in group 2 female $(M=3.042$, Se $=.675$ performance is higher than the group 2 male $(M=1.333, S e=.854)$.

The next part of the analysis is the follow up tests for factorial ANOVA interaction. Since there is a significant interaction the researcher conducted Independent sample T-tests to look at the effect of gender within each group (Table 52)

Table 52

\begin{tabular}{|c|c|c|c|c|c|c|}
\hline \multirow[b]{2}{*}{ type } & \multirow{2}{*}{$\begin{array}{l}\text { (I) male vs } \\
\text { female }\end{array}$} & \multirow{2}{*}{$\begin{array}{l}\text { (J) male vs } \\
\text { female }\end{array}$} & \multirow{2}{*}{$\begin{array}{l}\text { Mean } \\
\text { Diff (I-J) }\end{array}$} & \multirow[b]{2}{*}{ Sig. ${ }^{a}$} & \multicolumn{2}{|c|}{$\begin{array}{l}\text { t-tests for Equality of } \\
\text { Means } \\
95 \% \text { Con I for Diff }\end{array}$} \\
\hline & & & & & Lower & Upper \\
\hline $\begin{array}{l}1 \text { Light and } \\
\text { sound controlled }\end{array}$ & Female & Male & -2.246 & .091 & -4.859 & .367 \\
\hline $\begin{array}{l}2 \text { Sound only } \\
\text { controlled }\end{array}$ & Female & Male & 1.760 & .108 & -.390 & 3.911 \\
\hline $\begin{array}{l}3 \text { Light only } \\
\text { controlled }\end{array}$ & Female & Male & .019 & .986 & -2.173 & 2.212 \\
\hline $\begin{array}{l}4 \text { Neither light } \\
\text { nor sound } \\
\text { controlled }\end{array}$ & Female & Male & -1.934 & .092 & -4.189 & .321 \\
\hline
\end{tabular}

All the $p$ values obtained fell short of significance with adjusted $p$ values and no asterisks are observed. These analysis have concluded that gender is non significant even though the ANOVA results do not support it.

The next part of the analysis is the effect of age on diff 2 scores. Descriptive statistics Table 53 revealed the means and standard deviations of the independent variables group, and age during diff 2 . 


\section{Descriptive Statistics (Diff2 Group versus Age)}

Table 53

Descriptive Statistics Dependent Variable Ppost-Pre

\begin{tabular}{lclll}
\hline Group type & Age (2 categories) & Mean & $\begin{array}{l}\text { Std. } \\
\text { Deviation }\end{array}$ & $\mathrm{N}$ \\
\hline 1 Light and sound & 14 & 15.82 & 2.519 & 22 \\
controlled & 15 and 16 & 14.56 & 2.943 & 16 \\
& Total & 15.29 & 2.740 & 38 \\
2 Sound controlled & 14 & 3.63 & 3.975 & 19 \\
& 15 and 16 & 1.20 & 3.722 & 20 \\
& Total & 2.38 & 3.991 & 39 \\
3 Light controlled & 14 & 2.15 & 3.100 & 20 \\
& 15 and 16 & 1.88 & 3.612 & 16 \\
4 Neither light nor & 14 & 2.03 & 3.291 & 36 \\
sound controlled & 15 and 16 & 5.23 & 3.100 & 22 \\
& Total & 6.31 & 3.614 & 13 \\
Total & 14 & 5.63 & 3.291 & 35 \\
& 15 and 16 & 6.93 & 6.313 & 83 \\
& Total & 5.68 & 6.430 & 65 \\
& & 6.38 & 6.373 & 148 \\
\hline
\end{tabular}

The first row revealed that the subjects $(\mathrm{n}=22)$ in Group 1 (light and sound controlled) were of age $1(14$ years, $M=15.82, S D=2.519)$ and the subjects $(\mathrm{n}=16)$ were of age 2 of 15 and 16years $(M=14.56, S D=2.943)$.

The second row revealed that the subjects $(n=19)$ in Group 2 (sound only controlled) were of age $1(14$ years, $M=3.63, S D=3.975)$ and the subjects $(\mathrm{n}=16)$ were of age $2(15$ and 16years, $M=1.20, S D=3.722$ ). 
The third row revealed that the subjects $(\mathrm{n}=20)$ in Group 3 (light only controlled) were of age $1(14$ years, $M=2.15, S D=3.100)$ and the subjects $(\mathrm{n}=16)$ were of age $2(15$ and 16years, $M=1.88, S D=3.612)$.

The last row revealed that the subjects $(n=22)$ in Group 4 (neither light nor sound controlled) were of age $1(14$ years, $M=5.23, S D=2.289)$ and the subjects $(\mathrm{n}=13)$ were of age $2(15$ and 16years $M=7.54, S D=3.614)$.

Overall means and standard deviations indicated that the age 1 group 1 performed better than the age 2 Group 2. However, there is a significant decrease in performance compared to pretest scores in case of Group 2, Group 3 and Group 4 in both the age categories.

Table 54

Levene's Test of Equality of Error Variances Ppost-Pre

\begin{tabular}{llll}
\hline $\mathrm{F}$ & $\mathrm{df1}$ & $\mathrm{df2}$ & Sig. \\
\hline .580 & 7 & 140 & .771 \\
\hline
\end{tabular}

Levene's Test for Equality of Variances for the group versus age interaction in Table 54 indicated $F(7,140)=.540$ and a sig value $.771(P>0.05)$, hence the null hypothesis was not rejected and concluded that "the groups are homogenous."

The next part of the analysis is to find out the interaction effect of age on group performance. A two way ANOVA was conducted to look at the interaction effects. Table 55 revealed the results of ANOVA interaction between the group and age. The null hypothesis tested by ANOVA is that the population means for all conditions are the same. 
This can be expressed as follows:

$\mathrm{H}_{0}$ : There is no significant interaction between the group and age in diff 2 scores.

$\mathrm{H}_{\mathrm{a}}$. There is a significant interaction between the group and age in diff 2 scores.

Table 55

Two way ANOVA interaction Dependent Variable (Ppost-Pre) Diff 2

\begin{tabular}{lllllll}
\hline Source & $\begin{array}{l}\text { Type III Sum } \\
\text { of Squares }\end{array}$ & df & $\begin{array}{l}\text { Mean } \\
\text { Square }\end{array}$ & F & Sig. & $\begin{array}{l}\text { Partial } \\
\text { Eta } \\
\text { Squared }\end{array}$ \\
\hline $\begin{array}{l}\text { Corrected } \\
\text { Model }\end{array}$ & $4423.047(\mathrm{a})$ & 7 & 631.864 & 57.154 & .000 & .741 \\
Intercept & 5786.821 & 1 & 5786.821 & 523.436 & .000 & .789 \\
group & 4178.993 & 3 & 1392.998 & 126.001 & .000 & .730 \\
age2 & 18.644 & 1 & 18.644 & 1.686 & .196 & .012 \\
group * age2 & 59.205 & 3 & 19.735 & 1.785 & .153 & .037 \\
Error & 1547.764 & 140 & 11.055 & & & \\
Total & 11992.000 & 148 & & & & \\
$\begin{array}{l}\text { Corrected } \\
\text { Total }\end{array}$ & 5970.811 & 147 & & & & \\
\hline
\end{tabular}

A non significant interaction effect was obtained for group versus age, $F=1.785, p>.05$ (.153) hence the researcher concluded that the interaction was not statistically significant. A significant main effect was obtained for group, $F=126.001, p<.05(.000)$, hence the researcher concluded that the main effect for group is significant.

A non significant main effect was obtained for age, $F=1.686$ and the p-value is $.196, p>.05$. Since the probability (.196) is greater than .05 , the researcher concluded that the main effect for age is not significant. 


\section{Effect Size}

Effect size or the $\eta 2$ can be calculated from $2 \times 4$ ANOVA tables which has two

IVs and one DV: Group (1, 2, 3, and 4) and Gender (male/female) and the DV is achievement scores.

$\eta 2=$ SSbetween $/$ SStotal

$\mathrm{SST}=4178.993+18.644+59.205+1547.764=5804.606$

$\eta 2$ for Group $=4178.993 / 5804.606=0.72$

$\eta 2$ for Age $(2)=18.644 / 5804.606=0.003$

$\eta 2$ for interaction $=59.205 / 5804.606=0.01$

$\eta 2$ for error $=1547.764 / 5804.606=0.27$

The sum of the $\eta 2$ is 1.003 . In this example, the IVs explain $72 \%$ of the variance and Age explains $0.3 \%$.

\section{Estimated Marginal Means}

This section organizes the means into two tables, one for the marginal means of each of the two main effects. The marginal means for the main effect of age 1 and age 2 are shown in Tables 56 and 57 for different age levels.

Recall that the main effect of age was not significant $(p>.05)$. So even though the diff 2 scores for age 1 appears to be greater than that for age 2 , this is not a statistically significant difference. 
Table 56

Age (2 Categories) Dependent Variable Ppost-Pre Scores

\begin{tabular}{|c|c|c|c|c|}
\hline \multirow[t]{3}{*}{ Age } & \multirow[t]{3}{*}{ Mean } & \multirow{3}{*}{$\begin{array}{l}\text { Std. } \\
\text { Error }\end{array}$} & \multicolumn{2}{|c|}{ 95\% Confidence Interval } \\
\hline & & & Lower & Upper \\
\hline & & & Bound & Bound \\
\hline 114 years & 6.707 & .366 & 5.984 & 7.430 \\
\hline 215 and 16 & 5.986 & .417 & 5.161 & 6.811 \\
\hline
\end{tabular}

Table 56 is the estimates of marginal means for group versus age. As mentioned earlier, the main effect for group was significant $(p<.05)$ and the main effect for age is not significant $(P>.05)$. Thus, the appropriate interpretation is that there was not a significant difference in performance between age land age 2.

Table 57

(Diff2) Ppost-Pre for age

\begin{tabular}{llllll}
\hline Group & Age & Mean & $\begin{array}{l}\text { Std. } \\
\text { Error }\end{array}$ & $\begin{array}{l}95 \% \text { C I } \\
\text { Lower } \\
\text { Bound }\end{array}$ & $\begin{array}{l}\text { Upper } \\
\text { Bound }\end{array}$ \\
\hline $\begin{array}{l}\text { 1 Light and sound } \\
\text { controlled }\end{array}$ & 14 & 15.818 & .709 & 14.417 & 17.220 \\
& 15 and 16 & 14.563 & .831 & 12.919 & 16.206 \\
2 Sound only & 14 & 3.632 & .763 & 2.123 & 5.140 \\
controlled & 15 and 16 & 1.200 & .743 & -.270 & 2.670 \\
& & & & & \\
3 Light only & 14 & 2.150 & .743 & .680 & 3.620 \\
controlled & 15 and 16 & 1.875 & .831 & .232 & 3.518 \\
& & & & & \\
$\begin{array}{l}4 \text { Neither light nor } \\
\text { sound controlled }\end{array}$ & 14 & 5.227 & .709 & 3.826 & 6.629 \\
& 15 and 16 & 6.308 & .922 & 4.484 & 8.131 \\
\hline
\end{tabular}


The mean score of Light and Sound controlled Age 1 was greater when compared to the Age 1 of the other three groups. The performance of Light and Sound controlled Age 2 was greater than Age 2 participants of the other three groups. As indicated earlier that there is no significant interaction between the group and age, pairwise comparisons were performed to find out the age category that made the difference.

\section{Multiple Comparisons}

Table 58

Pairwise comparisons pretest achievement scores

\begin{tabular}{|c|c|c|c|c|c|c|}
\hline \multirow[b]{2}{*}{ type } & \multirow[b]{2}{*}{$\begin{array}{l}\text { (I) Age ( } 2 \\
\text { categories) }\end{array}$} & \multirow[b]{2}{*}{$\begin{array}{l}\text { (J) Age (2 } \\
\text { categories) }\end{array}$} & \multirow[b]{2}{*}{$\begin{array}{l}\text { Mean Dif } \\
(\mathrm{I}-\mathrm{J})\end{array}$} & \multicolumn{3}{|c|}{$\begin{array}{l}\text { 95\% CI for } \\
\text { Difference }^{a}\end{array}$} \\
\hline & & & & Sig. ${ }^{a}$ & $\begin{array}{l}\text { Lower } \\
\text { Bound }\end{array}$ & $\begin{array}{l}\text { Upper } \\
\text { Bound }\end{array}$ \\
\hline 1 Light and & 14 years & 15 and 16 & 1.544 & .179 & -.715 & 3.804 \\
\hline sound controlled & 15 and 16 & 14 & -1.544 & .179 & -3.804 & .715 \\
\hline 2 Sound only & 14 years & 15 and 16 & $2.245^{*}$ & .039 & .119 & 4.371 \\
\hline controlled & 15 and 16 & 14 & $-2.245^{*}$ & .039 & -4.371 & -.119 \\
\hline 3 Light only & 14 years & 15 and 16 & .296 & .792 & -1.916 & 2.508 \\
\hline controlled & 15 and 16 & 14 & -.296 & .792 & -2.508 & 1.916 \\
\hline 4 Neither light & 14 years & 15 and 16 & -1.008 & .390 & -3.321 & 1.304 \\
\hline $\begin{array}{l}\text { nor sound } \\
\text { controlled }\end{array}$ & 15 and 16 & 14 & 1.008 & .390 & -1.304 & 3.321 \\
\hline
\end{tabular}

To determine which group is significant pairwise comparisons for diff 2 scores were examined in Table 58. Asterisks in the "Mean difference" column indicated groups that are significant at the 0.05 alpha level. The means of Sound only controlled age category is statistically different from the other three groups. 


\section{Chapter Summary}

Univariate analysis and two-way ANOVA were performed to interpret the results. Factorial analysis was performed to analyze the interaction effects. Post hoc tests were performed to analyze the nature of the interactions. Dependent variable (achievement scores) was measured at different time scale (Pretest, posttest and pposttest). Bonferroni adjustment is used in multiple comparison procedures to calculate an adjusted probability of comparison-wise type I error from the desired probability $\mathrm{a}_{\mathrm{Fw} 0}$ of family-wise type I error questions 2, 3 and 4. The calculation guarantees that the use of the adjusted in pairwise comparisons keeps the actual probability $\mathrm{a}_{\mathrm{FW}}$ of family-wise type I errors not higher than the desired level, as specified by $\mathrm{a}_{\mathrm{Fw}}$. Independent sample t-tests were conducted to observe the gender effect on each group. Results were interpreted and conclusions were reported in Chapter 5. 


\section{CHAPTER V}

\section{CONCLUSIONS AND DISCUSSIONS}

This chapter presented the results of a study that examined the impact of eliminating extraneous sound and light on students' achievement. As discussed in Chapter 3, univariate analysis was used to answer the research questions 2,3 , and 4 measuring the learning outcome, and questions 5 and 6 were intended to measure the interaction effect of gender and age on achievement during posttest. Questions 7 and 8 were intended to measure interaction effect on the content retention under the treatment conditions. This chapter discusses the findings that emerged from the analysis of the data.

Upon completion of each of the three rounds of testing, data were entered into and analyzed using SPSS for Windows ${ }^{\circledR}$. To test the null hypothesis that several population means are equal, descriptive data were collected and included immediate and delayed posttest scores(time), gender, age, and group. All the variables are measured on a nominal scale. The descriptive data were analyzed and presented in the form of counts, percentages, means, and/or standard deviations. Data analysis was organized first by pretest scores of all the three variables, followed by the analysis of difference in posttest-pretest scores of all the three variables and finally by the analysis of difference in postposttest-pretest scores of all the three variables. Chapter 5 ends with a discussion of practical implications followed by limitations and future directions in Neuroscience. Finally, the study ends with concluding remarks. 


\section{Results}

To answer Research Question 1-Is the "Extraneous Light and Sound Elimination Chamber “effective in eliminating students' exposure to extrinsic sound and light? An "Extraneous Light and Sound Elimination Chamber" (ELSEC) was been constructed around each computer using double-layered cardboard padded with 4-inch Styrofoam to prevent light and sound interference from external sources. Only the front side of the chamber was open to participant usage of the keyboard. Noise cancellation head phones as described in the methods sections were used by the participants as an additional instrument to prevent noise to the maximum extent. Overhead lights were turned off during the intervention, but the safety light at the corner of the lab remained on for student safety purposes. Computers located close to the safety light were not used to avoid light interference.

The chamber was tested before the instrumentation began. The researcher also took extra precautions in selecting the computer lab that is adjacent to the library where silence is maintained as a rule. Periods during the lunch hours were not selected to prevent hallway noise. About 10 adults and 10 students who were not affiliated with the study were asked to use the chamber one at a time, for 10 minutes. They watched a multimedia presentation of a lesson on "Hormones." Two minutes after they started using the chamber, the researcher asked a series of questions irrelevant to the content, from a distance of 6 feet, in a normal conversational voice. 
The subjects continued to view the lesson without responding to the questions.

Later the researcher asked them, 'Did you hear me talking to you while you were watching the multimedia presentation?" The answer was "no," confirming that the ELSEC was effective in eliminating external sound and light.

\section{Reporting Pretest Results of Univariate Analysis $(\mu 1 \neq \mu 2)$}

As a test of hypotheses to Research Questions 2, 3, and 4 - "Does eliminating sound and light or either sound or light improve student achievement scores"- the researcher performed univariate analysis to analyze the pretest results on all the three factors Group, Gender and Age.

A pretest was administered before the intervention and achievement scores were compared in a group of three experimental conditions and one control condition. The hypothesis was that the participants in the experimental intervention would perform better than the participants in the controlled group.

\section{Group Pretest ANOVA results}

A one-way ANOVA was used to test the mean differences among the four treatment groups. The summary of the ANOVA Table 12 indicated a significant main effect was obtained for group, $F(3,144)=9.830$ and the $\mathrm{p}=.000$ and $\eta \mathrm{p} 2=$ .170 .

Post hoc analysis using Bonferroni adjustments (Table 15) indicated a significant difference between Group 1 and Group $4(M=2.385,95 \%$ CI [1.03, 3.74]), $p<$ .05 (.000), Group 2 and Group $4(M=2.389,95 \%$ CI $[1.04,3.74]), p<0.05$ (.000), and Group 3 and Group $4(M=1.876,95 \%$ CI $[.499,3.25]), p<0.05$ 
(.000). However, the means of Group 1, Group 2 and Group 3 were not statistically at $p>.05(\mathrm{sig}=1.000)$. Overall results indicated that simple main effect (group) is significant across the groups.

\section{Gender Pretest Two way ANOVA results}

Posttest scores were subjected to a two-way analysis of variance having four levels of treatment type (Groups) and two levels of gender (female, male). The hypothesis was that there would be no significant interaction effect between the Group and Gender.

Table 18 summarized 4 (group) x 2 (gender) interaction effect between Group and Gender revealed significant effect of Group.

The group effects were statistically significant at the .05 significance level. The main effect of Group yielded an $F$ ratio of $F(3,140)=11.188, p=.000$, indicating that the mean change score was significantly greater for Group $2(M=$ $10.85, S D=2.312)$ than Group $1(M=10.84, S D=1.952)$.

The main effect of Gender yielded an F ratio of $F(1,140)=7.108, p>.05$, indicating no effect.

The interaction effect was significant, $F(3,140)=6.347, p<.05(.000)$. However it does not indicate which Group behaved significantly so simple effects followed by post hoc test results were analyzed. 


\section{Reporting Post Hoc Comparisons}

Since there is a significant interaction between the group and the gender, the cells are examined to see the nature of the interaction. To find out if this simple main effect is significant gender $(\mathrm{p}<.05$ Independent sample T-tests in Table 20 indicated that the means of Light and Sound controlled and Neither light nor sound controlled gender is statistically different from the other two groups. Overall male vs female pairs were compared in table 20 indicated a significance in Group 1 $(p=.007)$ and Group $4(p=0.000)$ gender and vice versa $(p<0.05)$.

\section{Pretest results by Age (IV)}

Pretest scores were subjected to a two-way analysis of variance (Table 23) having four levels of treatment type (Groups) and two levels of age 2 (14 years, 15 and 16 years). The hypothesis was that there would be no significant interaction effect between the Group and Age.

Table 23 summarized 4 (group) x 2 (age) interaction effect between Group and Age revealed no significant interaction between the group and the age. The F statistics indicated $F(3,140)=.427$ and $p$-value is .734 greater than alpha $(p>$ $.05)$. However, it is not clear that this effect is due to which age category or due to the group effect. Hence, follow up test for analyzing the simple effects were conducted in the later part of the analysis.

A significant main effect was obtained for group, $F(3,140)=9.242$ and the pvalue is less than alpha. Since the $p<.05,(.000)$ the researcher concluded that the main effect for group is significant. 
A significant main effect was also obtained for age, $F(1,140)=9.223$ and the $p$ value is less $.000(p<.05)$.

\section{Reporting Post Hoc Pairwise Comparisons}

Pairwise comparisons between groups (Table 25 ) that Light and sound controlled and light only controlled age catergory was statistically different $(0.026)$ from the other three groups $(p<0.05)$ which fell short of statistical significance $(\mathrm{p}>0.05)$ of adjusted $\mathrm{p}$ value. Hence the null hypothesis was not rejected and concluded that the groups are equal in all age factors.

\section{Reporting Results of "Diff 1" (Post-Pre) by Group}

As a test to hypothesis for Question 5-“How do Group by Gender interactions affect the learning during diff 1?" A two way ANOVA has been performed. It was hypothesized that there will be no significant treatment effect on student's achievement scores.

ANOVA results for group diff 1 scores. Univariate ANOVA results in Table 28 indicated Sig. column (.000) is lesser than $.05, F(3,144)=59.187, p<$ 0.05 , and $\eta \mathrm{p} 2=.552$. It was clear that the main effect for group for diff1 was significant.

Estimated marginal means Table 29 revealed the means $(M)$ of the four treatment groups and their standard error $(\mathrm{Se})$. Diff 1 results showed an increase in performance in Group1 $(M=14.921, S e=.464)$ compared to the other three groups. Based on the above results, it could be concluded that Group 1, Light and Sound controlled subjects performed better in the post test. 
Post hoc analysis (Table 30) indicated that performance at treatment type Light and sound controlled (group 1) was significantly higher than the other three groups. Group 1 was statistically significant with all the other groups at $p<.05$ (.000). Overall results indicated that simple main effect (group) was significant across the groups in diff 1 .

\section{Diff 1 by gender (post-pre)}

As a test to hypothesis that there would be no interaction effect of Group by Gender on diff 1 scores (Research Question 5) 4 (Group) x 2 (Gender) ANOVA was performed.

Table 33, a two way ANOVA with 4 (group) x 2 (gender) between group test, revealed a significant interaction of group by gender $F(3,140)=3.912, p<$ 0.05(.01). significant main effect of Group, $F(3,140)=39.517, p=<0.05$ (.000). The main effect for gender was found to be non-significant $F(1,140)=$ $.373, p>0.05$ (.542). This indicated that there is a significant interaction between group versus gender in diff 1 noticed while gender by itself is not significant. Since the interaction is significant, the follow up test was performed to analyze the nature of this interaction.

\section{Reporting Post hoc comparisons}

Pairs were compared of all 8 groups (male versus females) on diff 1 scores. Results in Table 36 indicated a significant difference $(p<.05)$ in the diff 1 mean scores Sound only controlled groups. Sound only controlled group is statistically significant with a $\mathrm{p}$ value of 0.027 . Hence the null hypothesis was rejected and 
concluded that the effect of gender was not equal within the group. The above results led to the conclusion that the interaction effect was due to Group 2 gender.

\section{Diff 1 by Age (IV)}

To test the hypothesis that there would be a significant interaction effect of Group by Age performance in diff 1 scores (Research Question 6) 4 (Group) x 2 (Age) ANOVA was performed.

\section{Reporting Factorial ANOVA Results}

ANOVA with 4 (Group) x 2 (Age) between group test results in Table 39 indicated A non significant main effect was obtained for age $F=.409$ and the pvalue is $.524(p>.05)$.

A significant main effect of Group $\mathrm{F}$ ratio, $F(3,140)=55.488, p=<0.05(.000)$ and Age $2 \mathrm{~F}$ ratio, $F(1,140)=.409, p>0.05(.524)$.

The main effect of Age was non-significant across the groups. However, these main effects both Group, and its interaction with Age was found also nonsignificant, $F(3,140)=2.030, p>0.05(.112)$. However in order to know the effect of both the age groups, estimated marginal means of each age group was compared.

Table 40 and 41 are the results of estimated marginal means of Diff 1 showed an increase in performance in Age1 $(M=9.7151, S e=.312)$ compared to the Age $2(M=9.413, \mathrm{Se}=.356)$. Based on the above results, it was concluded that Age 1 subjects performed better in diff 1 scores. 


\section{Results Diff 2 (Ppost-Pre) by Group $(\mu 1 \neq \mu 2)$}

To test the hypothesis for Research Question 7-How do Group by Gender interactions affect the learning during postpost test (diff 2)?"

Since it was hypothesized that there would be a significant interaction effect

during postpost test, the researcher performed 4 (Group) x 2 (Gender) ANOVA.

\section{Reporting Diff 2 ANOVA Results by Group}

Results of ANOVA in Table 45 with dependent variable is the difference between post- posttest and pretest scores (diff 2) indicated the probability (.000) is lesser than $.05, F(3,144)=127.807, p<0.05$, it was concluded that the effect for group for diff 2 is significant.

Diff 2 results showed a decrease in overall performance in all groups compared to Diff 1. The performance in Group1 $(M=15.289, \mathrm{Se}=.546)$ is 12.904 greater compared to Group $2(M=2.385, S e=.539)$ performance. The results showed a decline in the performance of all the three groups except Group 1. Group 1 performance was greater than the pretest scores confirming the academic improvement with time.

The pairwise comparisons in Table 47 indicated a significant effect of the mean difference between Group 1 and all the other Groups "Sig" is .000 $(p<0.05)$. These results indicated that Group 1 scored better than the other groups. 


\section{Reporting Diff 2 ANOVA Results by Gender}

Table 50 ANOVA interaction between group versus gender indicated a significant interaction effect was obtained for Group versus Gender, yielded an F ratio of $F=2.714$ and the $p$-value is $.047, p<.05$. A significant main effect for Group yielded an F ratio of $F=(3,140) 88.867$, and $p$-value is $.000(p<.05)$. A non significant main effect was obtained for Gender yielded an $\mathrm{F}$ ratio of $F$ $(1,140)=1.404$ and the $p$-value is $.238, p>.05$.

Based on the Table 51 estimated marginal means data, it was found that Group 1 and Group 4 males performance was greater than the females and Group 2 and Group 3 female performance was greater than the males.

\section{Reporting Post Hoc comparisons}

Table 52 indicated the results of Independent sample T-test for diff 2 scores between the groups and gender. The mean differences are not statistically significant for Group versus Gender $(p>0.05)$ in all treatment types. All the $p$ values obtained fell short of significance with adjusted $p$ values and no asterisks are observed. These analysis have concluded that gender is non significant even though the ANOVA results do not support it.

\section{Reporting Diff 2 ANOVA Results for Age}

As a test to hypothesis 8 - How do Group by Age interactions affect the learning during postpost test (diff 2)?-It was hypothesized that there would be a 
significant age effect on achievement scores. A two-way ANOVA with 4 (group) x 2 (age) (Table 54) the interaction with Group and Age was found to be non significant, $F(3,140)=1.785, p>0.05(.153)$.

A significant main effect of group, $F(3,140)=126.001, p=<0.05(.000)$.

The main effect for Age was found to be non-significant across the groups $F$ (3, $140)=1686, p>0.05(.196)$. However, Overall results indicated that Age and its interaction with group have no effect on performance diff 2 scores. In order to understand which age group is significant marginal means were examined in table 66 and 67.

Table 55 indicated that Age 1 performance $(M=6.707, S D=.366)$ was greater by 0.79 higher than Age 2 performance $(M=5.986, S D=.709)$. Table 55 indicated that Group 1 Age 1 performance $(M=15.818, S D=.709)$ was greater by 1.255 greater the other groups. Based on the above results, it was concluded that in Group lagel performed better than all the other groups in the post test. Pairwise comparison Table 56 indicated that the Sound only controlled age category is statistically different from the other three groups $(p=0.039)$ however fell short of adjusted $\mathrm{p}$ value significance. Hence the null hypothesis was not rejected and concluded effect of age was equal within each group.

\section{Answers to Research Questions}

1. Is the "Extraneous Light and Sound Elimination Chamber" effective in eliminating students' exposure to extraneous sound and light?

Extraneous Light and Sound Elimination Chamber was effective in 
eliminating students' exposure to extrinsic sound and light below threshold levels.

2. Does eliminating extrinsic sound improve students' content learning?

Eliminating extrinsic sound alone did not improve students' content learning as measured by the posttest and the post-posttest.

3. Does eliminating extrinsic light improve students' content learning?

Eliminating extrinsic light alone did not improve student's content learning as measured by the posttest and the post-posttest.

4. Does eliminating extrinsic sound and light improve students' content learning?

Eliminating both extrinsic sound and light improved students' content learning as measured by the post-test and the post-posttest.

5. How do Group by Gender interactions affect the learning during posttest (posttest-pretest)?

(a) Extraneous light eliminated: There is a significant difference in gender related performance in extraneous light eliminated conditions. Females performed slightly better than the males however there is no significant improvement in posttest scores over the pretest scores. These result support the study of Lai and Huan (2005).

(b) Extraneous sound eliminated: There is a significant difference in gender-related performance in extraneous sound eliminated conditions. Females performed slightly better than the males; however, there is no significant improvement in posttest scores over the pretest scores. 
(c) Extraneous light and sound eliminated: There is a significant difference in gender-related performance in extraneous sound eliminated conditions. Males performed slightly better than the females and there is a statistically significant improvement in posttest scores over the pretest scores.

6. How does Group by Age interactions affect the learning during posttest (posttest-pretest)?

There is a no significant interaction between age and groups. However there is an age related difference in student performance under the following conditions contrary to the studies of Van Gerven et al. (2000) and consistent with the studies of Knez \& Kers,(2000):

(a) Extraneous light eliminated: Age 1 performed slightly better on the post test than Age 2. However there was no statistically significant difference between the posttest and pretest scores.

(b) Extraneous sound eliminated: Age 1 performed slightly better on the post test than Age 2. However there was no statistically significant difference between the posttest and pretest scores.

(c) Extraneous light and sound eliminated: Age 2 performed slightly better than Age1. However, the difference was not significant.

7. How do Group by Gender interactions affect the learning during post-posttest (Postpost-pretest)?

Results indicated a significant interaction effect between group and gender. However, gender alone is nonsignificant. Group 1 and Group 4 revealed increase 
in content retention as measured by post-posttest-pretest .

Group 1 males' performance was substantially higher than any other group.

8. Are there any age-related differences in content retention as measured by

postpost-pretest?

Results indicated that there were no age-related differences in students' content retention as measured by postpost-pretest.

\section{Practical Implications}

Many previous studies within the cognitive load framework have almost exclusively focused on reducing extraneous cognitive load central to learning or on inducing germane cognitive load, (Van Merriënboer \& Sweller, 2005). What these studies do not tell us, is how to deal with the elements that are not central to learning that might be potential sources of extrinsic load. These elements include light and sound (Campbell \& Murphy, 1998; Dalgleish et al., 1996). This study examined the impact of eliminating extraneous sound and light on student achievement. As noted earlier, neuroscience and cognitive psychology literature on the effect of sound and light on cognition and studies on the impact of sound on learning (Andrews, 1990; Bess et al., 1998; DiSarno et al., 2002; Dunn, 1990; Dunn \& Griggs, 1990; Gadwa \& Griggs, 1985; Kreisman, \& Crandell, 2002) have indicated that in the typical classroom (Bronzaft \& McCarthy, 1975; Evans \& Maxwell, 1975; Maxwell \& Evans,2000), various environmental and studentrelated factors interfere with listening and comprehending (Dockrell \& Shield, 2006; Flexer, 2009). 
Neuroscience researchers explored the effects of background noises in the auditory thalamus of rats (Merzenich, 2004) suggesting brain circuits received a message, but the message was scrambled (Bedenbaugh, 2004). Similar interactions occur during human audio reception and noise processing, which kindles the understanding that noise is more than just a nuisance (Edward \& Merzenich, 2003). There is a wealth of research indicating that the ergonomics of an environment significantly improve or slows down individual and group learning performance (McCloughan et al., 1999). Due to obvious lack of data in cognitive load theory's research and in neuroscience research on the combined effect of light and sound, the researcher attempted to combine the findings of neuroscience studies and cognitive psychology in this investigation. This experimental approach adds to the existing knowledge in providing a base that differed from the earlier research by focusing on eliminating the external sources of cognitive load rather than altering the instructional design to manage the cognitive load. If the findings of this study are replicated by future researchers, such findings can be used to design better learning environments. Such environments can be achieved with different electric lighting and sound systems that vary in their ability to provide good color rendering, low glare, low flicker, low noise, and reverberation (McGowan, Miller, \& Rubenstein, 2003). These environments will help people avoid unwanted distraction, drowsiness, levels of arousal, and photosensitive behavior (Dockrell \& Shield, 2006). 


\section{Limitations and Future Directions}

In this study, we focused on eliminating light and sound to determine if this has an impact on student learning. However, there may be other factors such as learning styles, personality traits and teaching methods that could be associated with cognitive load.

Since the population selected in this study is limited to only one school in the Dade County, the results cannot be generalized to all the Dade County Public Schools.

This type of study seems to be difficult in settings like public schools interfering with the school's operational methods where sound is practically impossible to control. The students were not selected randomly on an individual basis, but the entire group has been selected randomly as the students cannot be separated from their selective periods.

A problem with the current study is that the various measures of reducing extraneous cognitive load that are not central to the learning created a novel learning situation. Those students who participated in Light and Sound controlled treatment insisted that the teacher continue with the same environment even after the intervention period was over. During class discussions at the end of the study students who participated in Sound only controlled group reported that they missed teachers' explanation of the content used for during the intervention period. 


\section{Conclusion}

In spite of these limitations, this study has contributed to the knowledge base regarding the impact of controlling extraneous Sound and Light on student learning. Future studies need to be conducted with other ethnic groups, students at different age and grade levels, and using content materials in other disciplines such as social studies, mathematics, humanities, fine arts, and language arts. 


\title{
LIST OF REFERENCES
}

\author{
Abbott, C. L., Yost, B. A., and Harding, J.L. (2003). Personality Type as a Predictor of \\ Interviewer Performance. Poster Presentation at $58^{\text {th }}$ Annual AAPOR Conference \\ in Nashville, TN.
}

Allen, P., \& Wightman, F. L. (1992).Spectral pattern discrimination by children. Journal of Speech and Hearing Research, (35), 222-235.

American Speech-Language-Hearing Association (2005). Acoustics in educational settings: position statement. Retrieved April 11, 2008, from http://www.asha.org/docs/html/PS2005-00028.html.

Anderson, T. (2003). Getting the mix right again: An updated and theoretical rationale for interaction. The International Review of Research in Open and Distance Learning 4(2). http://www.irrodl.org/index.php/irrodl/article/view/149/230.

Anderson, K. 2004. The problem of classroom acoustics: The typical classroom sound scape is a barrier to learning. Semin. Hearing 25:117-129.

Andrews, R. H. (1990). The development of a learning styles program in a low socioeconomic, underachieving North Carolina elementary school. Journal of Reading, Writing, and Learning Disabilities International, (6), 307-314.

Ayres, P. (2006). Impact of reducing intrinsic cognitive load on learning in a mathematical domain. Applied Cognitive Psychology, 20, 287-298.

Baddeley, A. (1992). Working memory. Science, (255), 556-559. 
Baker, J.A.; Bridger, R.; \& Evans, K. (1998) Models of Underachievement among Gifted Preadolescent: The Role of Personal, Family, and School Factors. Gifted Child Quarterly, (42), 1, 5-15.

Banbury, S. P., Macken, W. J., Tremblay, S., Jones, D. M. (2001) Auditory distraction and short-term memory: Phenomena and practical implications. Hum. Factors, 43: $12-29$.

Bannert, M. (2002). Managing cognitive load-recent trends in cognitive load theory. Learning and Instruction (12) 139-146.

Baron et al., (1992). Irrelevant speech and indoor lighting: effects on cognitive load. Applied Cognitive Psychology, (16) 6, $709-718$.

Barrick, M. R., \& Mount, M. K. (1991). The Big Five personality dimensions and job performance: A meta-analysis. Personnel Psychology, 44, 1-26.

Baum, S. M., Renzulli, J. S., \& Hébert, T. (1995). The prism metaphor: A new paradigm for reversing underachievement (CRS95310). Storrs, CT: The National Research Center on the Gifted and Talented, University of Connecticut.

Berg, F. S. (1987). Facilitating classroom listening: A handbook for teachers of normal and hard of hearing students. Boston, MA: College-Hill Press/Little, Brown.

Berglund B, Lindvall T, Schwela D H, (1999) Guidelines for Community Noise (World Health Organization, Geneva).

Berglund, B., T. Lindvall, D. Schwela, and K.-T. Goh. 2000. Guidelines for Community Noise. Geneva: World Health Organization. http://www.who.int/docstore/peh/noise/guidelines 2.html. 
Bess, F., Dodd-Murphy, J., \& Parker, R. (1998). Children with minimal sensorineural hearing loss: Prevalence, educational performance, and functional status. Ear and Hearing, 19(5), 339-354.

Benya, J.R., Heschong, L., McGowan, T., Miller, M. and Rubenstein, F. (2003). Advanced Lighting Guidelines. White Salmon: WA. U.S., New Buildings Institute.

Bradley, M. M., \& Lang, P. J. (2000).Affective reactions to acoustic stimuli. Psychophysiology, 37, 204-215.

Bechtel, R.B. and Churchman, A., Editors, 2002. Handbook of environmental psychology. Wiley. New York, pp. 499-510.

Broadbent, D.E. (1971). Decision and stress. London: Academic Press.

Bronzaft, A.L., (2002). Noise pollution: A hazard to physical and mental well-being. In:

Bronzaft, A.L. \& McCarthy, D.P,(1975). The effects of elevated train noise on reading ability. Environment and Behavior, 7(6), 517-527.

Campbell and Murphy, (1998); Dalgleish et al., (1996) Irrelevant speech and indoor lighting: effects on cognitive performance and self-reported affect, Applied Cognitive Psychology (16)6, $709-718$.

Campbell, D. T. \& Stanley, J. C. (1963). Experimental and Quasi-Experimental Designs for Research. Chicago: Rand McNally.

Campanella Associates, 2006. Active Noise Control or Cancellation (ANC). Retrieved, May 2006. http://www.campanellaacoustics.com/anc.htm 
Chandler, P., \& Sweller, J. (1991). Cognitive load theory and the format of instruction. Cognition and Instruction, (8), 293-332.

Carroll, A., Bain, A. and Houghton, S. (1994). The effects of interactive video versus linear video on the levels of attention and comprehension of social behavior by children with attention disorders, School Psychology Review, (23)1, 29-43

Ching, Y.C., \& McPherson, B (2005). Noise Levels in Hong Kong Primary Schools: Implications for Classroom Listening. International Journal of Disability, Development and Education, 52, Retrieved December 5, 2006, from http://web.ebscohost.com/ehost/detail?vid=4\&hid $=5 \&$ sid $=02$ ce $7093-498 \mathrm{e}-4 \mathrm{e} 2 \mathrm{a}-$ 97b4-ddf8d08b3faa\%40SRCSM2.

Chipperfield, B. (2006). Cognitive Load Theory and Instructional Design Saskatoon. Saskatchewan, Canada: University of Saskatchewan (USASK). Retrieved on November 7, 2006 from http://www.usask.ca/education/coursework/802papers/ chipperfield/chipperfield.pdf.

Christie, D. J. and Glickman, C. D. (1980). The effects of classroom noise on children: evidence for sex differences. Psychology in School, 17, 405-408.

Clark, L. A. (2005). Temperament as a unifying basis for personality and psychopathology. Journal of Abnormal Psychology, 114 (4), 505-521.

Cobb, P. \& Steffe, L.P. (1983). The constructivist researcher as teacher and model builder. Journal for Research in Mathematics Education, (14), 83-94.

Cohen, S., D.C. Glass, and J.E. Singer. (1973). Apartment noise, auditory discrimination, and reading ability in children. Journal of Experimental Social Psych. 9: 407422 .

Cohen, S. \& Lezak, A.(1977). Noise and Inattentiveness to Social Cues. Environment and Behavior. 9(4), 559-572. 
Cohen, S. (1986) Knowledge and Context. Journal of Philosophy (83), 574-583.

Cohen, S., Evans, G., Krantz, D.S., \& Stokols, D. (1986). Behavior, Health, and Environmental Stress. New York: Plenum.

Cottrell, S (2003) Skills for Success: the Personal Development Handbook, Palgrave Macmillan.

Cothran, D., Kulinna, P., \& Garrahy, D. (2003). This is Kind of Giving a Secret Away: Students' Perspectives on Effective Class Management. Teaching and Teacher Education, 19(4), 435-44.

Cowan, N. (2001). The magical number 4 in short-term memory: A reconsideration of mental storage capacity. Behavioral and Brain Sciences, 24, 87-185.

Crandall, C., \& Smaldino, J. (1994). An update of classroom acoustics for children with hearing impairment. Volta Review, (96), 291-306.

Crandall, C. C. and Smaldino, J.J. (2000). Classroom Acoustics for Children with Normal Hearing and With Hearing Impairment. Language, Speech, and Hearing Services in Schools. 31, 362-370

Crandall, C.C., Smaldino, J.J., \& Flexer, C. (2005). Sound-Field amplification: Applications to speech perception and classroom acoustics. $2^{\text {nd }}$ ed. New York: Thomson Delmar Learning.

Czaja, S. J., \& Sharit, J. (1993). Age differences in the performance of computer based work as a function of pacing and task complexity, Psychology and Aging, 8, 5967.

Davidson, L., Bryan, T., and Griffiths, R. (1999). Reflecting Students Learning Styles. Working Paper, University of West England. 
DiSarno, N., Schowalter, M., \& Grassa, P. (2002). Classroom amplification to enhance student performance. Teaching Exceptional Children, 34(6), 20-26.

Dockrell, J.E. and Shield, B.M. (2006). Acoustical barriers in classrooms: the impact of noise on performance in the classroom. British Educational Research Journal 32(3): 509-525.

Dornic S, Ekehammar B (1990). Extraversion, neuroticism, and noise sensitivity. Person Individ Diff 11: 989-992.

Darai, B, (2000). Using sound field FM systems to improve literacy scores. Advance for Speech-Language Pathologists \& Audiologists. 10 (27): 5, 13.

Dalgleish et al., (1996) Irrelevant speech and indoor lighting: effects on cognitive performance and self-reported affect. Applied Cognitive Psychology 16 (6), $709-$ 718.

Dunn, R. (1990). Rita Dunn answers questions on learning styles. Educational Leadership, 48 (2), 15-19.

Dunn, R. \& Dunn, K. (1993). Teaching secondary students through their individual learning styles: Practical approaches for grades 7 - 12. Allyn \& Bacon: Boston.

Dunn, R., K. Dunn, and G. E. Price, Productivity Environmental Preference Survey (PEPS). Center for the Study of Learning and Teaching Styles, St. John's University, Jamaica, NY, 1991.

Dunn, R., Griggs, S. A. (1995). Multiculturalism and Learning Styles. Westport, CT: Praeger Publishers, Greenwood Press.

Edward, F. Chang and Michael M. Merzenich (2003), Environmental Noise Retards Auditory Cortical Development. Science 18 (300)5618, 498 - 502 
Emerick, L.J. (1992). Academic underachievement among the gifted: Students' perceptions of factors that reverse the pattern. Gifted Child Quarterly, 36, 140146.

Emmer, E. (1995) Teacher managerial Behaviours. In L. Anderson (Ed.), Encyclopaedia of Teacher Education. (2nd Ed). (219-223). Oxford: Pergamon.

Ericsson, K. A. \& Kintsch, W. (1995). Long-term working memory. Psychological Review, (102), 211-245.

Evans, G.W. \& Lepore, S. J. (1993). Non-auditory ejects of noise on children: A critical review. Children's Environments, 10(1), 31-51.

Evans, G.W. \& Maxwell, L., (1997). Chronic noise exposure and reading deficits: The mediating effects of language acquisition. Environment and Behavior, 29(5), pp.638-656.

Eysenck, M. W. (1979). Anxiety, learning, and memory: A reconceptualization. Journal of Research in Personality, 13(4), 363-385.Environ. Behav. 29, 638-656.

Fisher, R. A. (1959). Statistical Methods \& Scientific Inference. New York: Hafner Publishing.

Flexer, C., Richards, C., Buie, C., \& Brandy, W. (1994). Making the grade with amplification in classrooms. Hearing Instruments, 45(10), 24-26.

Flexer, C. (2009). Technology and listening. In L. Robinson, Literacy and deafness: Listening and spoken language, (pp. 43-63). San Diego: Plural Publishing Inc. 
Flexer C, Wray D, and Ireland J. (1989). Preferential seating is not enough: Issues in classroom management of hearing impaired students. Language, Speech and Hearing Services in the Schools, 20:11-21.

Fligor, B., \& Ives, T. (2006). Does earphone type affect risk for recreational noiseinduced hearing loss? presentation at Noise-induced Hearing Loss in Children Meeting, Cincinnati, Ohio.

Forehand, M. (2005). Bloom's taxonomy: Original and revised... In M. Orey (Ed.), Emerging perspectives on learning, teaching, and technology. Retrieved 10/10/2005, from http://projects.coe.uga.edu/epltt/.

Furnham, A., \& Strbac, L. (2002). Music is as distracting as noise: The differential distraction of background music and noise on the cognitive test performance of introverts and extroverts. Ergonomics, 45(3), 203-217.

Gadwa, K., \& Griggs, S. A. (1985). The school dropout (1): Implications for counselors. 33(1), 9-17.

Gathercole, S. E., \& Pickering, S. J. (2000). Assessment of working memory in six- and seven-year old children. Journal of Educational Psychology, 92, 377-390.

Gemake, J., Jalali, F., Zenhausern, R, Quinn, P., \& Spiridakis, J. (1990). Cross Cultural Differences in the Learning styles Journal of Secondary Gifted Education, (14), 2003.

Gerjets, P., Scheiter, K., Schorr, T (2003). Modeling Processes of Volitional Action Control in Multiple-Task Performance: How to Explain Effects of Goal Competition and Task Difficulty on Processing Strategies and Performance within ACT-R. Cognitive ScienceQuarterly, (3), 355-400.

Gilinsky, A. S., \& Judd, B. B. (1994). Working memory and bias in reasoning across the life span. Psychology and Aging, 9, 356-371. 
Glass, K. 91985). Sonic environment. CEFPI Journal, 23(4), 8-10.

Goolkasian, P. (2000). Pictures, words, and sounds: From which format are we best Able to Reason? The Journal of General Psychology, 127(4), 439-459.

Gowan, J. C. (1955). The underachieving gifted child- A problem for everyone. Exceptional Children, 22, 247-249, 270-271.

Hawkins, H.L. \& Lilley, H.E. (1992). CEFPI's guide for school facility appraisal. Columbus, Ohio: The Council of Educational Facility Planners International.

Hathaway, Warren E. (1995). Effects of School Lighting on Physical Development and School Performance. Journal of Educational Research, 88(4), 228- 242.

Herman, Lloyd and Bowlby William, 1998. Analysis of Proponent Mitigated Development Plans for Traffic Noise. Journal of Transportation Engineering 124:384-389.

Hygge \& Knez (2001). Effects of noise, heat, and indoor lighting on cognitive performance and self-reported affect. Journal of Environmental Psychology (21), 291-299.

Hygge, S. (2003). Classroom experiments on the effects of different noise sources and sound levels on long-term recall and recognition in children. Applied Cognitive Psychology, (17), 895-914.

Isen, A.M., \& Baron, R.A. (1991). Positive affect as a factor in organizational behavior. Research in Organisational Behaviour, 13(1), 1-53.

Jacobson, A. (2004). How do Noise Cancelling Headphones Work? Retrieved from: http://www.jacobsen.no/anders/blog/archives/2004/10/01/how_do_noise_cancelli ng_headphones_work.html 
Johnson-Laird, P.N., and Wason, P.C. (1970) Insight into a logical relation. Quarterly Journal of Experimental Psychology, 22, 49-61.

John Pastor (2004). Background Noise Jumbles Brain Circuits, UF Researchers Find. Retrieved from http://news.ufl.edu/2004/09/30/brainnoise/.

Jonassen, D. H., Beissner, K., \& Yacci, M. (1993). Structural knowledge: Techniques for representing, conveying, and acquiring structural knowledge (pg. 6). Hillsdale, NJ: Lawrence Erlbaum Associates, Inc.

Jones DM, Miles C, Page J (1990). Disruption of proofreading by irrelevant speech: effects of attention, arousal or memory? Applied Cognitive Psychology (4) 89108.

Kalyuga, S., Chandler, P., \& Sweller, J. (1999). Managing split-attention and redundancy in multimedia instruction. Applied Cognitive Psychology, 13, 351-371.

Kalyuga, S., Chandler, P., \& Sweller, J. (2000). Incorporating learner experience into the design of multimedia instruction. Australian Journal of Educational Technology 16(2), 161-172.

Kalyuga, S., Ayres, P., Chandler, P. \& Sweller, J. (2003). The expertise reversal effect, Educational Psychologist, (38), 23-32.

Kalyuga, S. (2006). Instructing and testing advanced learners: A cognitive load approach.NY: Nova Science Publishers.

Kalyuga, S. (2008). Managing cognitive load in adaptive multimedia learning. Hershey, PA: IGIGlobal. 
Katsikopoulos, K. V., Duseant-Anthony, Y., Fisher, D. L. and Duffy, S. A. (2000). The framing of drivers' route choices when travel time information is provided under varying degrees of cognitive load, Human Factors, (42) 3, 470-481.

Kaya, Naz (2004). Relationship between Color and Emotion: A Study of College Students, College Student Journal.

Keefe, J. W. (1982). Assessing student learning styles. In Keefe, J. W. (Ed.), Student learning styles and brain behavior (pp. 1-18). Reston, VA: National Association of Secondary School Principals.

Kirschner et al., (2006). Why minimal guidance during instruction does not work: An analysis of the failure of constructivist, discovery, problem-based, experiential, and inquiry-based teaching. Educational Psychologist. (46), 75-86.

Knez, I., \& Kers, C., (2000). Effects of Indoor Lighting, Gender, and Age on Mood and Cognitive Performance. Environment and Behavior, (32), 6, 817-831 DOI: $10.1177 / 0013916500326005$.

Knez, I., Enmarker, I. (1998). Effects of office lighting on mood and cognitive performance, and a gender effect in work-related judgment. Environment and Behaviour, 30, 553--567.

Kolmansberger Robert C, (2005). Making Sound Decisions About Noise Abatement (DVD). Harrisburg, PA: Pennsylvania Department of Transportation.

Kommers, P.A.M., Jonassen, D.H. and Mayes, J.T. (1992) (Eds) Cognitive Tools for Learning. NATO ASI Series, Vol. F 81, Berlin: Springer-Verlag.

Kreisman, B. M., \& Crandell, C. C. (2002). Frequency modulation (FM) systems for children with normal hearing. Audiology Online. Retrieved April 10, 2008, from http://www.audiologyonline.com/articles/pf_article_detail.asp?article id $=358$ 
Krejcie, R. V., \& Morgan, D. W. (1970). Determining sample size for research activities. Educational and Psychological Measurement, 30, 607-610.

Kuo, S.M. and Morgan, D.R. (1996). Active noise control systems. Algorithms and DSP implementations, (Wiley, New York).

Kurtus, R. (2007) Detecting Sound Waves. Retrieved from: http://www.school-forchampions.com/science/sound beat.htm.

Kurtus, R. (2009) Detecting Sound Waves. Retrieved from: http://www.school-forchampions.com/science/sound.htm.

Kyzar, B.L. (1977). Noise pollution and schools: How much is too much? Council of Educational Facilities Planners Journal, 10-11.

Lai, A. \& Huan, Y. (2005). The learning effect of cognitive load under different structure hypertext environments. In P. Kommers \& G. Richards (Eds.), Proceedings of World Conference on Educational Multimedia, Hypermedia and Telecommunications 2005 (pp. 1145-1150). Chesapeake, VA: AACE. Retrieved from http://www.editlib.org/p/20232.

Lajoie, (1993). Computer environments as cognitive tools for enhancing learning. In: Lajoie, S.P., Derry, S.J. (Eds.), Computers as cognitive tools, Lawrence Erlbaum Associates, Hillsdale, NJ.

Laliberte, R. (2006, March). The difference between boys and girls. Parents, 102-106.

Laney, M. O. (2002). The introvert advantage: How to thrive in an extravert world. New York: Workman Publishing.

Letty J. Rayneri, Brian L. Gerber, and Larry P. Wiley (2003). Gifted Achievers and Gifted Underachievers: The Impact of Learning Style Preferences in the 
Classroom. The Journal of Secondary Gifted Education, (14), 4, 197-204 DOI: $10.4219 /$ jsge-2003-434.

Lewis, R. (2000) Classroom Discipline and Student Responsibility: The Students' View. Teaching and Teacher Education. 17(3), 307-19.

Lewis, B. P., \& Linder, D. E. (1997). Thinking about choking? Attentional processes and paradoxical performance. Personality and Social Psychology Bulletin, 23, 937944.

Lorsbach, T., \& Simpson, G. (1988). Dual-task performance as a function of adult age and task complexity. Psychology and Aging, 243, 210-212.

Madell, J., \& Flexer, C. (2008). Pediatric Audiology: Diagnosis, Technology, and Management. New York: Thieme Medical Publishers, Inc.

Manning, C.J. \& Harris, G, J. (2003) Noise control in the transportation corridor. Noise \&Health. A quarterly Inter-disciplinary Journal, (5), 18, 43-45.

Mark A. W. Andrews, (2010). How does background noise affect our concentration? Scientific American Mind Retrieved from http://www.scientificamerican.com/article.cfm?id=ask-the-brains-backgroundnoise.

Martin, E. M. \& Bedenbaugh, P. H., 34th Annual Meeting of the Society for Neuroscience, Oct. 23-27, 2004, San Diego, Session 305.11 (abstr.).

Mayer, R., \& Anderson, R. (1991). Animations need narrations: An experimental test of a dual coding hypothesis. Journal of Educational Psychology, 83, 484-490.

Mayer, R. E., \& Moreno, R. (1998). A split-attention effect in multimedia learning: Evidence for dual processing systems in working memory. Journal of Educational Psychology, (90), 312-320. 
Mayer, R. E., Moreno, R., Boire, M. \& Vagge, S. (1999). Maximizing constructivist learning from multimedia communications by minimizing cognitive load. Journal of Educational Psychology, (91), 638-643.

Mayer, R. E. (2001). Multimedia learning. New York: Cambridge University Press.

Mayer, R. E. \& Sims, V. K. (1994). For whom is a picture worth a thousand words? Extensions of a dual-coding theory of multimedia learning. Journal of Educational Psychology, 86, 389-401.

Maxwell L, Evans G (2000). The effects of noise on pre-school children's pre-reading skills. Journal of Environmental Psychology (20), 91-97.

McCloughan C.L.B., Aspinall, P.A. \& Webb, R.S. (1998). The impact of lighting on mood. Lighting Research and Technology, 31 (3), 81-88.

Merriënboer, J. v., \& Ayres, P. (2005). Research on cognitive load theory and its design implications for e-learning. Educational Technology Research and Development, 53(3), 5-13.

Messick, S. (1996). Human abilities and modes of attention: The issue of stylistic consistencies in cognition. In I. Dennis \& P. Tapsfield (Eds.), Human abilities: Their nature and measurement (pp. 77-96). Hillsdale, NJ: Erlbaum.

McSporran, E., Butterworth, Y., \& Rowson, V. (1997). Sound field amplification and listening behaviour in the classroom. British Educational Research Journal, 23(1), $81-9$

Mike Fila, (2007) Bad sound top issue at hearing: PTA Council bulks at Hairton's response. The Owings Mills Times. Retrieved from http://www.teachlogic.com/assets/pdfs/news_articles/owings_mills_times.pdf 
Miller, G. A. (1956). The magical number seven, plus or minus two: Some limits on our capacity for processing information, Psychological Review 63 (2): 81-97.

Miyata, Y., Norman, D.A., 1986. Psychological issues in support of multiple activities. In: Norman, D.A., Draper, S.W. (Eds.), User Centered System Design: New Perspectives on Human-Computer Interaction. Lawrence Erlbaum Associates, Hillsdale, NJ

Moody, M., Schwartz, R., Gravel, J., \& Ruben, R (1999).Speech perception and verbal memory in children with and without histories of otitis media. Journal of Speech, Language, and Hearing Research, (42), 1069-1079.

Moreno, R., \&Mayer, R. E. (2002). Verbal redundancy in multimedia learning: When reading helps listening. Journal of Educational Psychology, 94, 156-163.

Moreno, R., \& Valdez, A. (2005). Cognitive load and learning effects of having students organize pictures and words in multimedia environments: The role of student interactivity and feedback. Educational Technology Research and Development, 53(3), 35-45.

Morrison, G. R., \& Anglin, G. J. (2005). Research on cognitive load theory: Application to e-learning. Educational Technology Research and Development, 53(3), 94-104.

Mousavi, S.Y., Low, R., \& Sweller, J. (1995). Reducing cognitive load by mixing auditory and visual presentation modes. Journal of Educational Psychology, (87), 319-334.

Nelson, P., Kohnert., K., Sabur, S., (2005). Classroom Noise and Children Learning Through a Second Language. Language, Speech, and Hearing Services in Schools, (5) 36, 219-229.

Nelson, P. \& Soli, S. (2000). Acoustical barriers to learning: Children at risk in every classroom. Language, Speech, and Hearing Services in Schools, 31(4), 356-361. Speech, and Hearing Services in Schools, 31(4), 354-355. 
Nist, S.L., Simpson, M.L., Olejnik, S., \& Mealey, D.L. (1991). The relation between self selected study processes and test performance. American Educational Research Journal (28), 849-874.

Nixon, C., McKinley, R., and Steuver, J. (1992). Performance of active noise reduction headsets. In A. Dancer, D. Henderson, R. Salvi, and R. Hamernik (Eds.), Noise Induced Hearing Loss (pp. 389-400). Baltimore, Maryland: Mosby Year Book.

Nurmi J and von Wright J (1983) Interactive effect of noise, neuroticism and state of anxiety in the learning and recall of a textbook passage. Human Learning 2: 119 125.

O’Brien, T. P., Bernold, L. E., and Akroyd. D. (1998). Myers-Briggs Type Indicator and Academic Achievement in Engineering Education. International Journal of Engineering Education, 14(5), 311-315.

O'Brien, L. (1989). Learning styles: Make the student aware. NASSP Bulletin, 73(519), 85-89.

Ohrstrom, E. (2000). Sleep disturbances caused by road traffic noise-Studies in laboratory and field. Noise and Health, 8: 71-78

Ohrstrom, E. (2002) Sleep studies before and after - Results and comparison of different methods. Noise and Health, 4: 65-67.

Ohrstrom, E. (2003). The effects of background noise on cognitive performance during a 70 hour simulation of conditions aboard the International Space Station. Noise \&Health. A quarterly-Interdisciplinary International Journal, (6), 3-16.

Olina, Z., Reiser, R., Huang, X., Lim, J. \& Park, S. (2006). Problem format and presentation sequence: Effects on learning and mental effort among U.S. High school students Applied Cognitive Psychology, 20, 299-309. 
Paas, F., \& Van Merriënboer, J. J. G. (1994). Instructional control of cognitive load in the training of complex cognitive tasks. Educational Psychology Review, (6), 351371.

Pass, F., Renkl, A., \& Sweller, J. (2003). Cognitive load theory and instructional design: Recent developments. Educational Psychologist, 38(1), 1-4.

Paas, F., Renkl, A., \& Sweller, J. (2004). Cognitive load theory: Instructional implications of the interaction between information structures and cognitive architecture. Instructional Science, 32, 1-8.

Paas, F., Tuovinen, J. E., Tabbers, H. K., \& Van Gerven, P. W. M. (2003). Cognitive load measurement as a means to advance cognitive load theory. Educational Psychologist, 38 (1), 63-71.

Paas, F., Tuovinen, J. E., Merriënboer, J. J. G. v., \& Darabi, A. A. (2005). A motivational perspective on the relation between mental effort and performance: Optimizing learner involvement in instruction. Educational Technology Research and Development, 53(3), 25-34.

Paivio, A (1986). Mental representations: a dual coding approach. Oxford. England: Oxford University Press.

Palomba, C. A., \& Banta, T. W. (1999). Assessment essentials: Planning, implemented, and improving assessment in higher education. San Francisco. Jossey Bass.

Peterson, J. S., \& Colangelo, N. (1996). Gifted achievers and underachievers: A comparison of patterns found in school files. Journal of Counseling \& Development, 74, 339-407.

Petersson, K. M., Forkstam, C., \& Ingvar, M. (2004). Artificial syntactic violations activate Broca's region. Cognitive Science, 28(3), 383-407. 
Pillay, H. (1994). Cognitive load and mental rotation: structuring orthographic projection for learning and problem solving. Instructional Science, (22), 91-113.

Pillay, H., \& Wilss, L. (1996). Cognitive style preferences in learning: does it matter? Australian Educational Computing, 11(2), 28-33.

Pollock, E. Chandler, P. and Sweller, J. (2002). Assimilating complex information. Learning and Instruction. 12(1), 61-86.

Pontari, B. A., \& Schlenker, B.R. (2000). The Influence of Cognitive Load on SelfPresentation: Can Cognitive Busyness Help as well as Harm Social Performance? Journal of Personality and Social Psychology, 78(6), 1092-1108.

Purvis Bedenbaugh, (2004). Masking and scrambling in the auditory thalamus of awake rats by Gaussian and modulated noises. Proceedings of the National Academy of Sciences of the United States of America (101) 14961-5.

Quilici, J. L., \& Mayer, R. E. (1996). Role of examples in how students learn to categorize statistics word problems. Journal of Educational Psychology, 88(1), $144-161$.

Raloff, J., 2006. "Illuminating Changes: Conventional Lightbulbs May Soon Be Obsolete," Science News 169 (May 20): 314.

Randall Fielding, (2006). Learning, Lighting and Color: Lighting Design for Schools and Universities in the 21st Century. Retrieved from: http://www.designshare.com/articles/1/133/fielding light-learn-color.pdf.

Randall Fielding, "What They See Is What We Get": Ten myths about lighting and color in schools. Retrieved June $10^{\text {th }} 2007$ from, http://www.edutopia.org/what-theysee-what-we-get. 
Rasinski, T., Flexer, C., \& Szypulski, T. (2006). The sound of learning: Why self amplification matters - A field guide. Minneapolis: Harebrain, Inc.

Reinhold, R. (2003). The Faces of Personality Type Development. Retrieved October $3^{\text {rd }}$ from: http://www.personalitypathways.com/faces.html

Reinhold, R. 2004. What is your Myers-Briggs personality type? Personality Pathways, http://www.personalitypathways.com/type_inventory.html\#Inventory (accessed February 24, 2004).

Renkl, 1997. Learning from worked-out examples: A study on individual differences. Cognitive Science, 21, 1-29.

Renkl, A., Stark, R., Gruber, H., \& Mandl, H. (1998). Learning from worked-out examples: The effects of example variability and elicited self-explanations. Contemporary Educational Psychology, 23, 90-108.

Restak, R. (1979). The brain: The last frontier. New York: Doubleday.

Riding, R. and Cheema, I. (1991). Cognitive Style - an Overview and Integration. Educational Psychology 11(3-4): 193-215.

Riding, R. J. and Rayner, S.G. (1998) Cognitive Styles and Learning Strategies: Understanding Style Differences in Learning and Behaviour London, David Fulton Publishers.

Ron Kurtus (revised 7 December 2007) Beat Frequencies in Sound. Retrieved December 7th, from http://www.school-for-champions.com/science/sound.html.

Ron Kurtus (2009). Overview of Sound Waves. Retrieved December 9th, from http://www.school-for-champions.com/science/sound.html. 
Salamé, P., \& Baddeley, A. D. (1982). Disruption of short-term memory by irrelevant speech: Implications for the structure of working memory. Journal of Verbal Learning \& Verbal Behavior, 21, 150-164.

Salamé, P., \& Baddeley, A. [D.] (1986). Phonological factors in STM: Similarity and the unattended speech effect. Bulletin of the Psychonomic Society, 24, 263-265.

Salas, E., Driskell, and Hughes, S. (1996). Introduction: The study of stress and human performance. In Stress and Human Performance. Driskell, J. E. and Salas, E. eds. Lawrence Erlbaum, New Jersey, pp 1-45.

Seeley, K. R. (1993). Gifted students at risk. In L.K. Silverman (Ed.), Counseling the gifted and talented (pp. 263-276). Denver: Love Publishing.

Schnotz, W., \&Rasch, T. (2005). Enabling, facilitating, and inhibiting effects of animations in multimedia learning: why reduction of cognitive load can have negative results on learning. Educational Technology Research and Development, 53(3), 47-58.

Shapiro, A. \& Niederhauser, D. (2004). Learning from hypertext: research, issues and findings, In: Jonassen, D. H. (coord.). Handbook of research on educational communications and technology. Second Edition. Mahwah, N.J.: Lawrence Erlbaum, 605-622.

Smith, A.P. (1989). A review of the effects on noise on human performance. Scand. J. Psychol., 30: 185-206.

Smith, A. P. \& Broadbent, D. E. 1980. Effects of noise on performance of embedded figures tasks. Journal of Applied Psychology, (65), 246 - 248.3.

Smith, A. P., and Miles, C. (1987). The combined effects of occupational health hazards: an experimental investigation of the effects of noise, night-work, and meals. International Archives of Occupational and Environmental Health, (59), 83-89. 
Solan H.A., Shelley-Tremblay, J., Larson S., \& Mounts, J. (2006) Silent Word Reading Fluency and Temporal Vision Processing: Differences Between Good and Poor Readers. Journal of Behavioral Optometry, 17, 1-9.

Supplee, P. L. (1990). Reaching the gifted underachiever. New York: Teachers College Press.

Sweller, J., \& Cooper, G. A. (1985). The use of worked examples as a substitute for problem solving in learning algebra. Cognition and Instruction, 2(1), 59-89.

Svinicki, M. D. \& Dixon, N. M. (1987). The Kolb model modified for classroom activities. College Teaching, 35 (4), 141-146. (available in the TRC).

Sweller, J. (1988). Cognitive load during problem solving. Cognitive Science, (12), 257285.

Sweller, J., \& Chandler, P. (1994). Why some material is difficult to learn. Cognition and Instruction, 12(3), 185-233.

Sweller, J. (1994). Cognitive load theory, learning difficulty and instructional design. . Learning and Instruction, 4, 295-312.

Sweller et al., 1998. Cognitive architecture and instructional design. Educational PsychologyReview. (10), 251-296.

Sweller, J., van Merrienboer, J. G., \& Paas, F. G. (1998). Cognitive architecture and instructional design. Educational Psychology Review, 10(3), 251-296.

Sweller, J. (1999). Instructional design in technical areas. Camberwell, Vic: Acer Press. 
Sweller, J. (2004). Instructional design consequences of an analogy between evolution by natural selection and human cognitive architecture. Instructional Science, (32), 931.

Tarmizi, R. \& Sweller, J. (1988). Guidance during mathematical problem solving. Journal ofEducational Psychology, 80, 424-436.

Tindall-Ford, S., Chandler, P., \& Sweller, J. (1997). When two sensory modes are better than one. Journal of Experimental Psychology: Applied, 3, 257-287.

Tremblay et al., (2006a ) K.L. Tremblay, C.J. Billings, L.M. Friesen and P.E. Souza, Neural representation of amplified speech sounds, Ear Hear. 27 (2) (2006), 93103.

Trimmel, Michael; Poelzl, Gerhard (2006) Impact of background noise on reaction time and brain DC potential changes of VDT-based spatial attention. Ergonomics, (49)2, 202-208.

Tokhi, M.O. Leitch, R.R. (1999). The Design of Active Noise Control Systems for Compact and Distributed Sources. Journal of Sound and Vibration (225)3, 401424.

Van Gerven, P.W.M., Paas, F.G.W.C., van Merriënboer, J.J.G., \& Schmidt, H.G. (2002). Cognitive load theory and aging: Effects of worked examples on training efficiency. Learning and Instruction, 12, 87-105.

Van Merrinboer et al., (2002). Redirecting learner's attention during training: effects on cognitive load, transfer test performance and training efficiency. Learning and Instruction.12, 11-37.

Van Merrinboer, J. J. G., \& de Croock, M. B. M. (1992). Strategies for computer-based programming instruction: Program completion vs. program generation. Journal of Educational Computing Research, 8(3) 365-394. 
Van Merrinboer, J. J. G., \& de Croock, M. B. M. (1993). Strategies for computer-based programming instruction: Program completion vs. program generation. Journal of Educational Computing Research, 8(3), 365-394.

Van Merriënboer, J. J. G., Kirschner, P. A., \& Kester, L. (2003). Taking the load off a learner's mind: Instructional design for complex learning. Educational Psychologist, 38, 5-13.

Van Merrienboer, J. G., \& Sweller, J. (2005). Cognitive load theory and complex learning: Recent developments and future directions. Educational Psychology Review, 17 (2), 147-177.

Vastfjall, D., (2002). Influence of Current Mood and Noise Sensitivity on Judgments of Noise Annoyance. Journal of Psychology, 4, 357-370.

von Wright, J. and Vauras, M. (1980). Interactive effects of white noise and irrelevant information on recall from semantic memory, Scandinavian J. Psychol., 21: 97101.

Whitmore, J. R. (1986). Understanding a lack of motivation to excel. Gifted Child Quarterly, 30, 66-69.

William , H. (2007). How Noise-canceling Headphones Work. Retrieved 15 February 2007 from http://electronics.howstuffworks.com/gadgets/audio-music/noisecanceling-headphone.htm.

Zamkova, M. A. \& Krivitskaya, E. 1. (1966, April). Effect of irradiation by ultraviolet erythema lamps on the working abilityof school children. Translated by Duro-Test Electric from original Russian in Gigiena in Sanitariia, 31, 41-44. 
APPENDICES 
APPENDIX A

\section{PARENT/GUARDIAN CONSENT FORM}




\section{PARENT/GUARDIAN CONSENT FORM}

Dear Parent/Guardian:

My name is M.V.S. Rajarajeswari, a doctoral student at Florida International University. I am also a teacher at G. Holmes Braddock Senior High School conducting a study called "The Impact Of Eliminating Extraneous Sound And Light On Student Learning: An Experimental Study". We would like to involve your child in our study.

This study includes an observation of your child's level of engagement in learning activities through the multimedia, under conditions where the impact of sound (noise), light or both are eliminated. . Your child will be using the computer for 30 minutes, each day, for four weeks. At no time will your child be separated from peers or the teachers.

Your child will be placed in the computer lab with the teacher and peers and the study will take a total time of about four weeks. All information will remain completely confidential. No child will be identified by name. You will be able to remove your child from the study at any time and your child will continue to receive quality childcare in this classroom. Participation in research will not involve a loss of privacy; and my records will be handled as confidentially as possible. They will remain in a locked cabinet in my office. When the research project is complete, the test scores will remain locked for three years (per federal regulations) and then destroyed. No individual identities will be used in any reports or publications that may result from this study.

There will be no direct benefit to your child from participating in this study. However, the information gained from this research may help education professionals better understand how children engage in learning activities through computers where the effect of external sound and light are eliminated. There will be no cost to you or your child as a result of taking part in this study. There will be no payment to you or your child as a result of your child taking part

In this study, If you have any questions or concerns about participation in this study, you should first contact with the investigator at 227234@dadeschools.net or call G.Holmes Braddock Senior High or Dr. Most at (305) 305-3053. If for some reason you do not wish to do this, you may contact Dr. Patricia Price, the chairperson, of the FIU Institutional Review Board 
(305)348-2494, which is concerned with the protection of volunteers in research projects. Should you or your child feel discomfort due to participation in this research, you may contact this free counseling service at G.holmes Braddock Senior High School.

PARTICIPATION IN RESEARCH IS VOLUNTARY. I understand that I can choose not to have my child participate in this study, or to withdraw my child from participating at any time. Declining participation will not interfere with my child's care or learning experiences in their classroom. I understand that by not participating in this study, my child will continue to be provided with developmentally appropriate activities and experiences. I also understand that at any time I can participate in parent activities and educational opportunities. I can also choose to move my child to a different classroom if space is available.

I will discuss this research study with my child and explain the procedures that will take place.

I will be given a copy of this consent form to keep.

I give my consent to allow my child to participate:

Print Name

Signature of Parent/Guardian

Date

I give consent to allow my child to participate 
Print Name

Signature of Parent/Guardian

Signature of Person Obtaining Consent
Date

Date 
APPENDIX B

INFORMED ASSENT FORM FOR THE STUDY 


\section{INFORMED ASSENT FORM FOR THE STUDY}

\section{THE IMPACT OF ELIMINATING EXTRANEOUS SOUND AND LIGHT ON STUDENT LEARNING: AN EXPERIMENTAL STUDY}

My name is M.V.S.Rajarajeswari, from Florida International University. I am also a teacher at G.Holmes Braddock Senior High School. I am asking you to participate in this research study because you are a High School Student.

The purpose of the study is to determine how well students learn when extraneous sound and light, that are potential sources of cognitive load, are eliminated. The study aims to test the impact of noise and light on the performance of high school students.

If you decide you want to be part of this study, you will be asked to view a multimedia based instructional unit "Chemical Bonding" for 30 minutes a day, for a period of 3 weeks. The multimedia based instructional unit is user-paced instead of system-paced. This study will take place over a 4 week- period during the second 9 weeks of the year on the unit of "Chemical Bonding". This study will determine if student learning and retention can be enhanced by eliminating extrinsic cognitive load imposed by sound and light when presenting the content. There are no risks or benefits are involved in this study. If you do not want to be in this research study, you have every right to inform the researcher and withdraw at any time and that will not go against your grades.

When I am finished with this study, I will write a report about what was learned. This report will not include your name or that you were in the study. Voluntary means that you do not have to be in this study if you do not want to be. I have already asked your parents if it is ok for me to ask you to take part in this study. Even though your parents said I could ask you, you still get to decide if you want to be in this research study. You can also talk with your parents, grandparents, and teachers (or other adults if appropriate) before deciding whether or not to take part. No one will be mad at you or upset if you decide not to do this study. If you decide to stop after we begin, that's okay too.

You can ask questions now or whenever you wish. If you want to, you may call me at (305) 225-9729, or you may call Dr. M.O. Thirunarayanan, at (305) 348-2085. or Dr. Most at (305) 3053053.

Please sign your name below, if you agree to be part of my study (signature line needed for participants 7-17;). You will get a copy of this form to keep for yourself. 
Signature of Participant

Date

Name of Participant

Signature of Investigator or Designee

Date 
APPENDIX C

PRETEST 


\section{PRETEST}

Name------------------------

Date----------------------

\section{Section 1: Tools of Astronomy \\ Tools of Astronomers}

Circle the correct answer.

1. The Very Large Array is an example of
A) an infrared telescope
B) a refracting telescope
C) interferometry
D) A refracting telescope

2. A_ is a technology developed for use in space, which now benefits society.
A) telescope
B) Very Large Array
C) Spinoff
D) Mare

3. How is electromagnetic radiation arranged on the electromagnetic spectrum?
A) by velocity
B) by color
C) by wavelength and frequency
D) by oscillations 
4. What instrument can be used to demonstrate that Earth is rotating?
A) Sonar
B) A GPS
C) A reflecting telescope
D) A Foucault pendulum

5. is a common term for electromagnetic radiation.
A) Radiation
B) Radio
C) Waves
D) Light

6. What type of telescope uses mirrors to bring visible light to a focus?
A) Reflecting
B) Very Large Array
C) Interferometer
D) Refracting

7. A_telescope uses lenses to bring visible light to a focus.
A) Refracting
B) Reflecting
C) Very Large Array
D) Interferometer 
8. What determines the light-collecting power of a microscope?
A) The area of the opening
B) The shape of the opening
C) The number of mirrors
D) The configuration of the lenses

Section 2: The Moon

The Moon

9. What are the highlands on the Moon made of?
A) Lunar breccias
B) Sandstones
C) Lunar conglomerates
D) Volcanic rocks

10. What is albino?
A) The amount of sunlight a surface absorbs
B) Meandering valley like structures
C) The light areas of the Moon
D) The amount of sunlight a surface reflects

11. The loose, ground-up rock on the surface of the Moon is called
A) rille
B) Sandstone
C) Regolith
D) Maria 
12. The of the Moon are light in color, mountainous, and heavily covered by ters.
A) Maria
B) Highlands
C) Rays
D) Rilles

13. What mineral are the lunar breccias primarily made of?
A) Plagioclase feldspar
B) Gypsum
C) Quartz
D) Orthoclase feldspar

14. What is pictured in the figure?

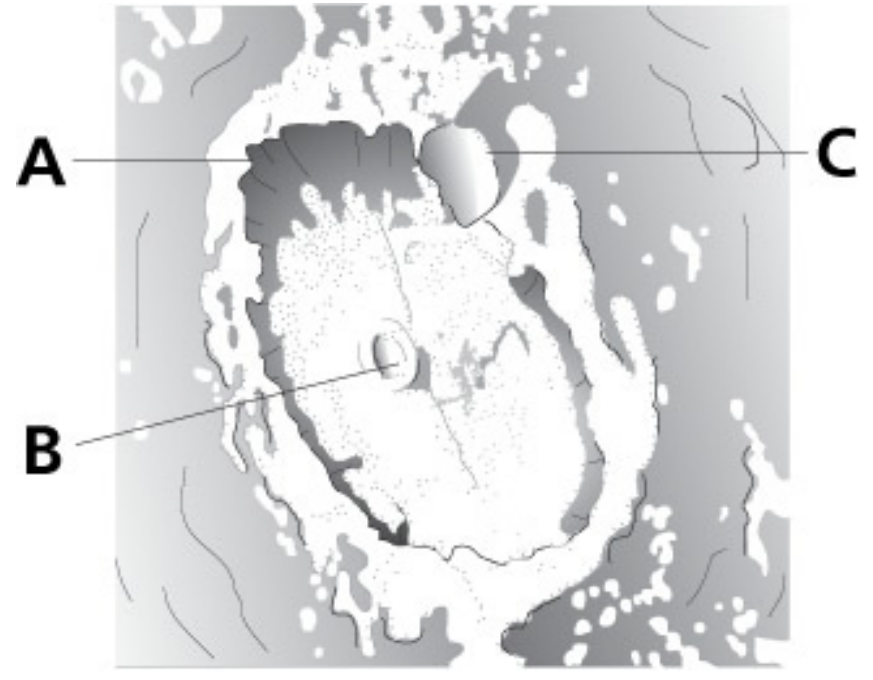
A) Rays
B) Highlands
C) rilles
D) impact crater 
15. What are the long trails of ejecta that radiate outward from craters called?
A) Rays
B) Highlands
C) rilles
D) Maria

16. In the photograph, which impact crater is the oldest?

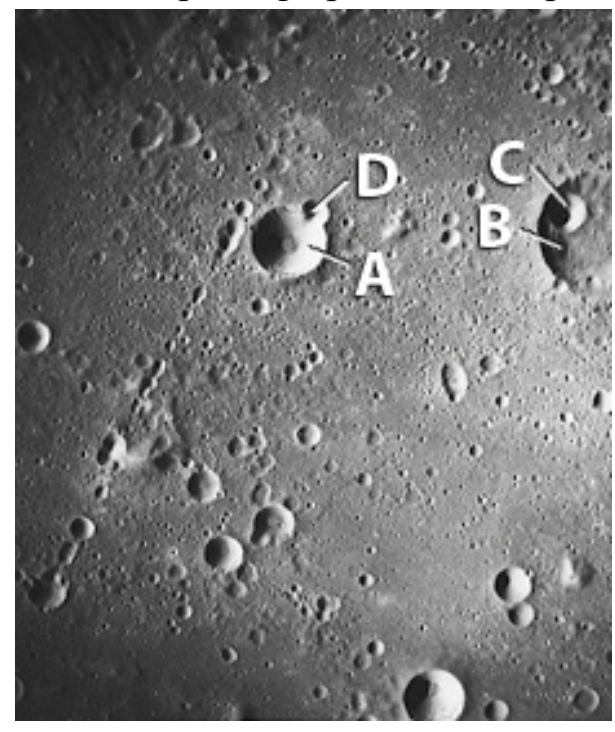

17. Which is NOT a layer of the Moon?
A) Core
B) Crust
C) Lower mantle
D) Outer core

18. What theory of formation is most widely accepted for Earth's moon?
A) The simultaneous formation
B) The plate tectonic theory
C) The impact theory
D) The capture theory 
19. All of the craters on the Moon are
A) oval in shape
B) Geologically young
C) filled with granite
D) Impact craters

20. The Earth Moon is in size and has an orbit its planet relative to other moons in the solar system.
A) Larger, closer to
B) Larger, farther from
C) Smaller, closer to
D) Smaller, farther from

21. Why does no Maria exist on the far side of the Moon?
A) The crust is half as thin on the far side.
B) There were no impacts on the far side.
C) Lava did not fill in the far side.
D) The crust is twice as thick on the far side.

22. Why is there no erosion on the Moon?
A) There are no living organisms.
B) There are no rocks.
C) There are no people on the moon.
D) There is no atmosphere. 
23. In the photograph, which feature on the moon has been there the longest?
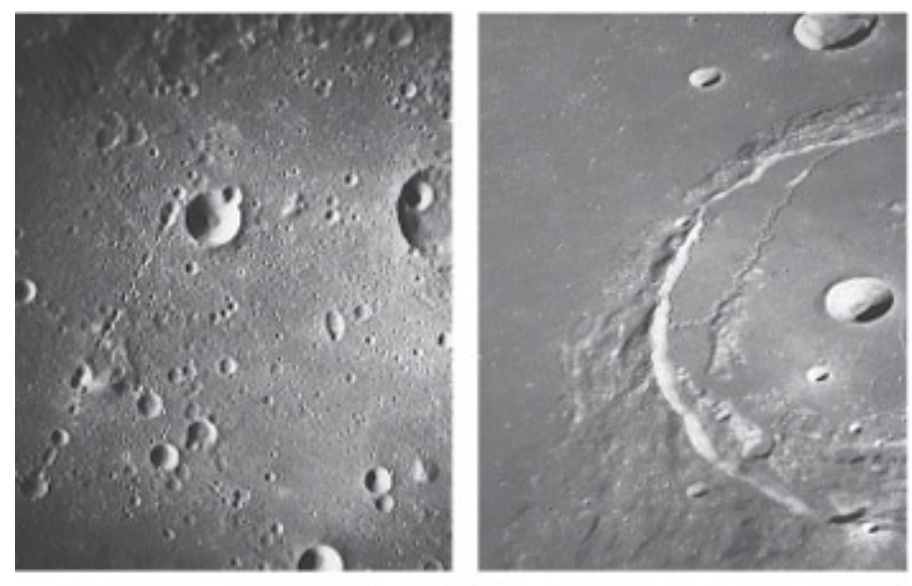

1.

2.
A) C
B) D
C) A
D) E

24. What are smooth, dark, plains on the Moon called?
A) Highlands
B) Rays
C) rilles
D) Maria 
Section 3: The Sun- Earth- Moon System

25. Which image of the moon in the figure shows a gibbous?

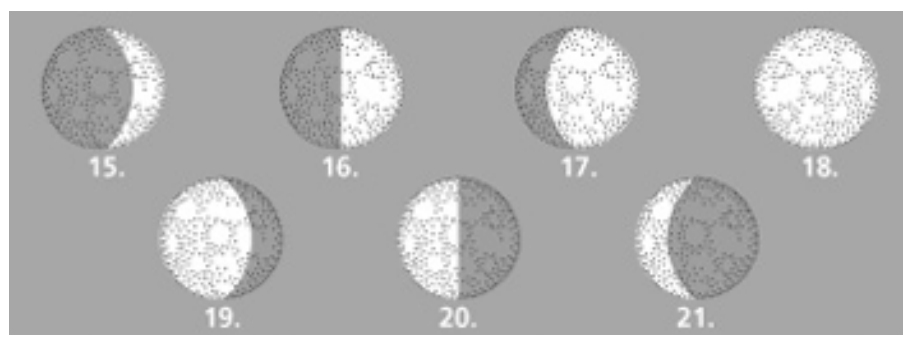
A) 15
B) 17
C) 18
D) 16

26. The plane of Earth's orbit around the Sun is called
A) The ecliptic
B) The altitude
C) The solar day
D) The revolution

27. Which series of the moon in the figure are waxing?

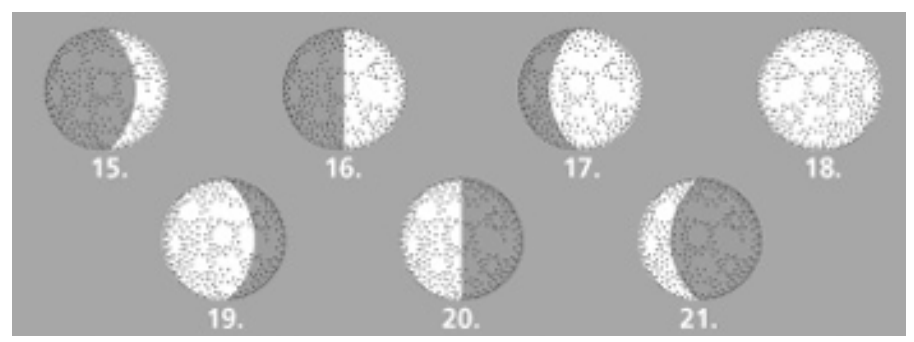



A) $19-21$
B) $15-17$
C) $17-19$
D) 21-15

28. On the summer solstice, the Sun is directly above the , and the number of daylight hours for the northern hemisphere is
A) Tropic of Cancer, at a maximum
B) Equator, at a maximum
C) Tropic of Capricorn, at a minimum
D) Tropic of Capricorn, at a minimum

29. When the Moon is aligned with and between the Sun and Earth, the Moon is at the stage.
A) Full moon
B) Waxing crescent
C) New moon
D) Waning gibbous

30. When the Sun and Moon are aligned the tides are , which is called a
A) Less than normal, neap tide
B) Greater than normal, neap tide
C) Greater than normal, spring tide
D) Less than normal, spring tide 
APPENDIX D

EXPERT RATING SCALE 


\section{Ratings on a 30 item Scale by 8 Experts:}

\section{Items Rated 4 or 5 point Relevance Scale.}

\begin{tabular}{|c|c|c|c|c|c|c|c|c|c|c|}
\hline \multirow{3}{*}{$\begin{array}{l}\text { Item } \\
6 \\
1\end{array}$} & \multirow{2}{*}{\multicolumn{2}{|c|}{$\begin{array}{l}\text { Expert } 1 \\
\text { Expert } 7\end{array}$}} & \multirow{2}{*}{\multicolumn{2}{|c|}{$\begin{array}{l}\text { Expert } 2 \\
\text { Expert } 8\end{array}$}} & \multicolumn{2}{|c|}{ Expert 3} & \multicolumn{2}{|c|}{ Expert 4} & \multirow{2}{*}{\multicolumn{2}{|c|}{$\begin{array}{l}\text { Expert } 5 \\
\text { Item CVI }\end{array}$}} \\
\hline & & & & & & $\mathrm{A}$ & ne & & & \\
\hline & - & $\mathrm{X}$ & $\mathrm{x}$ & $\mathrm{X}$ & $\mathrm{x}$ & $\mathrm{X}$ & $\mathrm{X}$ & - & 6 & 0.75 \\
\hline 2 & $\mathrm{x}$ & - & $\mathrm{X}$ & $\mathrm{X}$ & $\mathrm{x}$ & $\mathrm{X}$ & $\mathrm{x}$ & $\mathrm{x}$ & 7 & 0.88 \\
\hline 3 & $\mathrm{x}$ & $\mathrm{X}$ & - & $\mathrm{X}$ & $\mathrm{X}$ & $\mathrm{X}$ & $\mathrm{X}$ & $\mathrm{x}$ & 7 & 0.88 \\
\hline 4 & $\mathrm{x}$ & $\mathrm{X}$ & $\mathrm{X}$ & - & $\mathrm{x}$ & $\mathrm{X}$ & $\mathrm{X}$ & $\mathrm{X}$ & 7 & 0.88 \\
\hline 5 & $\mathrm{x}$ & $X$ & $\mathrm{X}$ & $\mathrm{X}$ & $\mathrm{x}$ & $\mathrm{X}$ & $\mathrm{X}$ & $\mathrm{x}$ & 8 & 1 \\
\hline 6 & $\mathrm{x}$ & $X$ & $\mathrm{X}$ & $\mathrm{X}$ & $\mathrm{x}$ & $\mathrm{X}$ & $\mathrm{X}$ & $\mathrm{x}$ & 8 & 1 \\
\hline 7 & $\mathrm{x}$ & $\mathrm{X}$ & $\mathrm{x}$ & $\mathrm{X}$ & $\mathrm{x}$ & $\mathrm{X}$ & $\mathrm{X}$ & $\mathrm{x}$ & 8 & 1 \\
\hline 8 & $\mathrm{x}$ & $X$ & $\mathrm{X}$ & $\mathrm{X}$ & $\mathrm{x}$ & $\mathrm{X}$ & $\mathrm{X}$ & $\mathrm{X}$ & 8 & 1 \\
\hline 9 & $\mathrm{x}$ & $\mathrm{X}$ & $\mathrm{X}$ & $\mathrm{X}$ & $\mathrm{x}$ & $\mathrm{X}$ & $\mathrm{X}$ & $\mathrm{X}$ & 8 & 1 \\
\hline 10 & $\mathrm{x}$ & $X$ & $\mathrm{X}$ & $\mathrm{X}$ & $\mathrm{x}$ & $\mathrm{X}$ & $\mathrm{X}$ & $\mathrm{x}$ & 8 & 1 \\
\hline 11 & $\mathrm{x}$ & $\mathrm{X}$ & $\mathrm{x}$ & $\mathrm{X}$ & $\mathrm{x}$ & $\mathrm{X}$ & $\mathrm{x}$ & $\mathrm{x}$ & 8 & 1 \\
\hline 12 & $\mathrm{x}$ & $\mathrm{X}$ & $\mathrm{X}$ & $\mathrm{X}$ & - & $\mathrm{X}$ & $\mathrm{X}$ & $\mathrm{x}$ & 7 & 0.88 \\
\hline 13 & $\mathrm{x}$ & $X$ & $\mathrm{X}$ & $\mathrm{X}$ & $\mathrm{x}$ & $\mathrm{X}$ & $\mathrm{X}$ & $\mathrm{x}$ & 8 & 1 \\
\hline 14 & $\mathrm{x}$ & $X$ & $\mathrm{X}$ & $\mathrm{X}$ & $\mathrm{X}$ & $\mathrm{X}$ & $\mathrm{X}$ & $\mathrm{x}$ & 8 & 1 \\
\hline 15 & $\mathrm{x}$ & $\mathrm{X}$ & $\mathrm{X}$ & $\mathrm{X}$ & $\mathrm{X}$ & $\mathrm{X}$ & $\mathrm{X}$ & $\mathrm{x}$ & 8 & 1 \\
\hline 16 & $\mathrm{x}$ & $\mathrm{X}$ & $\mathrm{X}$ & $\mathrm{X}$ & $\mathrm{x}$ & $\mathrm{X}$ & $\mathrm{X}$ & $\mathrm{x}$ & 8 & 1 \\
\hline 17 & $\mathrm{x}$ & $\mathrm{X}$ & $\mathrm{X}$ & $\mathrm{X}$ & $\mathrm{x}$ & $\mathrm{X}$ & $\mathrm{X}$ & $\mathrm{x}$ & 8 & 1 \\
\hline 18 & $\mathrm{x}$ & $\mathrm{X}$ & $X$ & $\mathrm{X}$ & $\mathrm{X}$ & _ & $\mathrm{X}$ & $\mathrm{X}$ & 7 & 0.88 \\
\hline
\end{tabular}




\begin{tabular}{|c|c|c|c|c|c|c|c|c|c|}
\hline 19 & $\mathrm{X}$ & $\mathrm{X}$ & $\mathrm{X}$ & $\mathrm{X}$ & $\mathrm{X}$ & $\mathrm{X}$ & $\mathrm{X}$ & $\mathrm{X}$ & 8 \\
\hline 20 & $X$ & $\mathrm{X}$ & $\mathrm{X}$ & $\mathrm{X}$ & $\mathrm{x}$ & $\mathrm{X}$ & $\mathrm{X}$ & $\mathrm{X}$ & 8 \\
\hline 21 & $\mathrm{X}$ & $\mathrm{X}$ & $\mathrm{X}$ & $\mathrm{X}$ & $\mathrm{X}$ & $\mathrm{X}$ & $\mathrm{X}$ & $\mathrm{X}$ & 8 \\
\hline 22 & $X$ & $\mathrm{X}$ & $\mathrm{X}$ & $\mathrm{X}$ & $\mathrm{x}$ & $\mathrm{X}$ & $\mathrm{X}$ & $\mathrm{X}$ & 8 \\
\hline 23 & $x$ & $\mathrm{x}$ & $\mathrm{X}$ & $\mathrm{X}$ & $\mathrm{x}$ & $\mathrm{X}$ & $\mathrm{X}$ & $\mathrm{X}$ & 8 \\
\hline 24 & $X$ & $\mathrm{X}$ & $\mathrm{X}$ & $\mathrm{X}$ & $\mathrm{x}$ & $\mathrm{X}$ & $\mathrm{X}$ & $\mathrm{X}$ & 8 \\
\hline 25 & $\mathrm{X}$ & $\mathrm{x}$ & $\mathrm{x}$ & $\mathrm{x}$ & $\mathrm{x}$ & $\mathrm{X}$ & $\mathrm{X}$ & $\mathrm{X}$ & 8 \\
\hline 26 & $\mathrm{X}$ & $\mathrm{X}$ & $\mathrm{X}$ & $\mathrm{X}$ & $\mathrm{X}$ & $\mathrm{X}$ & $X$ & $\mathrm{X}$ & 8 \\
\hline 27 & $\mathrm{X}$ & $\mathrm{X}$ & $\mathrm{x}$ & $\mathrm{x}$ & $\mathrm{x}$ & $\mathrm{X}$ & $\mathrm{X}$ & $\mathrm{X}$ & 8 \\
\hline 28 & $\mathrm{X}$ & $\mathrm{X}$ & $\mathrm{X}$ & $\mathrm{X}$ & $\mathrm{X}$ & $X$ & $X$ & $\mathrm{X}$ & 8 \\
\hline 29 & $\mathrm{X}$ & $\mathrm{X}$ & $\mathrm{X}$ & $\mathrm{X}$ & $\mathrm{x}$ & $\mathrm{X}$ & $\mathrm{X}$ & $\mathrm{X}$ & 8 \\
\hline 30 & $\mathrm{X}$ & $\mathrm{X}$ & $\mathrm{X}$ & $\mathrm{X}$ & $\mathrm{X}$ & $\mathrm{X}$ & $\mathrm{X}$ & $\mathrm{X}$ & 8 \\
\hline
\end{tabular}

$\begin{array}{lllllllll}\text { Proportion } & 0.97 & 0.97 & 0.97 & 0.97 & 0.97 & 0.97 & 0.97 & 0.97\end{array}$

Mean I-CVI $=097$

$\mathrm{S}-\mathrm{CVI} / \mathrm{UA}=.80$

Mean expert

proportion $=0.97$ 
APPENDIX E

SWELLER'S TABLE (TABLE 1) 
Table 1

Some Effects Studied by Cognitive Load Theory and Why They Reduce Extraneous Cognitive Load

\begin{tabular}{|c|c|c|}
\hline Effect & Description & Extraneous load \\
\hline Goal-free effect & $\begin{array}{l}\text { Replace conventional } \\
\text { problems } \\
\text { with goal-free problems that } \\
\text { provide learners with an } \\
\text { a-specific goal }\end{array}$ & $\begin{array}{l}\text { Reduces extraneous cognitive } \\
\text { load caused by relating a } \\
\text { current problem state to a } \\
\text { goal state and attempting to } \\
\text { reduce differences between } \\
\text { them; focus learner's attention }\end{array}$ \\
\hline $\begin{array}{l}\text { Worked example } \\
\text { Effect }\end{array}$ & $\begin{array}{l}\text { Replace conventional } \\
\text { problems with worked } \\
\text { examples that } \\
\text { must be carefully studied }\end{array}$ & $\begin{array}{l}\text { Reduces extraneous cognitive load } \\
\text { caused by weak-method problem } \\
\text { solving; focus learner's attention }\end{array}$ \\
\hline $\begin{array}{l}\text { Completion } \\
\text { problem effect }\end{array}$ & $\begin{array}{l}\text { Replace conventional } \\
\text { problems with completion } \\
\text { problems, providing a partial } \\
\text { solution }\end{array}$ & $\begin{array}{l}\text { Reduces extraneous cognitive load } \\
\text { because giving part of the } \\
\text { solution reduces the size of } \\
\text { the problem space; focus } \\
\text { attention }\end{array}$ \\
\hline $\begin{array}{l}\text { Split attention } \\
\text { effect }\end{array}$ & $\begin{array}{l}\text { Replace multiple sources of } \\
\text { information (frequently } \\
\text { pictures and accompanying } \\
\text { text) with a single, integrated }\end{array}$ & $\begin{array}{l}\text { Reduces extraneous cognitive load } \\
\text { because there is no need to mentally } \\
\text { integrate the information sources }\end{array}$ \\
\hline
\end{tabular}




\begin{tabular}{|l|l|l|}
\hline Modality effect & $\begin{array}{l}\text { source of information } \\
\text { text and another source of } \\
\text { visual information (unimodal) } \\
\text { with a spoken explanatory text } \\
\text { and a visual source of } \\
\text { information (multimodal) }\end{array}$ & $\begin{array}{l}\text { Reduces extraneous cognitive load } \\
\text { because the multimodal } \\
\text { presentation uses both the visual } \\
\text { and auditory processor of working } \\
\text { memory }\end{array}$ \\
\hline $\begin{array}{l}\text { Redundancy } \\
\text { Effect }\end{array}$ & $\begin{array}{l}\text { Replace multiple sources of } \\
\text { information that are self- } \\
\text { contained ) with one source of } \\
\text { information }\end{array}$ & $\begin{array}{l}\text { Reduces extraneous cognitive load } \\
\text { caused by unnecessarily processing } \\
\text { redundant information }\end{array}$ \\
\hline
\end{tabular}


VITA

RAJARAJESWARI MANGIPUDY

\begin{tabular}{|c|c|c|}
\hline EDUCATION & UNIVERSITY/BOARD & $\begin{array}{l}\text { YEAR } \\
\text { PASSING }\end{array}$ \\
\hline $\begin{array}{l}\text { Junior College } \\
\text { Government Girl's College } \\
\text { Board of Intermediate } \\
\text { Education(India) }\end{array}$ & $\begin{array}{l}\text { Biology (Major) Physics } \\
\text { and Chemistry (minor). }\end{array}$ & $1974-76$ \\
\hline $\begin{array}{l}\text { Bachelor of Science } \\
\text { Government Girl's College } \\
\text { Andhra University (India) }\end{array}$ & $\begin{array}{l}\text { Botany(Major) Zoology } \\
\text { and Chemistry(minor) }\end{array}$ & $1976-79$ \\
\hline $\begin{array}{l}\text { Bachelor of Education } \\
\text { Devi Ahilya Viswavidhyalay, } \\
\text { Indore, (India) }\end{array}$ & $\begin{array}{l}\text { Secondary Sciences } \\
\text { (Major) English } \\
\text { language (minor) }\end{array}$ & $1884-85$ \\
\hline $\begin{array}{l}\text { Master's in Life Sciences } \\
\text { Devi Ahilya Viswavidhyalay, } \\
\text { Indore, (India) }\end{array}$ & $\begin{array}{l}\text { Photobiology (major) } \\
\text { Biochemistry(minor) }\end{array}$ & $1886-88$ \\
\hline $\begin{array}{l}\text { Master's in Learning } \\
\text { Technologies } \\
\text { Florida International } \\
\text { University }\end{array}$ & $\begin{array}{l}\text { Education Technologies } \\
\text { (Major) }\end{array}$ & $1998-2000$ \\
\hline Doctoral Candidate & $\begin{array}{l}\text { Curriculum and } \\
\text { Instruction }\end{array}$ & 2010 \\
\hline
\end{tabular}

\section{EXPERIENCE}

South Indian Cultural Association (Jr. College, India)

Biology Lecturer, 1987-1988

Responsible for teaching Botany, Chemistry, conducting laboratory practicals, "Science debates, fairs and field trips for academy students. 
Ekamai International School (Bangkok, Thailand)

Biology Lecturer, 1991-1996,

Responsible for teaching Biology, Chemistry, and Life Sciences for seniors.

Miami Edison Senior High School

Science teacher for Dropout Prevention Program, 1998-2003

Responsible for teaching Earth Science, Physical Science

Responsible for infusion of technology in Science Curriculum.

GHolmes Braddock Senior High School

Science teacher, 2003- current

Responsible for teaching Earth Science, Physical Science

Responsible for infusion of technology in Science Curriculum. 